\title{
SNAPSHOTS WITH AN EDGE
}

\section{A STUDY OF THE DECKLE EDGE IN THE NORTH AMERICAN SNAPSHOT}

\author{
By \\ Anna Krentz \\ Bachelor of Arts \\ St. Francis Xavier University \\ Antigonish, Nova Scotia, Canada \\ 2009 \\ A thesis \\ presented to Ryerson University \\ in partial fulfillment of the \\ requirements for the degree of \\ Master of Arts \\ in the program of
}

Photographic Preservation and Collections Management

Toronto, Ontario, Canada, 2014

(C) Anna Krentz 2014 


\section{Author's Declaration}

I hereby declare that I am the sole author of this thesis. This is a true copy of the thesis, including any required final revisions, as accepted by my examiners.

I authorize Ryerson University to lend this thesis to other institutions or individuals for the purpose of scholarly research.

I further authorize Ryerson University to reproduce this thesis by photocopying or by other means, in total or in part, at the request of other institutions or individuals for the purpose of scholarly research.

I understand that my thesis may be made electronically available to the public. 


\begin{abstract}
Snapshots With an Edge: A study of the deckle edge in the North American snapshot Master of Arts, 2014

Anna Krentz

Photographic Preservation and Collections Management

Ryerson University
\end{abstract}

This thesis takes an object-based approach to the amateur snapshot through an in-depth examination of the deckle edge, a form of snapshot presentation popular in the mid-twentieth century. Research draws primarily from a sample of 321 dated deckle edge snapshots in the collection of the Archive of Modern Conflict, Toronto, and from Kodak trade periodicals held by Ryerson University Special Collections.

The thesis examines the formerly undelineated dates of the deckle edge snapshot's popularity, the various devices used to create the deckle edge, the multiplicities of edge variation blanketed under the term "deckle edge," the appearance of the deckle edge in Kodak advertising, and the routes by which the deckle edge came to the snapshot. By situating the deckle edge snapshot in these contexts, the thesis demonstrates the value of approaching snapshots as dynamic, physical objects, and the kinds of information that can be derived from their non-image areas. 


\section{Acknowledgements}

First off I would like to thank my parents, Catherine and Hartmut Krentz, for their constant support throughout my academic career. None of it would have been possible without them.

Many thanks to Jill Offenbeck, Andrea Raymond, and the staff at the Archive of Modern

Conflict, Toronto, for their support and assistance in mining through their incredible collections and for enabling me to use some of those collection materials in this thesis.

Thanks to Alison Skyrme and Cassandra Rowbotham at Ryerson Special Collections, for helping me pore through Kodak materials, and for digitizing all the Kodak illustrations found in this work.

A great number of thanks to the professors of PPCM, many of whom turned on the various lights in my mind that ultimately led to this thesis, and all of whom reinforced my conviction that my choice of this program was the right one. Many thanks, as well, to my fellow students, whose ideas and perspectives - both shared within the course generally and on this specific thesis- have opened paths I never would have found on my own.

Thank you to my first reader, Gerda Cammaer, for understanding the goals of my thesis and helping me to articulate them as well as I can. Thanks you as well to my second reader, Don Snyder for his edits and insights.

Finally, thank you to those unknown people who took the snapshots examined for this thesis, thank you to those who printed them and those who kept them. Thank you to those who chose not to throw them out when their time came but passed them on, and thank you to all of those whose hands they passed through before ending up in mine. 


\section{Table of Contents}

List of Figures vi vi v v v v

List of Tables viii

$\begin{array}{ll}\text { Introduction } & 1\end{array}$

$\begin{array}{lr}\text { Chapter 1. Literature Survey } & 4\end{array}$

$\begin{array}{ll}\text { Chapter 2. Sources and Methodology } & 13\end{array}$

$\begin{array}{ll}\text { Chapter 3. Dates } & 16\end{array}$

$\begin{array}{ll}\text { Chapter 4. Methods of Manufacture } & 20\end{array}$

$\begin{array}{ll}\text { Chapter 5. Edge Types } & 31\end{array}$

Chapter 6. Advertising $\quad 55$

$\begin{array}{ll}\text { Chapter 7. Influences } & 65\end{array}$

$\begin{array}{ll}\text { Conclusion } & 72\end{array}$

$\begin{array}{ll}\text { Bibliography } & 79\end{array}$ 


\section{List of Figures}

1. Illustration accompanying the patent application for a device to apply deckle edges to photographs, 1929

2. Illustration accompanying the patent application for an updated device to apply deckle edges to photographs, 1930

3. Advertisement for a deckle edge trimmer from the British Kodak dealer's catalogue, 1934

4. Advertisement for the Eastman Deckle edge Trimmer from Studio Light, 1940

5. Advertisement for Kodak album print folders, with deckle edge snapshots printed on album print paper, The Photo Finisher, 1950

6. Advertisement for a cutting device to create album prints, The Photo Finisher, 1949

7. Advertisement for the Kodak Direct Roll Paper Cutter, The Photo Finisher, Winter 1954

8. Advertisement for the Kodak Velox Rapid Printer type IV, with illustrations of print types possible, The Photo Finisher, Spring 1955

9. Advertisement for the Kodak Power Trimmer, The Photo Finisher, Summer 1956

10. Snapshot with an irregular deckle edge, dated 1934

11. Snapshot with an irregular deckle edge, dated 1940

12. Snapshot with a serrated deckle edge, dated 1939

13. Snapshot with a serrated deckle edge, dated 1939

14. Snapshot with a scalloped deckle edge, dated 1942

15. Snapshot with a scalloped deckle edge, no date

16. Snapshot with a basic deckle edge, dated 1958

17. Snapshot with a basic deckle edge, dated 1944

18. Snapshot with chunky edges, dated 1962

19. Snapshot with chunky edges, dated 1959

20. Two snapshots attached by chunky edges, no date

21. Examples of album prints from the advertisement for their release, The Photo Finisher, 1949

22. Examples of album prints from an advertisement for the Velox Rapid Printer (detail of figure 8), The Photo Finisher, 1955

23. Album print snapshot with attached hinge of the earlier type, no date

24. Album print snapshot of the five-hole type, 1954

25. Album print snapshot with hinge traces and feathering, dated 1951

26. Album print snapshot with feathering, dated 1956 
27. Album print snapshots bound in their original album, dated 1956

28. Polaroid snapshot with four deckle edges, dated 1950

29. Polaroid snapshot with two deckle edges, dated 1959

30. Polaroid snapshot with two deckle edges and attached tear sheet, no date

31. Snapshot with a concave deckle edge, dated 1958

32. Snapshot with a concave deckle edge, dated 1959

33. Snapshot with ornamental edges, dated 1962

34. Snapshot with ornamental edges, dated 1959

35. Snapshot with a variant edge type, no date

36. Snapshot with a variant edge type, backstamped Agfa-Lupex, no date

37. Illustration of Kodak's various print ads for their summer campaign, Kodak Salesman, May 1937

38. Listing of an advertisement for dealer use, Kodak Salesman, December 1937

39. Listing of an advertisement for dealer use, Kodak Dealer News, July-August 1954

40. Advertisement for Kodak film, Kodak Salesman May 1938

41. Newspaper advertisement for the Brownie Holiday Flash Camera showing a snapshot with clear deckle edges, 1955

42. Advertisement for Velox paper featuring deckle edge snapshots, The Photo Finisher, Autumn 1954

43. Advertisement for Velox paper featuring deckle edge snapshots, The Photo Finisher, Summer 1957

44. Advertisement for Velox paper featuring a roll of snapshots with deckle edges, The Photo Finisher, 1957

45. Cabinet card with decorative edges, late $19^{\text {th }}$ century

46. Snapshot with printed decorative border, dated 1934

47. Advertisement for a portrait folder with deckle edges, Studio Light, 1928

48. Detail of a portrait folder with deckle edges, 1920s-1930s

49. Advertisement for new Christmas cards with deckle edges, Kodak Dealer News, September- October 1954

50. Sample deckle edge Christmas card, insert in The Photo Finisher, 1954

51. Studio portrait with deckle edges, undated

Image credits: Figure 1: U. S. Patent 1,820,303; Figure 2: U.S. Patent 1,846,094; Figures 3-9, 21-22, 34-44, 48, 49-50: Ryerson University Special Collections; Figures 10-20, 23-36, 46, 51 : Archive of Modern Conflict, Toronto; Figures 45, 48: personal collection of the author 


\section{List of Tables}

1. Breakdown of date types in the study sample

2. Comparison of border printed dates to whole of dated snapshots in the study sample

3. Date distribution of snapshots in the study sample

4. Date distribution of the irregular deckle edge

5. Date distribution of the serrated deckle edge

6. Date distribution of the scalloped deckle edge

7. Date distribution of the basic deckle edge

8. Date distribution of the chunky deckle edge

9. Date distribution of album prints

10. Date distribution of the concave deckle edge

11. Date distribution of the ornamental deckle edge 


\section{Introduction}

While the amateur snapshot has been the focus of much academic discussion in the last twenty years, all approaches overlook one key factor: a snapshot is not simply an image. While non-image areas of snapshots such as white borders, deckle edges, and date stamps are increasingly included in reproductions, their existence and variety are never addressed. Yet these aspects of presentation are telling. They indicate a contemporary interest in non-image aspects of the snapshot. Moreover, types of snapshot presentation varied over time, demonstrating impacts on snapshots from the changing tastes of consumers and changing methods of manufacture. Examination of these physical characteristics is important in drawing attention to the snapshot not just as an image, but as a dynamic object.

As a starting point to this approach, my thesis addresses one of the most commonly seen physical characteristics of amateur snapshots: the deckle edge. The deckle edge is a purely decorative aspect of presentation, and as such indicates an overt choice on behalf of producers, marketers, and consumers. It was in use only during a particular time frame, testifying to the periodic change in ideas of how a snapshot should look. At present the deckle edge is not discussed in any key sources. There is no information on when the deckle edge snapshot was introduced, when it was popular, how it was made, how it was sold, where it came from, or why it was popular. This thesis addresses these questions. 
Snapshots are physical objects whose appearance is shaped not only by photographic motive and technology, but also by social use, consumerism, and cultural trends. It is my goal, through this case study of deckle edges, to demonstrate a new way of studying them in this light.

Before beginning, some notes on terminology. The term "deckle edge" comes from papermaking and refers to the rough untrimmed edge of a sheet of paper resulting from the process of making paper by hand using a device known as a deckle. Most major English dictionaries, including the Oxford English Dictionary, define the word only in this papermaking context. ${ }^{1}$ Only Collins adds the secondary definition "a trimmed edge imitating [the rough edge of handmade paper]. ${ }^{2}$ None make reference to the term as applied to photographs.

The first usage of "deckle edge" in a photographic context that I have identified is in a patent filed in 1929 (discussed in Chapter 4). The patent creator refers to his device as designed to impart a "rough or 'deckled' edge" to photographic prints. ${ }^{3}$ After this first usage, he uses the terms "deckled edge" (without quotation marks) and "deckle edge" interchangeably. From the 1930s onwards the definition of the term "deckle edge" in a photographic print context appears to have been widely understood, as its use in periodicals aimed at tradesman and consumers without any sort of definition is widespread. This lack of definition, however, led "deckle edge" to become something of an umbrella term, at its core meaning only, essentially, not "straight edge." This finding is discussed in chapter 5.

\footnotetext{
${ }^{1}$ Oxford English Dictionary Online, “deckle edge," s.v. accessed July 2014, http://www.oed.com; Merriam-Webster Online, "deckle edge," s.v. accessed July 2014, http://www.merriam-webster.com; American Heritage Dictionary Online, "deckle edge," s.v. accessed July 2014, http://www.ahdictionary.com.

${ }^{2}$ Collins Dictionary Online, “deckle edge," s.v. accessed July 2014, http://www.collinsdictionary.com.

${ }^{3}$ Prestel O. Dodge, Deckle-edging device. U. S. Patent 1,820,303, filed February 12, 1929, and issued August $25,1931$.
} 
There is, additionally, the question of the exact term—-deckle edge" vs. "deckle-edge" vs. "deckled edge"4. All three are used interchangeably throughout the period in question. Indeed, sometimes they are used interchangeably in the same text. The patent noted above, for instance, uses both "deckled edge" and "deckle edge" as adjectives; a "deckle-edge trimmer" (with hyphen) in a 1940 ad cuts "clean deckle edges" (without a hyphen); a 1957 article discussing paper types refers first to "deckle- or straight-edge rolls", then, a paragraph later, to "deckle edge or straight edge" paper. ${ }^{5}$ As the slight preference seems to be for the term "deckle edge" without a hyphen, it is this format that shall be used in this paper, with the exception of direct quotations.

\footnotetext{
${ }^{4}$ The four dictionaries cited above agree the adjective form of "deckle edge" is "deckle-edged" (although the American Heritage Dictionary omits the hyphen). However, "deckle-edged" was never used in the literature of the North American photographic industry.

${ }^{5}$ Dodge, Deckle-edging device; Eastman Kodak Company, Advertisement, Studio Light, December 1940, Volume 30, Number 4, p. 18; Eastman Kodak Company, The Photo Finisher, Volume 29 Number 4, Autumn 1957, p. 10.
} 


\section{Chapter 1. Literature Survey}

As deckle edge snapshots have not yet been the focus of any academic study, and indeed are rarely mentioned at all, this literature survey aims to examine the ways snapshots have been treated in the literature more generally. Publications on snapshots can generally be divided into two categories: those coming from a history of photography and/or art context, and those coming from the social sciences. This survey aims to analyze the general trends within each approach, with an emphasis on discussions of the physical object and the context of its creation. As a part of the former, the ways in which publications reproduce snapshots have also been considered.

\section{Snapshots in the History of Photography}

Until the last two decades of the twentieth century, the amateur snapshot was rarely discussed in works on photography, except as a contrast to other types of photographs. ${ }^{6} \mathrm{~A}$ notable exception is Brian Coe and Paul Gates' slim volume The Snapshot Photograph, 18881939, published in 1977.7 Though the authors do discuss the development of the snapshot over the period in question, this discussion is couched entirely in terms of technology, advertisements, and contemporary literature. The only aspect of snapshot appearance mentioned is the size of the

\footnotetext{
${ }^{6}$ For example, the 1974 book The Snap-Shot, edited by Jonathan Green (also published as an edition of Aperture), focused on the relation of the "snapshot aesthetic" to art photography.

7 This book, comprising of 46 pages of illustrated text and another 90 of captioned images, draws from the collection of the British Kodak Museum, which has since been absorbed into the National Media Museum.
} 
negative. Snapshots are grouped according to subject matter and reproduced without borders.

Dates and inscriptions are rarely noted.

From 1998 snapshots regularly made their way into museums and into these museum's catalogues. The first was the San Francisco Museum of Modern Art's Snapshots: The Photography of Everyday Life, in $1998 .{ }^{8}$ In this volume snapshots are reproduced at approximately actual size, including borders. Inscriptions and dates are noted in an index. In his accompanying essay, curator Douglas Nickel emphasizes that snapshots are "cultural object[s]" influenced by many factors, but he does not discuss the specific routes and effects of these influences. ${ }^{9}$ Once again, snapshots are treated as a mass entity, with no delineations of time, context, or form made within the genre.

While Snapshots: The Photography of Everyday Life aimed to treat the snapshot as an object, the same is not true for the two major exhibitions/publications following. Both Mia Fineman's essay in the Metropolitan Museum of Art's Other Pictures. Anonymous photographs from the Thomas Walther collection in 2000 and D. J. Waldie's essay in the Getty Museum's Close to Home: An American Album in 2004 centre on the qualities snapshots can evoke rather than those they possess. Other Pictures reproduces snapshots without their borders, although close to their original sizes; Close to Home enlarges, shrinks, and even crops its snapshots. Only a handful of borders are reproduced. Interestingly, most of these have deckle edges.

The Art of the American Snapshot, 1888-1978, was published in 2007 to accompany an exhibition at the National Gallery of Art, aiming to present the snapshot as a changing object. In

${ }^{8}$ Edited and with an essay by Douglas R. Nickel.

${ }^{9}$ Nickel, Snapshots, p. 12. 
her introduction, Sarah Greenough emphasizes that the subjects, approaches, and styles of the snapshot "have evolved over time in response to changing technologies and cultural influences." ${ }^{10}$ Here, snapshots are divided into chronological periods, the key attributes of each period delineated in individual essays. The various authors draw on advertisements, publications, and wider social histories to explain the trends observed in the snapshots of the time periods of covered in each of their respective chapters. Snapshots are reproduced in approximately their actual sizes, with borders, and with dates and captions noted below. As they are divided into chronological chapters, the reader can visually note the time periods in which trends such as decorative borders, deckle-edges, and date stamps are commonly seen-more readily, in fact, than the image trends suggested in the chapters. However, these physical forms are not included in the discussion of the ways in which snapshots have evolved over time. Only occasionally are non-image areas of snapshots referenced. In the chapter on 1888-1919, Diane Waggoner notes the change from the circular format of snapshots to the rectangular format and the way this in turn allowed for cropping, affecting the ways in which these photographs were composed. ${ }^{11}$ Greenough, in her chapter on the period 1940-1959, describes the original Polaroid as having "deckled edges" but makes no other mention of the existence of the deckle-edge in the period, although two-thirds of the snapshots reproduced in the chapter display them. ${ }^{12}$ Matthew S.

Witkovksy mentions the fact that snapshots in the period of the 1950s-1970s were often square rather than rectangular and notes the way in which this gives the period a "look" but does not

\footnotetext{
${ }^{10}$ Greenough, "Introduction," in The Art of the American Snapshot, p. viii.

11 Waggoner, "Photographic Amusements 1888-1919," in The Art of the American Snapshot, p. 23.

12 Greenough, "Fun Under the Shade of the Mushroom Cloud 1940-1959," in The Art of the American Snapshot, p. 157.
} 
address factors influencing this look. ${ }^{13}$ These three authors recognize that the physical characteristics of snapshots varied over time, but do not follow through with discussion or analysis. The book's aim to approach the snapshot as an object changing in response to its social world is significant, but all the authors overlook the most obvious changes in the snapshot object: those to its physical form.

The essays in Now is Then: Snapshots from the Maresca Collection, published in 2008 alongside an exhibition at the Newark Museum, are similar in emphasizing the importance of social context in the study of snapshots without extending the discussion to the interaction between context and physical object. In this book, snapshots are reproduced at about their actual size, inclusive of borders, with dates and inscriptions noted below the image. Despite the context-based perspective of the essays, however, the snapshots are not ordered chronologically. Marvin Heiferman's essay "Now is Then. The Thrill and the Fate of Snapshots" emphasizes the role of social, cultural, and visual context in the creation of a snapshot, using the 1920s and 1930s as a case study. ${ }^{14} \mathrm{He}$ argues the importance of considering the snapshot as a three-dimensional cultural object, not just an image. However, his discussion centres on approaching snapshots with the context of their period in mind, rather than beginning with the snapshots themselves and examining the physical objects for clues about the contexts of their creation. Nor does he tie his discussion to any specific snapshots or body of them.

Geoffrey Batchen's article in the same book, titled "From Infinity to Zero," has the same shortcoming. He emphasizes the importance of the context in which snapshots were made, but

\footnotetext{
${ }^{13}$ Witkovsky, "When the Earth Was Square 1960-1978, "in The Art of the American Snapshot, 231

${ }_{14}$ Heiferman, "Now is Then. The Thrill and the Fate of Snapshots" in Now is Then, pp. 43-45.
} 
leaves the examination of this context to future scholars. Like Heiferman he discusses "snapshots" in general, using only three specific snapshots from the volume as stand-ins for the whole. ${ }^{15}$ Notably, while providing detailed descriptions of each snapshot, he focuses only on the image. ${ }^{16}$ Another article by Batchen appeared in the journal Photographies in 2008, one of only two articles on snapshots published in any of the four journals on the history of photography in the last twenty years. This article reproduces much of the argument from Batchen's essay in Now Is Then, while adding a discussion of both the importance of and challenges in writing a history of snapshots. ${ }^{17}$ Interestingly, when the same three snapshots Batchen describes in Now is Then are reproduced, this time it is without their borders — an especially surprising choice for an academic journal in the history of photography. The main issue with Batchen's article, his tendency to speak of snapshots only theoretically, is an issue that recurs in Lynn Berger's 2011 article "Snapshots; or, Visual Culture's Cliches," also published in Photographies. Berger, in fact, mostly describes snapshots by quoting Batchen. ${ }^{18}$ The bulk of her essay is dedicated to a theoretical examination of the meaning of cliché and the way this can be observed in the visual repetitiveness of the snapshot, with little grounding in either its physical form or social context. Indeed, not a single photograph is reproduced. While this type of theoretical discussion may

\footnotetext{
${ }^{15}$ Batchen, "From Infinity to Zero," in Now is Then, pp. 121-122.

${ }_{16}$ This is a common lack in descriptions of snapshots. The only exception the author has yet discovered is in Martha Langford's Suspended Conversations. The Afterlife of Memory in Photographic Albums (Montreal and Kingston: McGill-Queen's University Press, 2001), where Langford not only describes the decorative borders of several snapshots in an album, but uses them in her analysis (8).

${ }^{17}$ Geoffrey Batchen, "Snapshots. Art history and the ethnographic turn," Photographies Vol. 1, No. 2, September 2008: 21-142.

${ }^{18}$ For instance Berger, "Snapshots," 178, 182.
} 
have value in discussing the importance of the study of snapshots, its lack of a basis in objects or even primary literature does little to advance the actual study of snapshots.

Overall, the general recent trend in the history of photography has been to put more emphasis on the snapshot photograph as an object. However, even in more recent publications, much of this discussion still consists of preliminary suggestions for future study. The snapshot's physical attributes, though recognized implicitly through the way they are reproduced in these publications, are rarely addressed. Scholars have yet to analyze any of the information about the contexts of a snapshot's creation that can be derived from the physical object itself.

\section{Snapshots in the Social Sciences}

Since the early 1980s snapshots have been the subject of study in a variety of interrelated fields of social science, including anthropology, sociology, psychology and communication studies. Generally speaking, a social science approach centres on social and cultural contexts, employing both qualitative and quantitative research methods.

In his 1981 article "Redundant Imagery: Some Observations on the Use of Snapshots in American Culture," published in the Journal of American Culture, Richard Chalfen argues for the inseparability of the snapshot from its social context, emphasizing its role as a consumer object. Unlike many other writers, he focuses his ongoing study on the analysis of a sizeable body of work. However, no snapshots are ever reproduced or described in detail, and his analysis 
focuses only on the content of the image. David L. Jacobs's article "Domestic Snapshots: Toward a Grammar of Motives," in the same publication, goes a step farther by beginning to group snapshots according to various "types." These types, however, are thematic rather than chronological or object-based, and his approach centres on meanings relating to social psychology. Julia Hirsch does something similar in her book Family Photographs: Content, Meaning, and Effect, also published in 1981, by analyzing the conventions of snapshot images, such as recurrent poses and settings. These authors provide examples of the ways the division of snapshots into sub-categories can be meaningful, a thread that our examination of snapshots according to physical characteristics w take up.

In his 1987 book Snapshot Versions of Life, Richard Chalfen expands on the ideas of his earlier article mentioned above to provide a more detailed discussion of "the social context of visual representation" in the realm of snapshots. ${ }^{19}$ Here, Chalfen focuses on photographs as messages, cultural products designed for communication. In his analysis he focuses on the creation, use, and emotions associated with snapshots rather than on the photographs themselves; indeed, no photographs are reproduced anywhere in the volume. While he explicitly notes that the physical form of a snapshot affects its role, he groups these physical forms only in general terms, such as "wallet photo" and "framed portrait." ${ }^{20}$ Oddlaug Reiakvam, in his article "Reframing the Family Photograph," published in the Journal of Popular Culture (1993), uses an approach similar to Chalfen's in a qualitative study of the staging in a dozen specific snapshots from a family album to examine the way they express the wider cultural contexts of their

${ }^{19}$ Chalfen, Snapshot Versions of Life, p. 161.

${ }^{20}$ Ibid., 31. 
creation. ${ }^{21}$ Reiakvam's approach is notable in using specific snapshots themselves as a starting point for a study, even if the study is image-based.

The significance of cultural context is examined from a different angle by Nancy Martha West in Kodak and the Lens of Nostalgia (2000). West discusses the snapshot as a commodity shaped by those selling it and influenced by related industries such as the leisure and fashion trades. West's principal source is Kodak print advertising, and she does not discuss the ways her conclusions might manifest themselves at the level of the snapshot itself.

While West's analysis focuses on advertising, Christina Kotchemidova, in her article “Why We Say 'Cheese': Producing the Smile in Snapshot Photography,” published in the journal Critical Studies in Media Communication (2005), applies this method to the snapshot image. Kotchemidova considers the ways Kodak and other major players in the photographic industry influenced society's expectations of what a snapshot should look like. Although her approach is based on image content, it does provide an intriguing example of the impact larger socioeconomic forces can have on personal products.

Social science works on snapshots bring the effects of social and cultural contexts to the fore. However, the tendency to focus exclusively on the content of images remains dominant. Not one of the publications in this section reproduces snapshots with borders. In many of the works, as well, the construction of theories overlooks the examination of snapshots as physical objects. Nonetheless, the examination of the world of snapshots beyond the photograph itself is valuable.

\footnotetext{
${ }^{21}$ The article includes reproductions of three full album pages, though specific snapshots reproduced later are reproduced without the borders seen on the album pages.
} 
The trend in more recent publications in the history of photography has been to view the snapshot as something more than an image. This approach is not only laid out in the essays themselves, but implied by graphic layouts that reproduce snapshots with borders, keeping the original dates and inscriptions on the snapshots on the same page. Historians of photography are now paying more attention to the contexts of the work they are discussing, a topic that is expanded on by a several social scientists in interrelated fields. However, the snapshot has not yet been approached principally as a material object. Its physical characteristics have yet to be read for the evidence they provide about its creation and the methods of that creation. The foundation has been laid for an in-depth analysis of the snapshot's physical characteristics in an evolving context; it is this foundation upon which my study builds. 


\section{Chapter 2. Sources and Methodology}

The research for this study is based on two main sources: a carefully selected study sample of deckle edge snapshots, and contemporaneous trade literature.

The study sample consists of 321 dated deckle edge snapshots. Due to the small size of this sample, the conclusions drawn from it have been viewed as a starting point rather than as definitive in their own right. The sample was selected from a number of unrelated snapshot collections in the holdings of the Archive of Modern Conflict (AMC), Toronto. These collections came to the AMC via private collectors, photograph dealers, and family archives from Canada and the United States. The total number of snapshots examined to create the sample was over $15,000 .{ }^{22}$ Each snapshot in within these collections was meticulously examined while searching for and selecting those with deckle edges.

As the establishment of the dates of the deckle edge snapshot is a key aspect of this study, deckle edge snapshots were only selected for the sample if they were dated; the various types of dates found shall be discussed further in the next chapter. When several dated deckle edge snapshots appeared to be part of the same group_-defined as sharing at least two of: subject matter, exact dates, handwriting, and/or physical arrangement within the collection-only one was selected for the sample, as the inclusion of multiple snapshots from the same source would

\footnotetext{
${ }^{22}$ As some of the larger snapshot collections of the AMC Toronto have not yet been individually counted, this number is an estimate.
} 
destabilize the otherwise random nature of the sample. Dated deckle edge snapshots were not excluded for any other reason. This use of selection criteria based entirely on the existence of a deckle edge and a date eliminated subjectivity in sample selection. Occasional undated deckle edge snapshots have been reproduced in this thesis as illustrations of pertinent points not represented in the dated set; however, these are not a part of the study sample and do not make up any part of the numerical data.

All snapshots in the sample are gelatin silver prints. Sizes range from 5 x $6 \mathrm{~cm}(2 \times 2.4$ inches) to $9 \times 14.2 \mathrm{~cm}$ (3.5 x 5.6 inches). 97 (30\%) are square in shape. As well as bearing deckle edges, 33 are embossed, 35 have rounded corners, and 8 have photographically printed borders, all examples of other unstudied physical characteristics of snapshots.

The majority of the snapshot collections surveyed derived their materials from a variety of sources themselves, ensuring a high degree of randomness at the outset. All collections contained mixtures of straight-edge and deckle edge snapshots. Unfortunately no information currently exists on the distribution of dates within the snapshot collections overall. The snapshots appear mainly to date from ca. 1910 to ca. 1965, with apparently random distribution. However, the trends in deckle edge snapshot dates derived from the sample would be stronger if they could be compared against the trends of all dated snapshots in the collection. This point, as well as the relatively small size of the sample, means the data derived from it can only be viewed as a starting point. Conclusions, particularly about dates, are tentative until they can be reinforced by other sources and/or a larger sample. 
The trade literature consulted primarily comprised of Kodak trade periodicals published from the 1920 s to the 1960 s. Within the limited scope of this project Kodak publications were deemed most significant, due to the company's status as industry leader in the amateur photography market in North America through the early to mid-twentieth century, and because a very large proportion of materials for the creation and finishing of snapshots were produced, promoted, and sold by Kodak. In fact, Kodak was frequently sued for monopolizing the market for photographic materials. ${ }^{23}$ Additionally, as scholars such as Christina Kotchemidova have noted, Kodak actively worked to influence the public's perception of the look of a snapshot. ${ }^{24}$ It would thus be expected that Kodak would also play a dominant role in the manufacture and dissemination of the deckle edge.

The principal periodicals consulted were: Kodak Salesman, aimed at dealers of Kodak products, which in 1949 changed its name to Kodak News, and again in 1951 to Kodak Dealer News, The Photo Finisher, aimed, of course, at photofinishers; Studio Light, aimed at professional photographers, particularly commercial portrait photographers; and the Condensed Price List, Kodak's yearly wholesale listing of products. These publications have never been the subject of any study, and there is no central source of information on them. Researching the publication dates, circulation, and expressed aims of Kodak's trade periodicals was out of the scope of this project, but future work in the area would be advantageous in clarifying and solidifying the information derived from it, both for this topic and related ones.

${ }^{23}$ Kotchemidova, “Why We Say 'Cheese,” p. 4.

${ }^{24}$ Ibid., 9-16. 


\section{Chapter 3. Dates}

An essential starting point for the study of the deckle edge snapshot is the establishment of the dates in which it was seen and in which it was most popular. These dates can be derived from two sources of testimony: that of the objects, and that of the literature. This chapter focuses on the former, as represented in the study sample. The dates offered by the sample were then used as a starting point for the investigation of the literature, which is addressed into the discussions of manufacture methods and advertising in chapters four and six respectively.

Dates for the snapshots in the sample were drawn from three sources: handwritten inscriptions, photofinishing stamps, and dates printed in the white border on snapshot rectos. Handwritten inscriptions may be on the recto or verso, and may be a precise date (June 7, 1957) or simply a year (1965). Photofinishing stamps are impressed onto the verso with ink, and include the precise date or month and year the photograph was processed, generally along with the name and sometimes location of the photofinisher. Border-printed dates are, of course, printed in the white border on the front of the print. While the dates in the earliest examples in the sample appear to be stamped, border-printed dates from the 1950s onwards are printed by automated photofinishing machines. ${ }^{25}$ Border-printed dates most commonly include the month and year of photofinishing, printed along one edge of the border, generally that above or to the

\footnotetext{
${ }^{25}$ Though border-printed dates are another aspect of snapshot presentation yet to be studied, examples of machine attachments for their creation can be found alongside advertisements for photofinishing machines in the 1950s, for instance with the Kodak Velox Rapid Printer, Type IV, in The Photo Finisher, Spring 1955, Volume 27 Number 1, page 10 .
} 
left of the image. ${ }^{26}$ Variations include one in which the year is printed diagonally at all four edges of the print, and another in which the year is incorporated into a decorative border. ${ }^{27}$

Handwritten dates comprise

the majority, seen in 146 instances

(45.5\%). Border dates are seen in 141

instances (44\%), with 30 instances

(9.3\%) of stamped dates. 3 snapshots

(0.9\%) have both a border-printed

date and a hand-written date (table

1).

The preponderance of the

border-printed date is somewhat

problematic. Though snapshots with

border-printed dates make up a large

number of the whole, their

distribution through the sample is

uneven. The border-printed date

gained popularity much later

\section{Border-Printed Dates vs. All Dates}

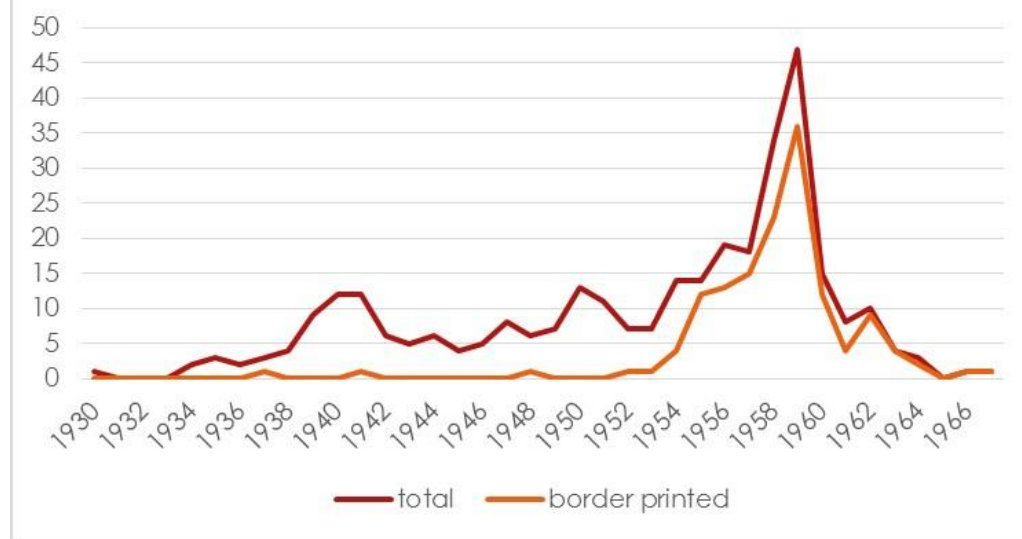

Table 1. Comparison of border printed dates to whole of dated snapshots in the study sample

than the deckle edge (table 2). While the earliest deckle edge in the sample dates from 1930, the earliest border-printed date is 1937 . Only two more examples are seen before 1952. This creates

${ }^{26}$ For examples, see figures. 23, 26-27, 35-36, 41-42, and 44.

${ }^{27}$ For an example of the decorative border with date, see figure 18. 
an undeniable bias. The border-printed date was quite popular in the period in which it appears, from 1952 onwards, almost certainly resulting in more snapshots from that period coming with dates and thus skewing the sample. However, border-printed dates make handwritten dates less likely - the sample contains only three examples displaying both. Their elimination would thus create an opposite bias for the period of their popularity. A study of border-printed dates has not yet been done, much less an examination of their ubiquity relative to the total numbers of snapshots in their period (whether deckle edge or straight edge), so it is impossible to estimate the degree of this bias. However, the trends seen in the study sample can be compared to the trends seen in the literature. As shall be discussed, the patterns of frequency seen in the study sample do in fact generally correlate with the patterns in availabilities of deckle edge materials, indicating the date type bias does not overly distort the data.

Results of Date Survey:

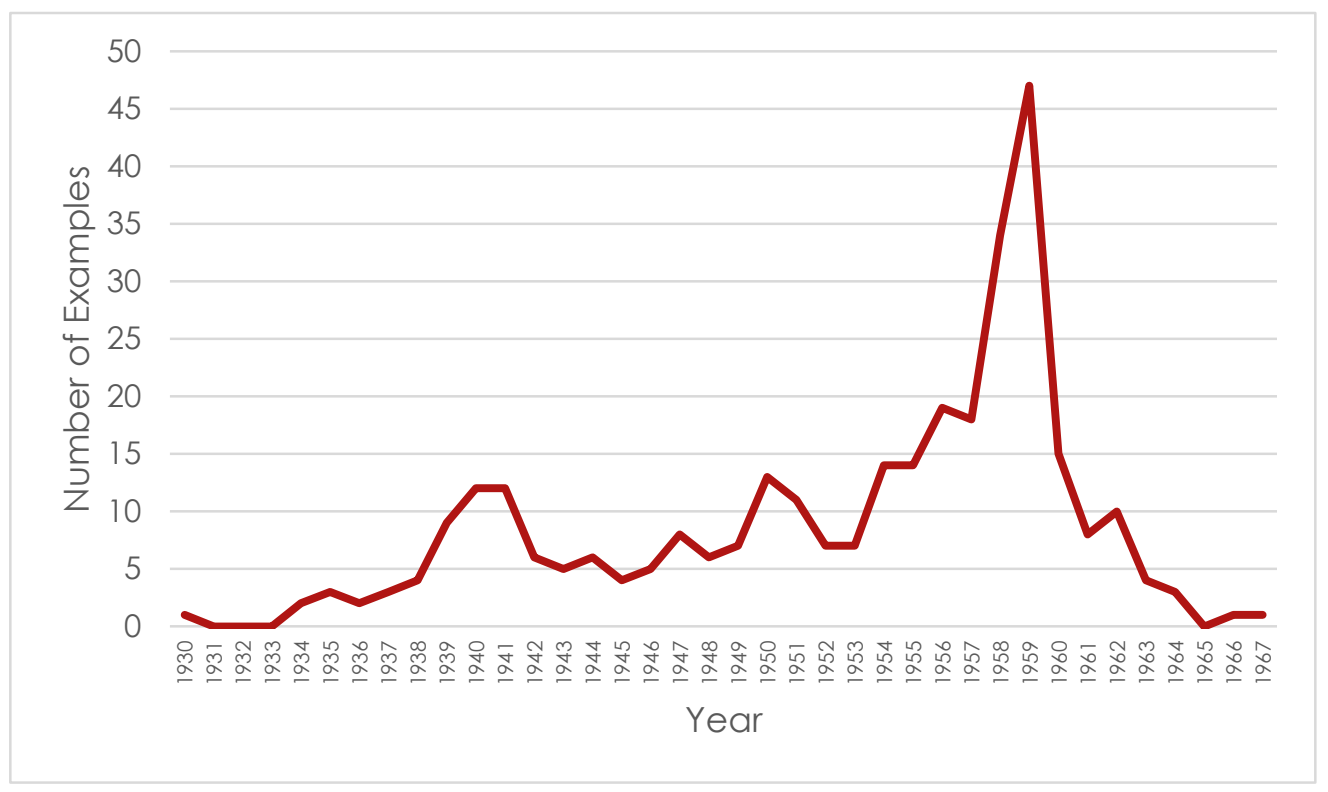

Table 2. Date distribution of snapshots in the study sample 
The earliest snapshot in the sample is dated 1930, while the latest is dated 1967, a 37-year range. However, the vast majority $(83.8 \%)$ date from the 20 -year period $1940-1960$. The mean is 1953 and the median is 1955, significantly later than the midpoint of the range (1944).

The year with the highest number of snapshots is 1959 , with 47 snapshots in the sample dating from that year; 34 snapshots date from 1958, 19 snapshots date from 1956, 18 snapshots date from 1957, and 15 snapshots date from 1960. Out of the years included in the range, four do not have any snapshots: 1931-1933 and 1965, and for 1930, 1966, and 1967 there is only one example each.

The sample thus suggests that the deckle edge snapshot arose around 1930 and gained popularity only slowly over the next decade. The 1940s and early 1950s saw gradually increasing numbers (taking into consideration the rationing of film during World War Two), before a strong surge of interest in the late 1950s, and a similarly strong drop in interest in the early 1960s. The next chapter examines the trade literature of the 1930 s to 1960 s to examine corroborative testimony. Nuances of dating within the general trends can be detected based on edge types, as will be discussed in Chapter 5 . 


\section{Chapter 4. Methods of Manufacture}

The first examples of devices to impart a deckle edge specifically to a photograph appear around roughly the same time as the first snapshot in the sample. These devices were found in two patents, filed in 1929 and 1930 by the same man, Prestel O. Dodge. While more research must be conducted to discover if these or similar devices were ever used commercially, the patents are nevertheless interesting documents for their discussion of the deckle edge photograph.

The earlier patent, filed on February 12, 1929 and patented on August 25, 1931, describes a "deckle edging device" that resembles a stylus, which fits into an irregular groove to tear the print in a deckle design (figure 1). ${ }^{28}$ In his introduction Dodge argues that before this device, the creation of a simulated "soft roughly torn edge" that was also straight was difficult and "had to be manufactured by expensive machines and purchased by the photographer in a completely formed condition." ${ }^{29}$ This statement is interesting as it implies that pre-made deckle edges did exist prior to 1929, although they were only purchased by photographers and photo-finishers rather than created by them. ${ }^{30}$ Unfortunately, I was not able to find any information about the machines to which he is referring, nor could I locate examples of deckle edge photographs predating 1930.

\footnotetext{
${ }^{28}$ Prestel O. Dodge, Deckle-edging device. U. S. Patent 1,820,303, filed February 12, 1929, and issued August $25,1931$. 29 Ibid.

30 Though the quote refers to "photographers," Dodge elsewhere refers to photofinishers as a part of his audience for deckle edge creation
} 

Aug. 25, 1931.
P. O. DODGE
$1,820,303$
DECKLE EDGING DEVICE
Filad Feb. 12, 1929
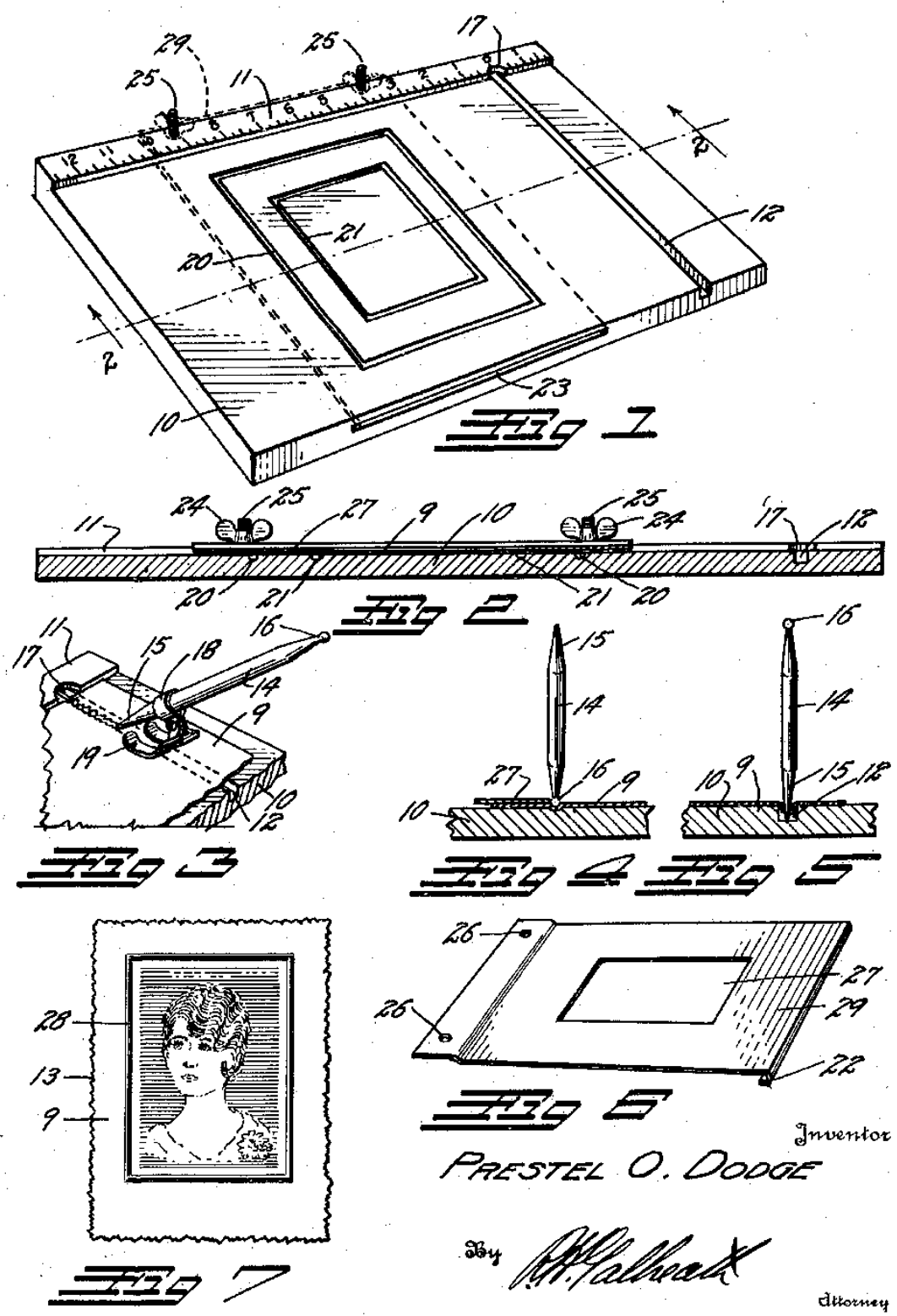

Figure 1. Illustration accompanying the patent application for a device to apply deckle edges to photographs, 1929 
Feb. 23, 1932.

P. O. DODGE

$\mathbf{1 ; 8 4 6 , 0 9 4}$

PAPER DECKLING DBVICE

Filed May 13. 1930
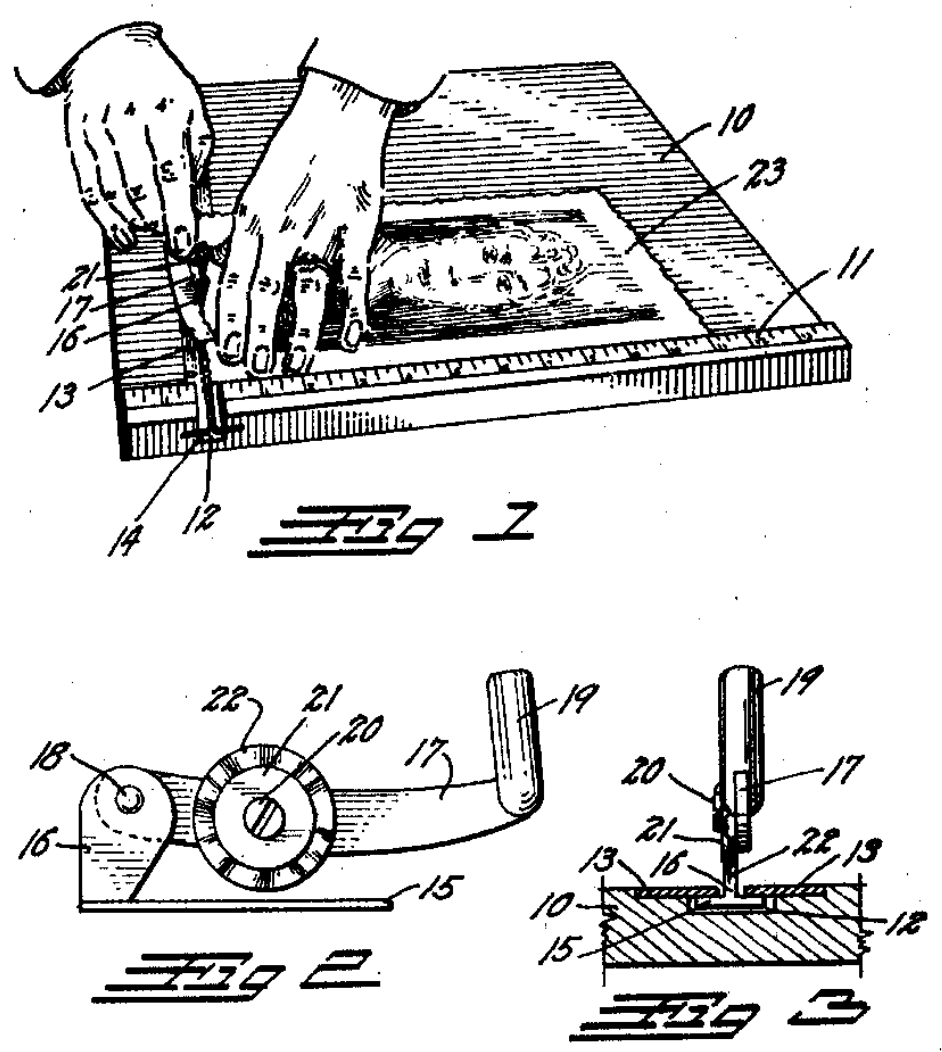

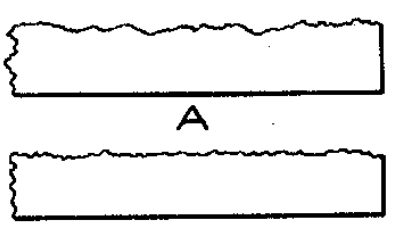

B
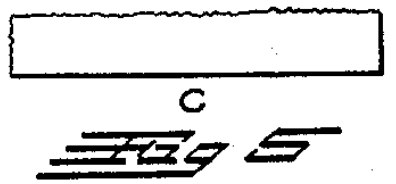
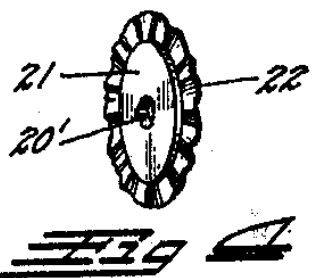

Inventor

Prestel O. DODOL

ony

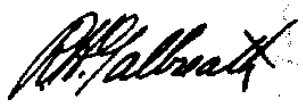

attorney

Figure 2. Illustration accompanying the patent application for an updated device to apply deckle edges to photographs, 1930 
Dodge emphasizes the fact that his device does not cut—it breaks the paper to create a "soft" edge. ${ }^{31}$ His second patent stresses the same point: "a perfect deckle edge," he writes, "has in addition to a regular contour a broken, frayed, or feathery appearance. This cannot be obtained by a cutting process." 32 This second patent, filed on May 13, 1930 and patented February 23, 1932, is for a handheld "deckling wheel," which again fits into a groove to tear the paper edge (figure 2). ${ }^{33}$ This wheel also makes varying styles and degrees of deckle edges possible.

Whether or not his inventions ever saw popular use, Dodge's conviction that deckle edges should be torn instead of cut was certainly overruled, especially by Kodak. From 1934 A "deckle edge trimmer" was sold by Kodak in the United Kingdom, although this product does not appear in any North American price lists or catalogues. ${ }^{34}$ This product, which "trims and gives deckle edges at the same time" resembles a regular paper cutter, with a serrated blade (figure 3).
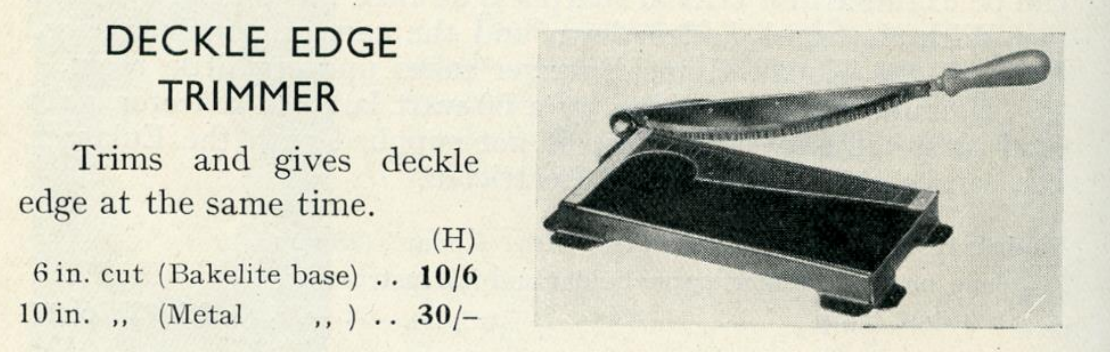

Figure 3. Advertisement for a deckle edge trimmer from the British Kodak dealer's catalogue, 1934

\footnotetext{
${ }^{31}$ Dodge, Deckle-edging device.

${ }^{32}$ Prestel O. Dodge, Paper deckling device, U.S. Patent 1,846,094, filed May 13, 1930, and issued February 23, 1932.

${ }_{33}$ Dodge, Paper deckling device.

${ }^{34}$ Kodak Limited., Kodak Photographic Apparatus and Materials (London: Kodak Limited, 1934), p.192.
} 
While North American Kodak branches sold various paper cutting devices through the 1930s, here a deckle edge trimmer does not appear as a Kodak product until 1940. ${ }^{35}$ Ads for this "Eastman Deckle edge Trimmer" appear in Studio Light in the same year, containing both an image and a description (figure 4). ${ }^{36}$ Described as new and modern, it differs in construction from the earlier device sold in the United Kingdom. Indeed, its new design is used as a selling point, with half the sentences of the ad's copy devoted to a description of its use. According to this description: "the handle acts as a lever, rotating a cylindrical cutting blade. Teeth on this plate are machined to mesh with a plate on the base, producing a shearing action which cuts a clean deckle edge." ${ }^{37}$ This device was sold through 1946; in 1947 it disappears from the price list, outsold, perhaps, by the other deckle edge materials Kodak introduced in the meantime. ${ }^{38}$

Through this period Kodak sold pre-cut sheets of photographic paper in a variety of sizes. The paper designed specifically for printing from amateur negatives was Velox. Regular Velox was intended for contact printing, while Velox Rapid was the paper used for printing enlargements from negatives. From 1941 pre-cut sheets of both Velox and Velox Rapid could be purchased with deckle edges "in the same price" for a variety of popular snapshot sizes, ranging from 1 7/8 x 2 3/4 inches to 4 1/8 x 6 3/8 inches. ${ }^{39}$ In 1949 Kodak introduced Velox Unicontrast Rapid F, an enlargement paper with an even longer scale than Velox Rapid. ${ }^{40}$ The paper came in five

\footnotetext{
35 Eastman Kodak Company, Condensed Price List (Rochester NY: Eastman Kodak Company, 1940), p. 36.

36 Eastman Kodak Company, Advertisement, Studio Light, December 1940, p. 18.

37 Ibid.

38 Eastman Kodak Company, Condensed Price List (Rochester NY: Eastman Kodak Company, 1941), p. 41-42.

39 Ibid.

${ }^{40}$ Eastman Kodak Company, Condensed Price List (Rochester NY: Eastman Kodak Company, 1955), p. 30.
} 


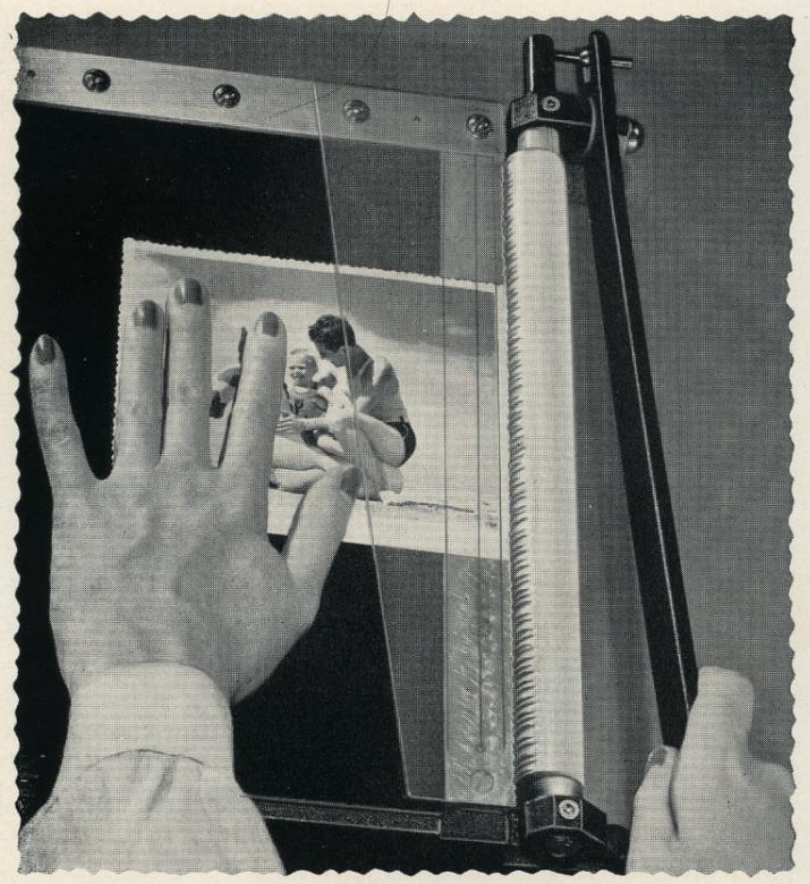

\section{EASTMAN}

\section{DECKLE-EDGE TRIMMER}

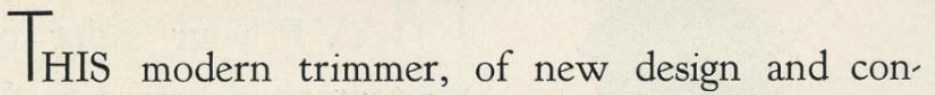
struction, produces deckle edges on either single or double weight prints up to Io inches. As will be seen by the illustration, the handle acts as a lever, rotating a semicylindrical cutting blade. Teeth on this blade are machined to mesh with a plate on the base, producing a shearing action which cuts a clean deckle edge. A transparent trimming gauge is ruled for wide or narrow margins. The price is $\$ 30$, at your dealer's.

EÁSTMAN KODAK COMPANY, Rochester, N. Y.

Figure 4. Advertisement for the Eastman Deckle edge Trimmer from Studio Light, 1940 
pre-cut sizes, from $3 \times 3 \frac{1}{12}$ inches to $3 \frac{1}{2} \times 5 \frac{3}{3}$ inches, and two roll sizes ( $3 \frac{1 / 4}{4}$ and $3 \frac{1}{1 / 2}$ inch width); deckle edges were an option for all. ${ }^{41}$ Deckle edge options for Velox, Velox Rapid, and Velox Unicontrast Rapid F were available, with slight variations in the numbers of sizes offered, at least until 1955, when the Condensed Price List ceased publication. ${ }^{42}$

From 1949 Kodak also offered "Kodak album print paper," a sub-variety of Velox, which was precut with punched holes and an extra wide, hinged border on one side, so prints could easily be assembled into a small album or torn out of it as desired (figure 5; see also figures 21-27). ${ }^{43}$

Notably, this paper came only in deckle edge form. This choice may have been a tie-in with the decorative context of the album, and/or a practical choice-uneven edges are more easily torn in a straight line, while the tear marks of a removed hinge would be less noticeable with an already torn-looking border. The album print paper came in four slightly different sizes, ranging from 3 $1 / 4 \times 3 \frac{1 / 4}{4}$ inches to $3 \frac{1 / 2}{2} \times 5 \frac{3 / 4}{4}$ inches, and was sold at least through $1955 .{ }^{44}$ Alongside these pre-cut sheets, Kodak sold an album print cutter for use with rolls, also introduced in 1949 (figure 6). ${ }^{45}$ Though Kodak offered over twenty paper types through the period, the only non-Velox variety sold with pre-cut deckle edges was Azo, a contact printing paper intended for a variety of uses. Azo paper was used for Kodak's photographic Christmas cards, which shall be discussed in Chapter 7, and from 1938 it was seasonally available with deckle edges in the standard Christmas card size, $41 \frac{1 / 4}{4} 5$ 1/2. ${ }^{46}$ From 1941 deckle edge Azo paper in this size was available year-round,

\footnotetext{
${ }^{41}$ Eastman Kodak Company, Condensed Price List (Rochester NY: Eastman Kodak Company, 1949), p. 30.

${ }^{42}$ Condensed Price List, 1955, p. 30.

43 Eastman Kodak Company, January 1949, Volume 21, Number 7, pp. 6-7.

${ }^{44}$ Eastman Kodak Company, Trade Circular, June 1949, p. 2; Condensed Price List, 1955.

45 Eastman Kodak Company, The Photo Finisher, Volume 21 Number 7, January 1949, p. 6.

46 Eastman Kodak Company, The Kodak Salesman, Volume 24 Number 10, October 1938, p. 8.
} 


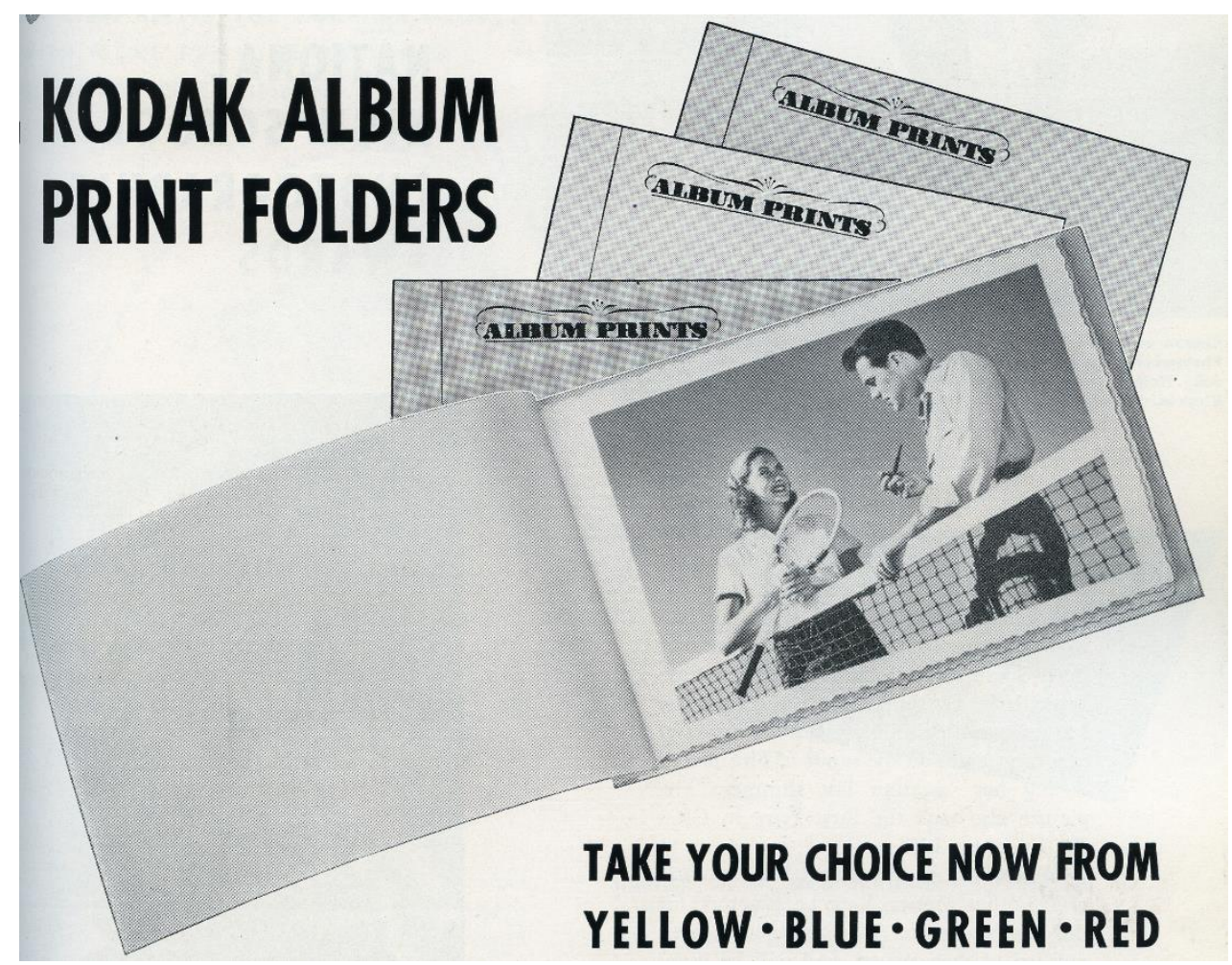

Figure 5. Advertisement for Kodak album print folders, with deckle edge snapshots printed on album print paper, The Photo Finisher, 1950

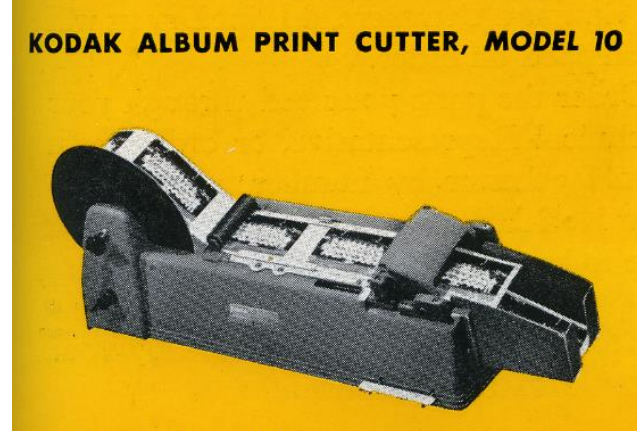

... for cutting roll paper

into prints for the new Folders

THIS new Kodak Album Print Cutter, Model 10, was designed with but one purpose in view - to cut prints of appropriate shape from roll paper for the Kodak Album Print Folders. Its deckle blade accurately stamps out an Album Print as you depress the release bar. Supply spindle is ball-bearing mounted. Lighted, recessed mirror for easy reading of print identification numbers. Takes $31 / 4$ - or $31 / 2$-inch roll paper. Has cast aluminum body with 12 -foot cord. 115-volt, 60-cycle A.C. only.

(7)

\section{THE PHOTO FINISHER ... A Kodak Publication}

Figure 6. Advertisement for a cutting device to create album prints, The Photo Finisher, 1949 
through 1955. By 1955 Azo could also be purchased with deckle edges in rolls of $3 \frac{1}{2} 2$ and 4 1/4 inch width. Though it is unclear if Kodak offered any kinds of deckle edge paper trimmers or cutters between 1947 and 1953, a variety of devices that cut deckle edges were introduced by the company from 1954. Aligning with the increasing mechanization of photofinishing, these devices are more mechanical and usually more multi-purpose than the earlier cutters. In 1954 Kodak introduced the Direct Roll Paper Cutter, an automated cutting device (figure 7). This machine was offered with three blades: a straight blade, a deckle edge blade, and a blade designed to cut deckle edges along with hinges like those seen in the Album Print Paper. ${ }^{47}$ In 1955 the Kodak Velox Rapid Printer type IV was introduced, an automated combined printer cutter. Four blades came with this device, three of which cut deckle edges, and two of which cut holes and hinges for album use. ${ }^{48}$ The two page spread in the trade publication announcing this device includes illustrations of snapshots cut with all four options (figure 8).

A motor-driven "power trimmer" that was introduced in 1956 similarly includes both straight and deckle edge blades (figure 9), as does a device for combined cutting and embossing released the same year. ${ }^{49}$ These products were all designed to be used with roll paper, bearing testament to the increasing mechanization of the photofinishing industry. The sources for this study unfortunately trail off by the late 1950s, leaving undetermined the question of when Kodak's deckle edge products ceased to be produced. However, from the 1930s to the 1950s the availability of deckle edge products corresponds to the general trends seen in the study sample.

\footnotetext{
${ }^{47}$ Eastman Kodak Company, The Photo Finisher, Volume 26 Number 4, Winter 1954, p. 10.

${ }^{48}$ Eastman Kodak Company, The Photo Finisher, Volume 27 Number 1, Spring 1955, p. 10.

${ }_{49}$ Eastman Kodak Company, The Photo Finisher, Volume 28 Number 3, Summer 1956, p. 10.
} 


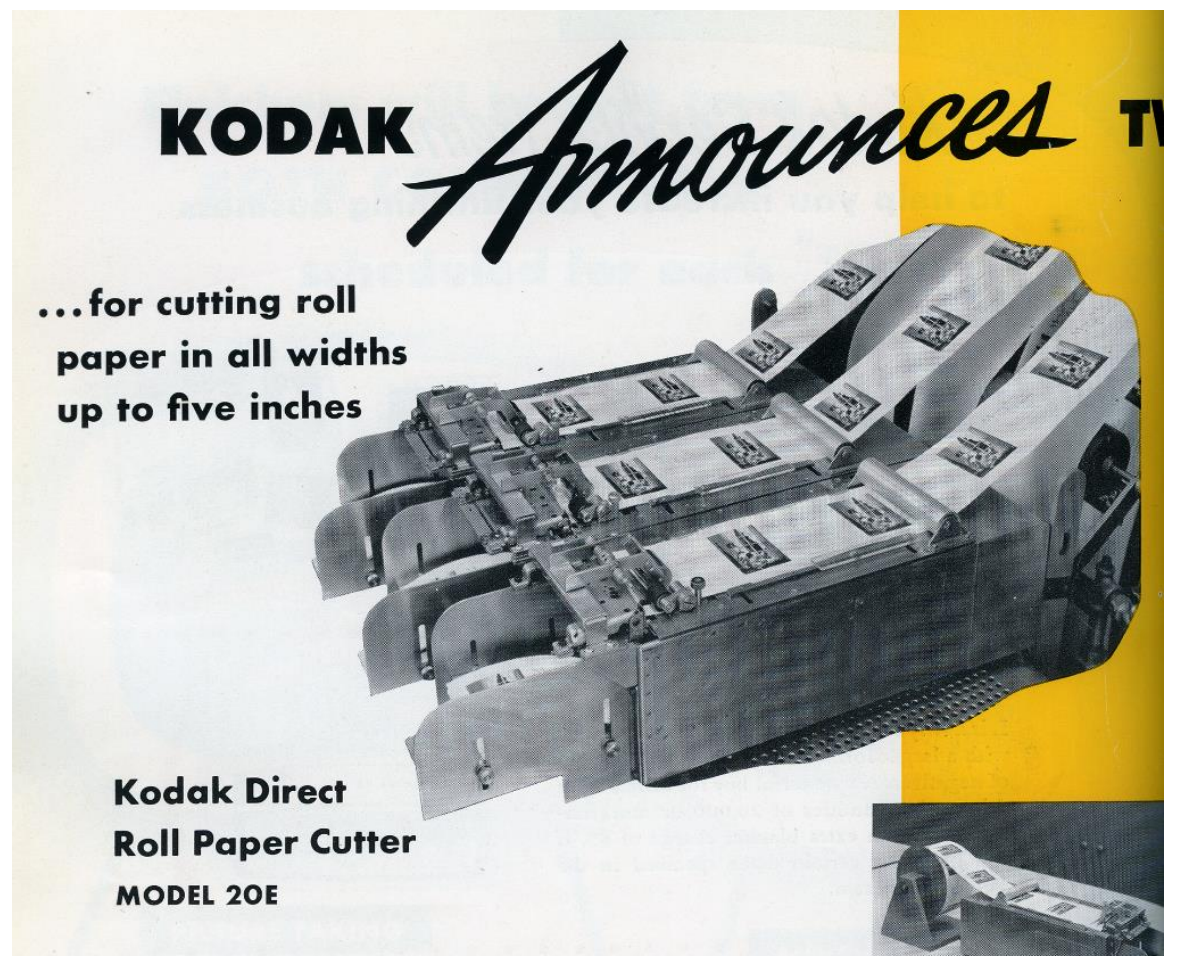

Figure 7. Advertisement for the Kodak Direct Roll Paper Cutter, The Photo Finisher, Winter 1954

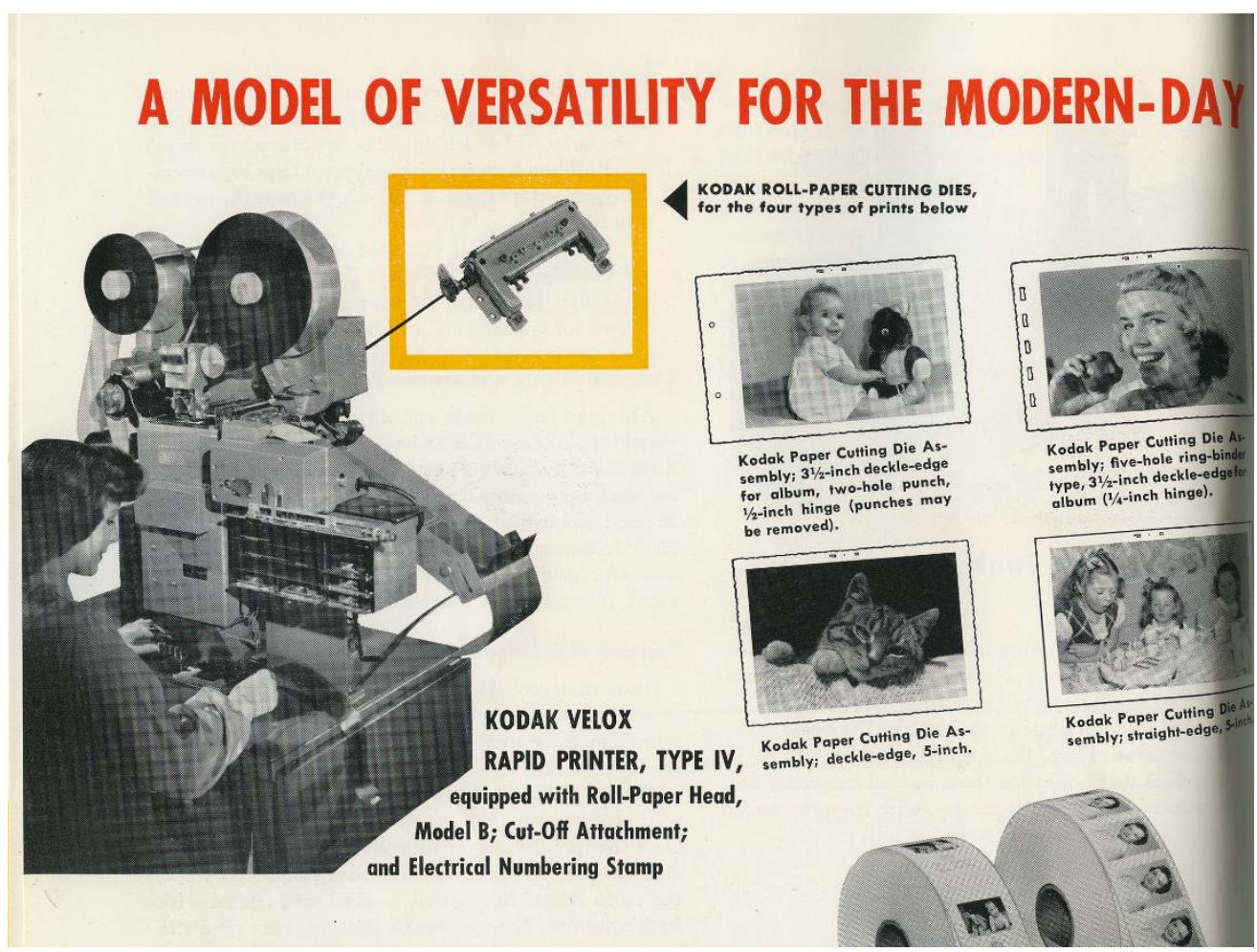

Figure 8. Advertisement for the Kodak Velox Rapid Printer type IV, with illustrations of print types possible, The Photo Finisher, Spring 1955 


\section{KODAK POWER TRIMMER}

Model 1

Designed to cut or trim single- or double-weight paper up to 10 inches wide. Cutting blades (straight- or deckleedge) are rotary type, motor driven, and actuated by a foot switch. Can be used with a Roll Paper Holder or at the end of a roll-paper processor dryer. List price of the Kodak Power Trimmer, Model 1 , is $\$ 375$. From Rochester only.

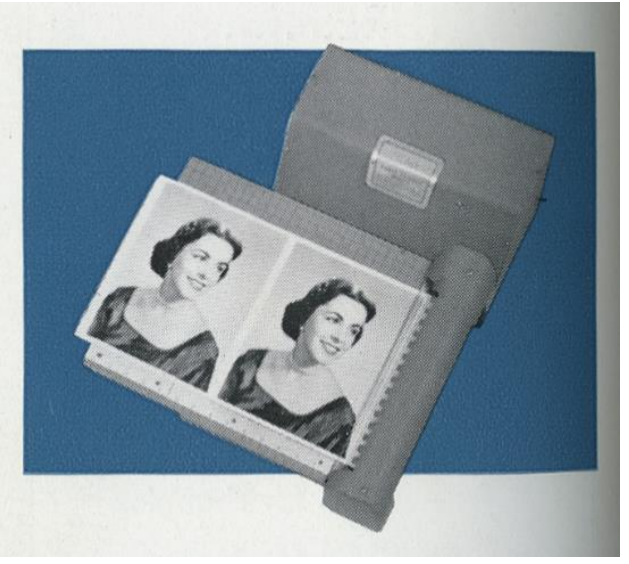

Figure 9. Advertisement for the Kodak Power Trimmer, The Photo Finisher, Summer 1956

First appearances of deckle edges occur in the early 1930s, rising through the 1940s, with the peak in the mid-1950s. It can thus be inferred that the introduction and availability of deckle edge papers, cutters, and other devices declined fairly quickly in the early 1960s, probably ending production by the middle of the decade, though this remains to be confirmed. 


\section{Chapter 5. Edge Types}

As touched upon in the introduction, "deckle edge" is something of an umbrella term. As has been discussed, deckle edges were created through various methods, from hand-cutting with paper cutters to mass production with automated machines. Knowing this, it comes as little surprise the resulting edges would vary. The term, however, did not. An edge described as a "deckle edge" could be irregular, sharp, and rough, as described in the 1929 and 1930 patents of Prestel Dodge (see page 21) or it could be rounded, repeating, and clean-cut, as in fact the majority of snapshots in the sample are. The patterns of edges could in fact vary within the same print. No distinction was made in the literature contemporary to deckle edge manufacture, and no distinctions seem to have been made since. Ultimately, it seems that deckle edge snapshots have been defined mostly by the simple fact of their difference from straight edge snapshots.

There is much value in examining the nuances whitewashed by the term. The different edge types were the results of differing methods of manufacture, reflecting changes in the photofinishing industry. The dates seen for different edge types vary accordingly, allowing for more precise dating of deckle edge snapshots. In many cases, the date of an edge type's first appearance appears to correlate to the release date of one of Kodak's deckle edge related products, illuminating the interaction between company and consumer.

The variations of deckle edge seen in the sample studied here can be grouped into nine different types. Some of these types contain more internal variation than others, and perhaps sub-categories can be determined in the future; however, the boundaries of the nine types 
provide a meaningful way of dividing, analyzing, and potentially dating groups of deckle edge snapshots.

For each edge type I have described the key characteristics distinguishing it from others, focusing on patterns of peaks, hills, and valleys as well as the existence of "feathering." Feathering is the term I have chosen to describe edges that are not clean-cut, with feathery wisps of paper fibres remaining. This term is used elsewhere to differentiate soft edges from crisp ones, for instance referring to ink, make-up, and the blurring of edges by computer rendering software. The choice is informed also by the reference in Dodge's 1930 patent to the "feathery appearance" of a deckle edge that is not produced by cutting. ${ }^{50}$

I have noted the date ranges of each edge type in the sample and charted their frequency of appearance over the period of the wider snapshot sample (1930-1967). With the exception of the rarest edge types I have included the mean as well, as a shorthand indication of the period most associated with the type.

As the sample size is limited, these numbers should not be taken as definitive; rather, they should be regarded as a starting point. The dates of first appearance for many of the edge types appear to correspond to the dates of Kodak's release of new deckle edge related products; however, suggestive as they may be, these proposed links must be regarded as tentative. If examples of the relevant machines, deckle edge blades, and/or packages of pre-cut paper could be located, the suggested links between edge appearance and products could be tested and perhaps verified.

${ }^{50}$ Dodge, Paper deckling device. 
Since these edge types have not previously been differentiated, I had to come up with terms for each type. In the sections following, the deckle edge types are arranged in chronological order, starting with that seen in the first deckle edge in the sample. 


\section{The Irregular Deckle Edge}

The classic deckle edge, characterized by an irregular pattern of hills and/or peaks with a "torn" appearance. Feathering on multiple sides is common, but not always seen.

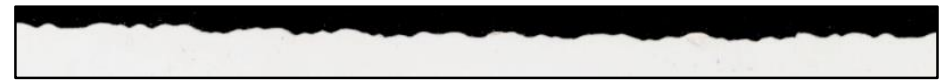

The study sample contains 67 examples of snapshots with irregular deckle edges, comprising 20.9 $\%$ of the total (first in overall frequency). These snapshots span the period from 1930 to 1961 , although they appear with most frequency in the 1930s and 1940s. The mean date of irregular deckle edge snapshots in the sample is 1944. The latest two examples, from 1958 and 1961, bear Eastern European handwriting and a Cyrillic backstamp respectively.

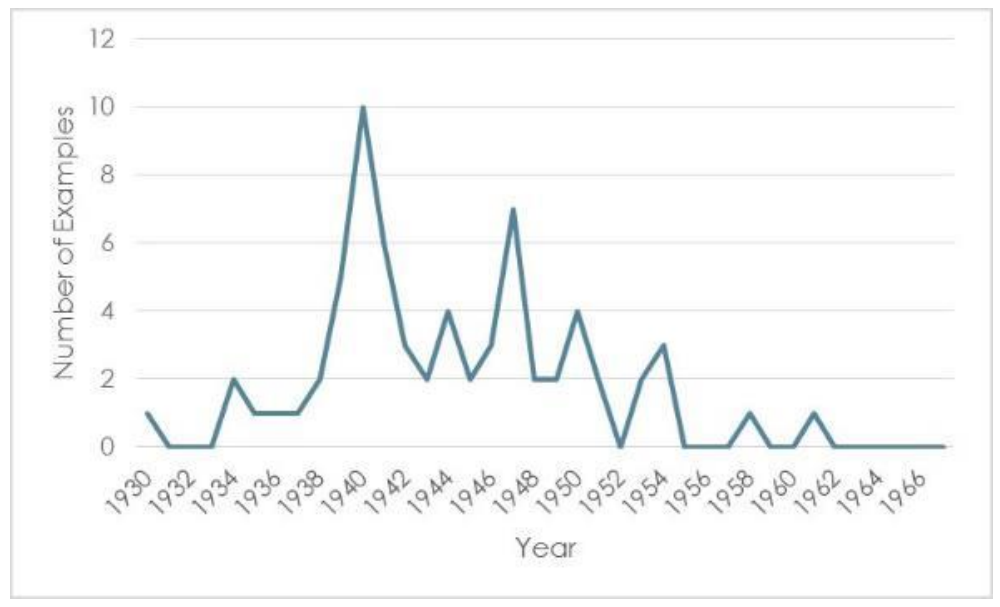

Table 4. Date distribution of the irregular deckle edge

Based on the dates and frequency of feathering, it is likely that this type of edge would have been created with a paper cutter type trimmer and/or a deckling device similar to those patented in the early 1930s. As newer ways of acquiring deckle edges were introduced through the 1940s and 
1950s, the use of these older techniques declined, accounting for the downward trend in this type from the late 1940s onward. The later dates of the Eastern European snapshots suggest regional variation in trends and/or methods of manufacture, as shall be further discussed below.

Examples:

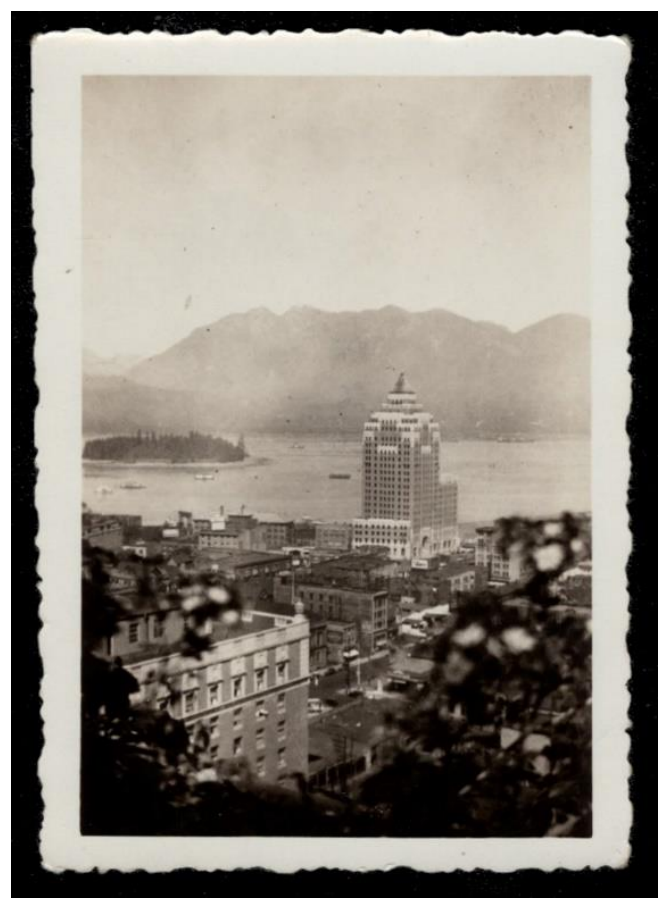

Figure 10. Snapshot with an irregular deckle edge, dated 1934

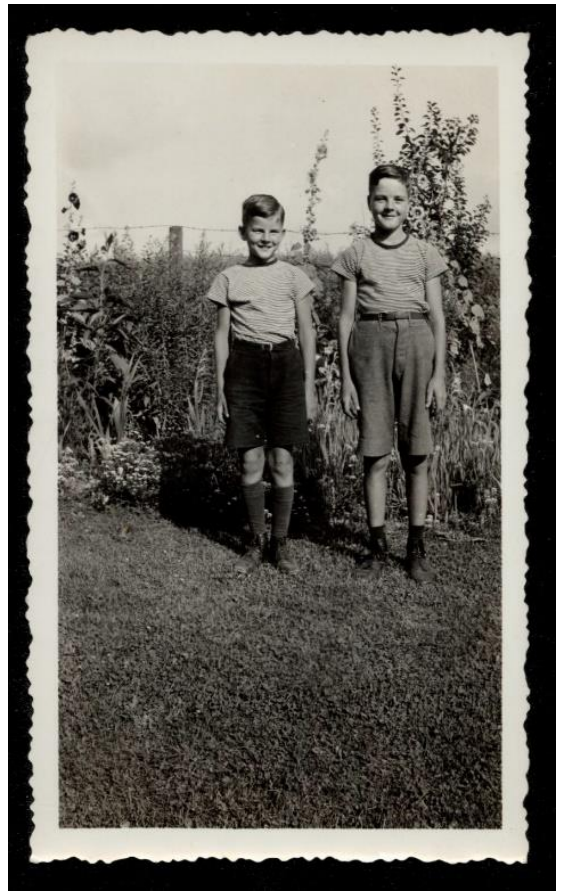

Figure 11. Snapshot with an irregular deckle edge, dated 1940 


\section{The Serrated Deckle Edge}

This edge type is characterized by a slightly irregular pattern of closely spaced peaks with steep sides and rounded tops.

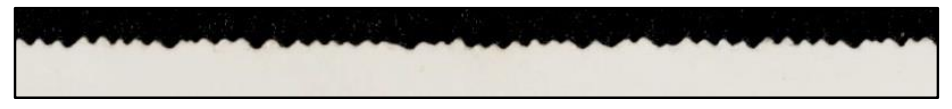

The study sample contains 18 examples of snapshots with serrated deckle edges, comprising 5.6\% of the total. The earliest example is from 1935 and the latest from 1947, with a mean of 1940.

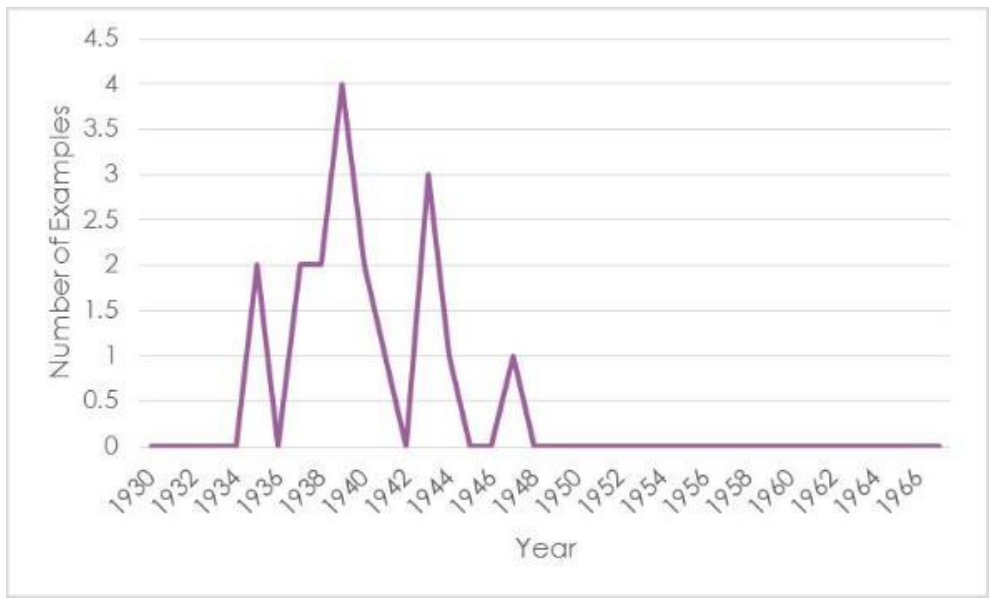

Table 5. Date distribution of the serrated deckle edge

The rounded tops of the edge peaks and lack of feathering suggest these edges are cleanly cut rather than torn. It is therefore probable that they were created with a currently unidentified deckle edge trimmer sold in the late 1930s. 
Examples:
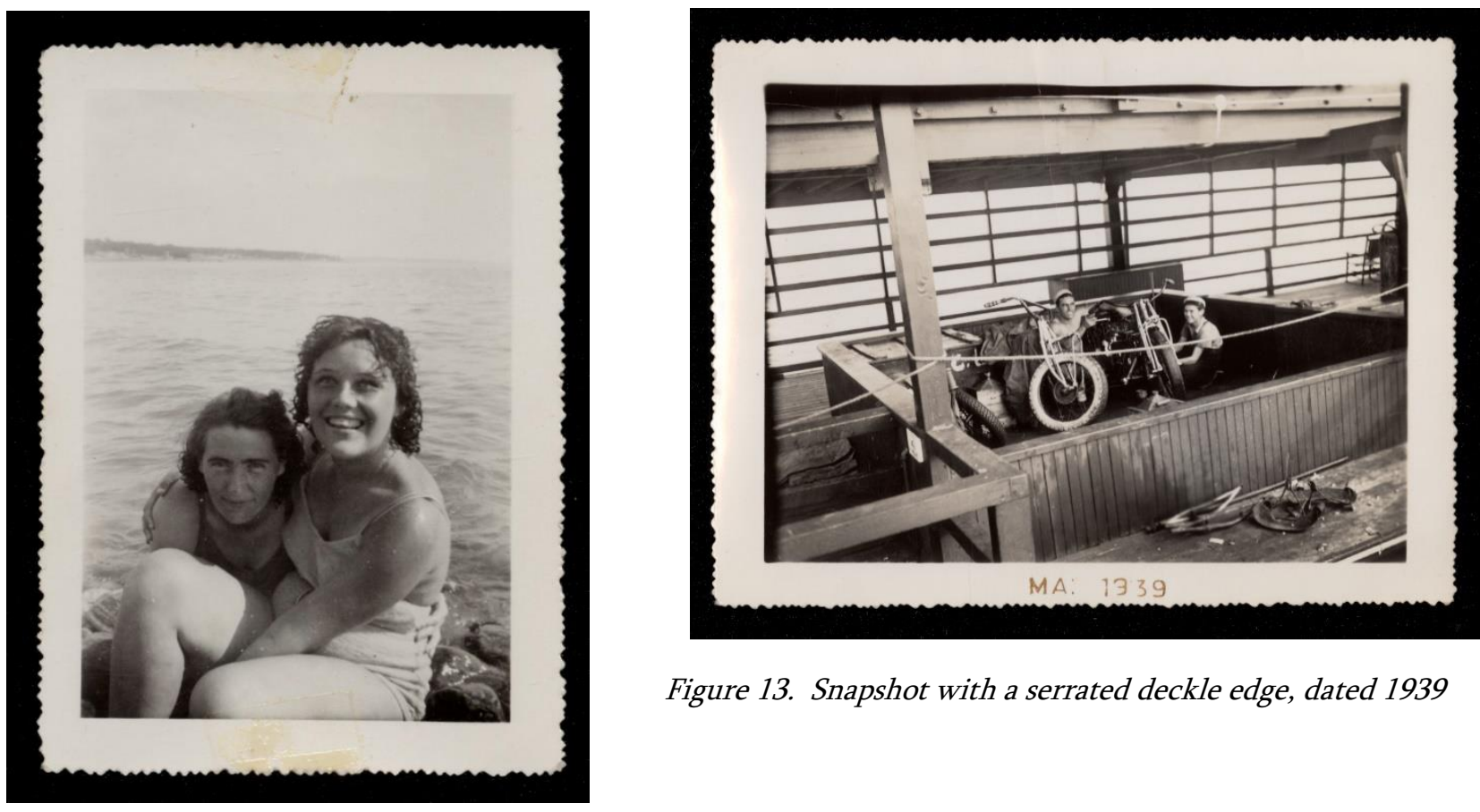

Figure 13. Snapshot with a serrated deckle edge, dated 1939

Figure 12. Snapshot with a serrated deckle edge, dated 1939 


\section{The Scalloped Deckle Edge}

This edge type is characterized by a mostly regular undulating pattern, similar to that produced by pinking shears.

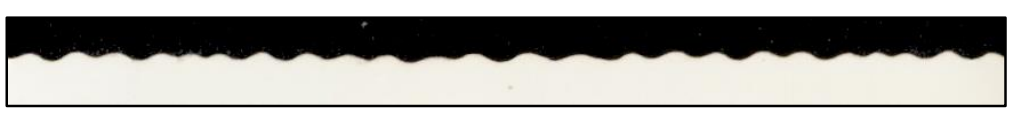

The study sample contains 8 examples of snapshots with this edge, comprising $2.5 \%$ of the total. They are seen only between 1936 and 1942.

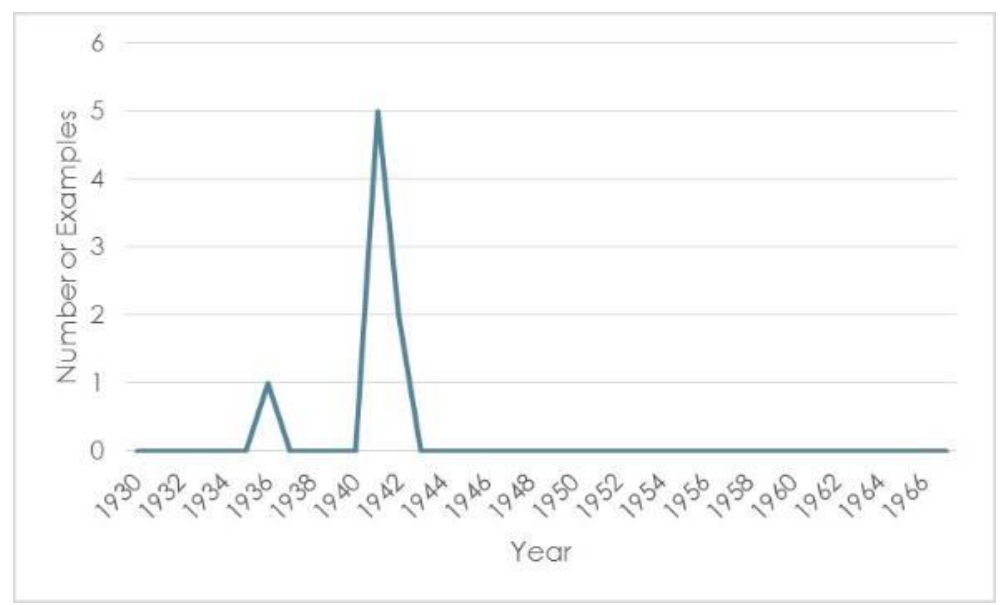

Table 6. Date distribution of the scalloped deckle edge

The regular pattern, smooth rounded peaks, and lack of feathering indicate this kind of edge is also cut, although the particular device used for this remains unknown. 
Examples:
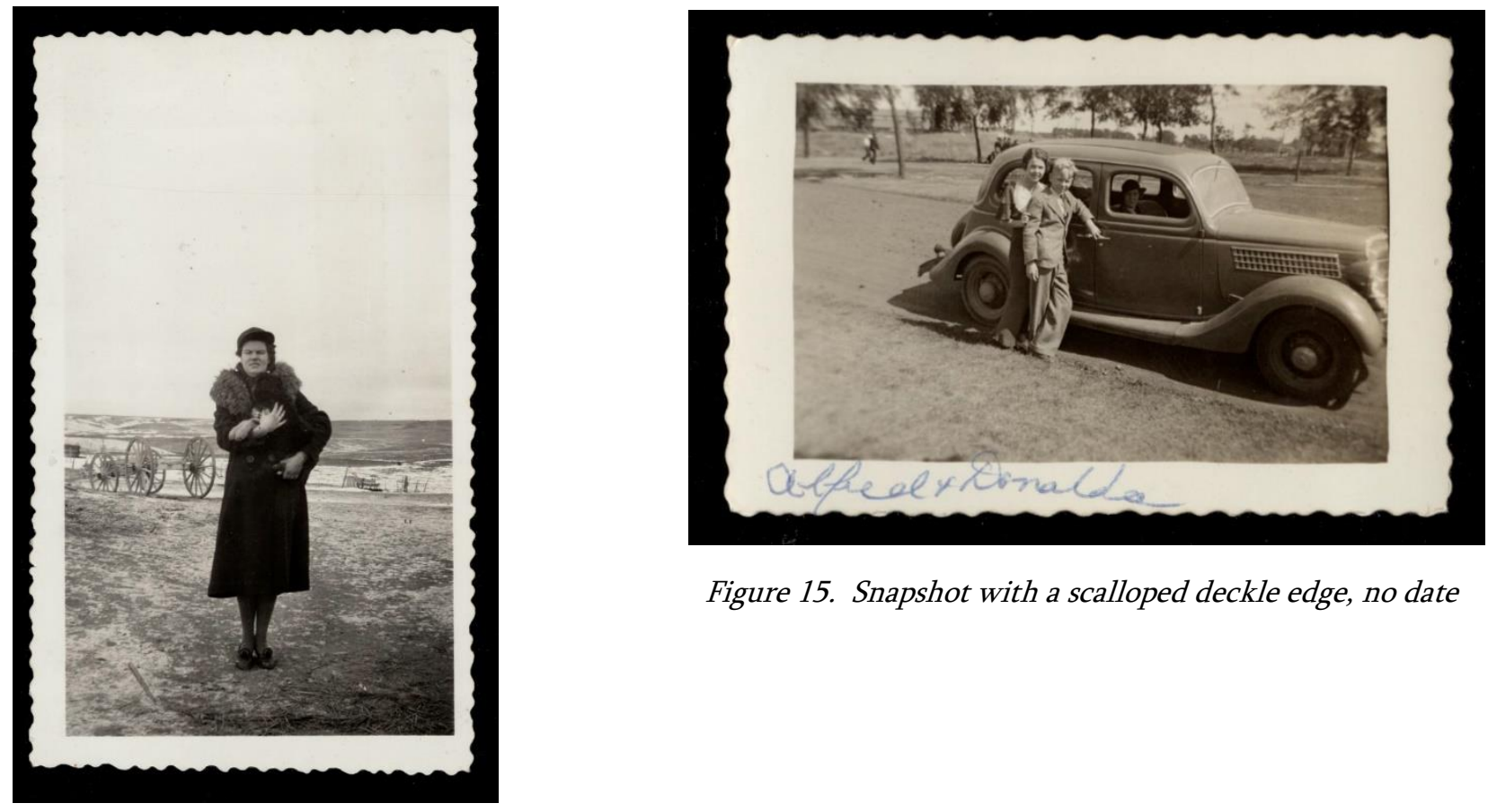

Figure 15. Snapshot with a scalloped deckle edge, no date

Figure 14. Snapshot with a scalloped deckle edge, dated 1942 


\section{The Basic Deckle Edge}

The basic deckle edge is characterized by a slightly irregular pattern of gentle peaks with broad rounded tops. The edge is clean-cut, without feathering. The pattern is seen with only minimal variation on all four sides of the snapshot. Feathering or variation in the pattern on one or more edges indicates the snapshot belongs to another of the categories detailed below. The frequent pairing of this type with other deckle edge types is the reason for the name "basic."

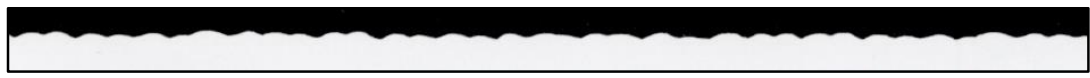

The study sample contains 61 examples of snapshots with a basic deckle edge on all four sides, comprising $19.0 \%$ of the sample ( $2^{\text {nd }}$ in frequency). These are seen from 1942 to 1964 , with a mean of 1955.

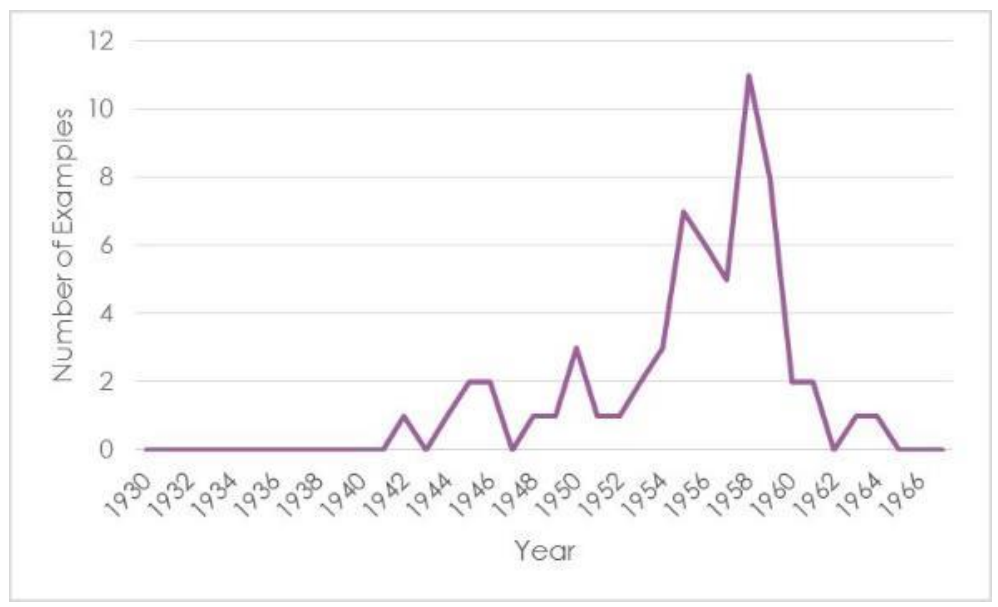

Table 7. Date distribution of the basic deckle edge 
The appearance of this edge type in 1942 implies a likely connection with the appearance of the Kodak Deckle-Edge Trimmer, released in 1940, and/or the introduction of sheets of Velox with pre-cut deckle edges in 1941. The long date range of this type and its appearance in conjunction with other varieties of deckle edge suggest the latter.

\section{Examples:}

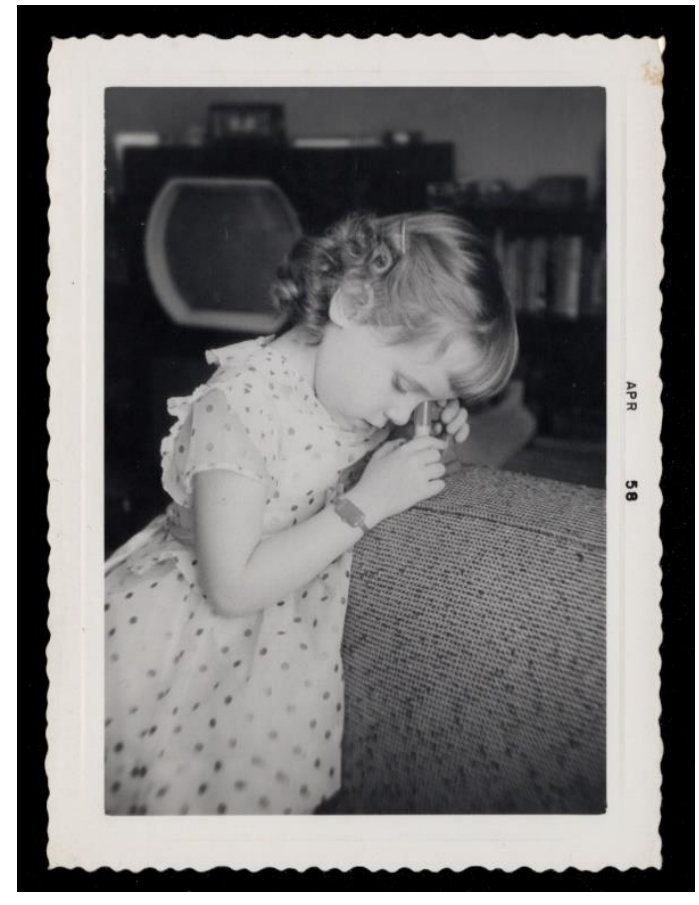

Figure 16. Snapshot with a basic deckle edge, dated 1958

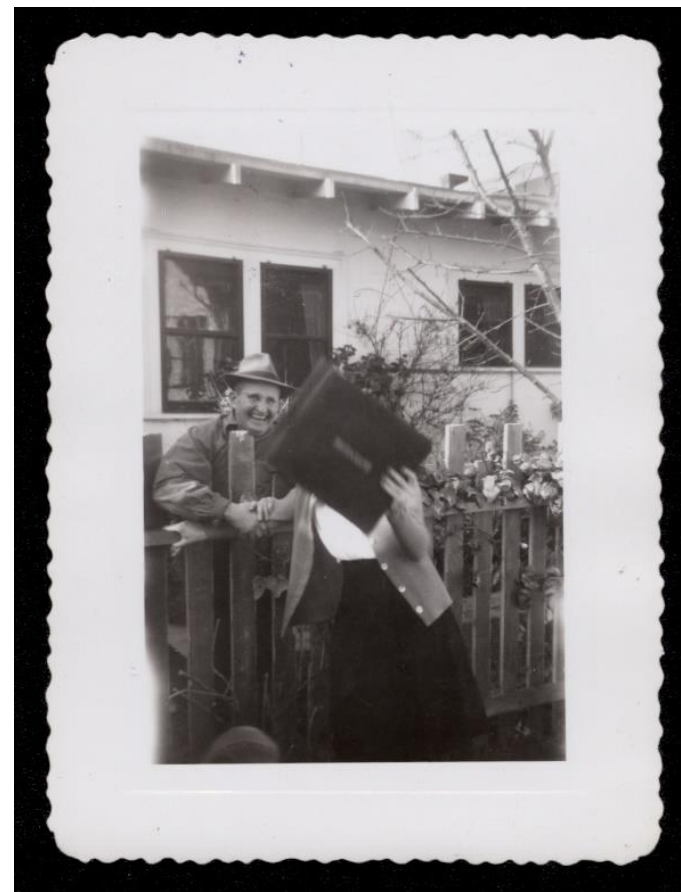

Figure 17. Snapshot with a basic deckle edge, dated 1944 


\section{The Chunky Deckle Edge}

In this edge type, two opposing sides (the long sides on a rectangular print) bear the basic deckle

edge pattern, while the other two sides display a regular pattern of dips and flat-top plateaus. Feathering at the tops of these plateaus is very common.

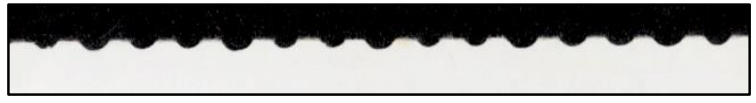

The study sample contains 28 examples of snapshots with this edge, comprising $8.7 \%$ of the total. The dates range from 1948 to 1966 and the mean is 1955.

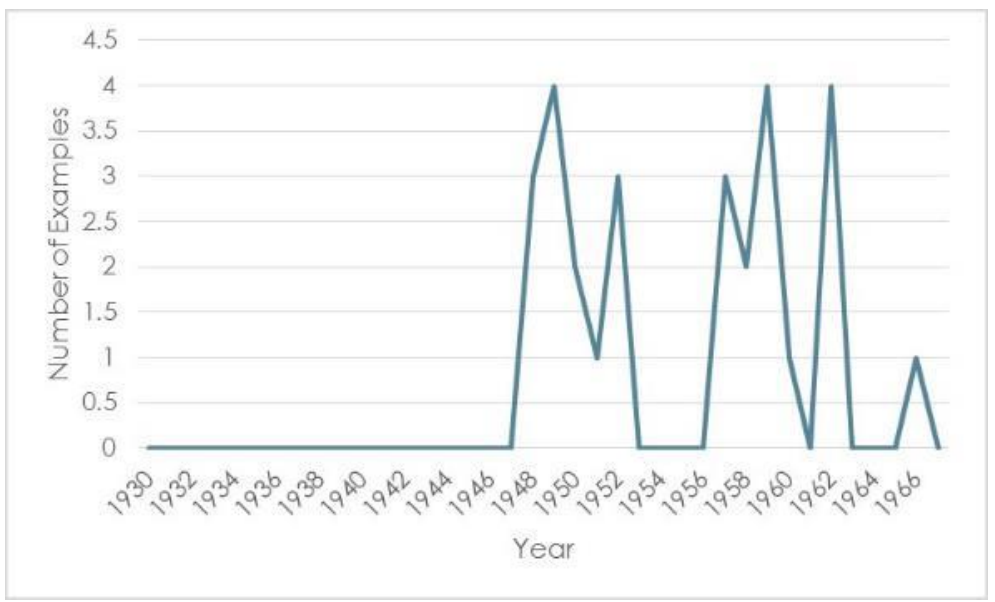

Table 8. Date distribution of the chunky deckle edge

Tellingly, several non-dated examples show snapshots with this edge type attached at the chunky deckle edges, including one strip of 6 (see figure 28). These attached strips indicate that snapshots with this edge are cut from roll paper. Additionally, the snapshots with this edge begin to appear in 1948, the same year Kodak began to sell roll paper with deckle edges. It is unknown, however, which cutting device created this particular edge. 
Examples:

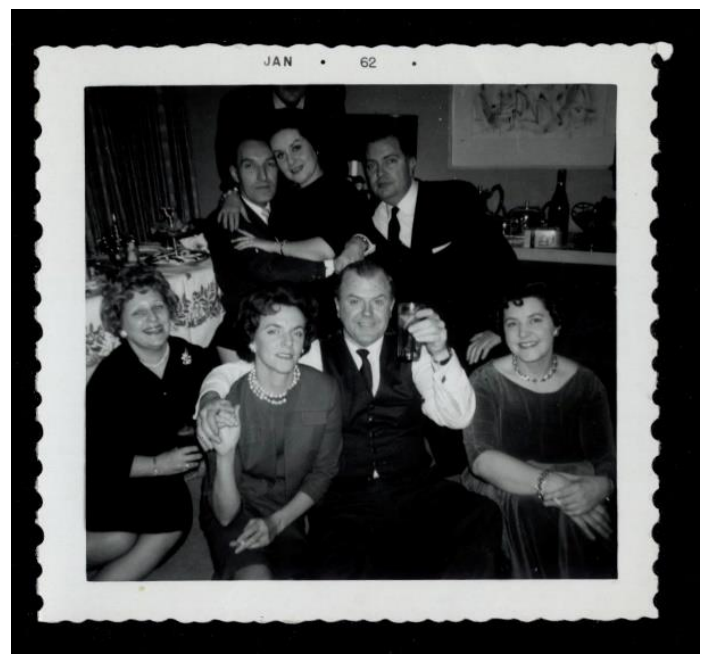

Figure 18. Snapshot with chunky deckle edges, dated 1962

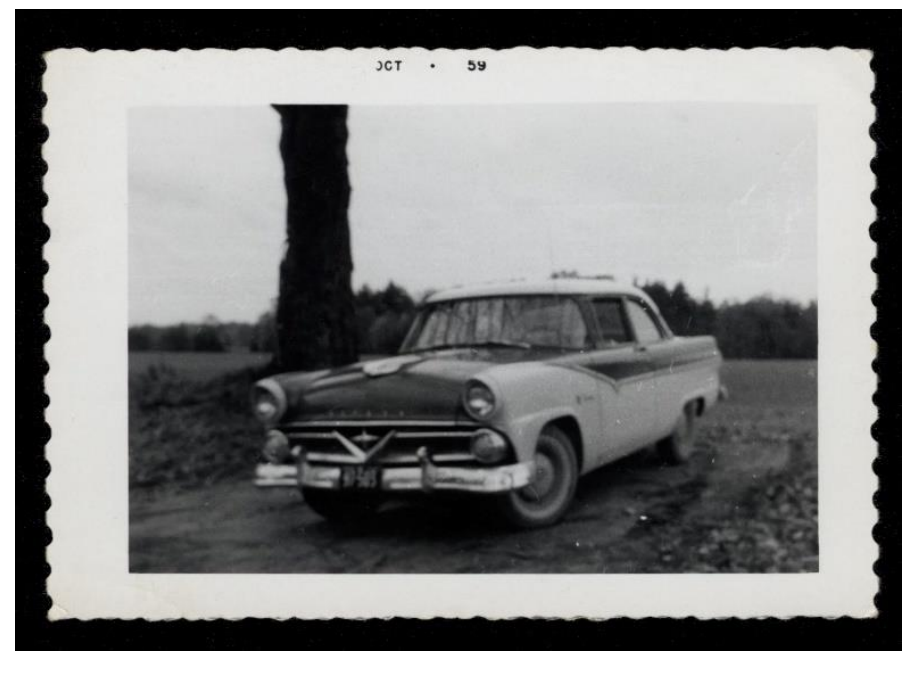

Figure 19. Snapshot with chunky deckle edges, dated 1959

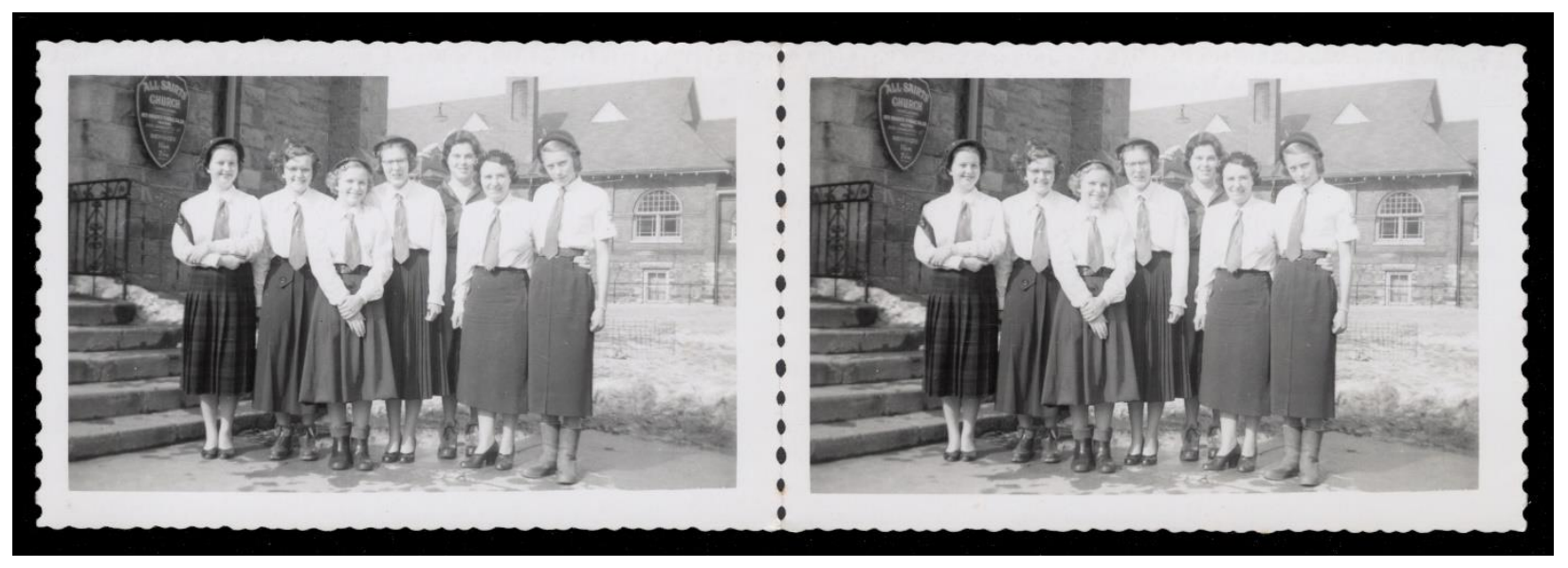

Figure 20. Two snapshots attached by chunky deckle edges, no date 


\section{The Album Print}

As discussed above, in 1949 Kodak introduced Kodak Album Print Paper, which only came in a deckle edge variety. The paper was attached to a hole-punched hinge on one side, so the print could easily be inserted into a specially made album or torn off the hinge as desired. Kodak's trade publication The Photo Finisher provides illustrations of the unbound prints, which display different hinges (figures 21 and 22).

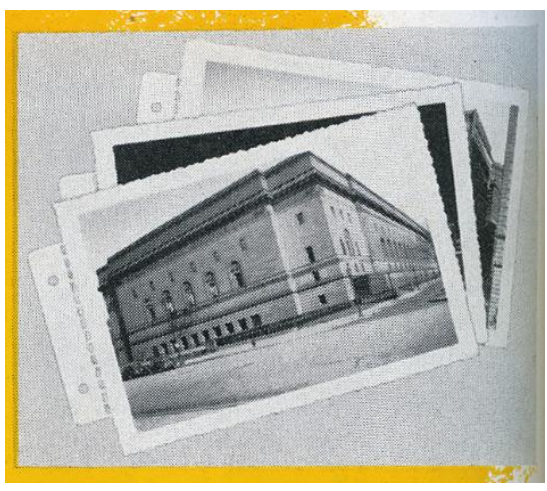

Figure 21. Examples of album prints from the advertisement for their release,

The Photo Finisher, 1949

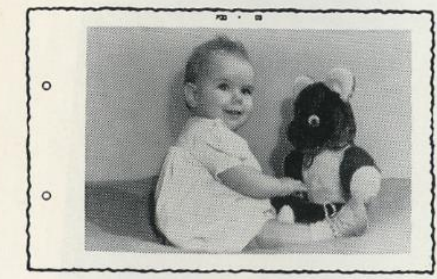

Kodak Paper Cutting Die Assembly; 31/2-inch deckle-edge for album, two-hole punch, $1 / 2$-inch hinge (punches may be removed).

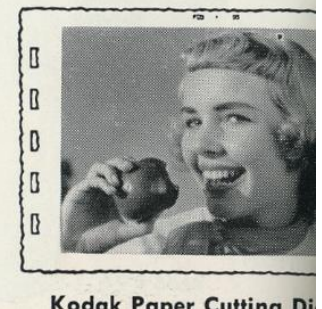

Kodak Paper Cutting Di sembly; five-hole ringtype, $3 \frac{1}{2} 2$-inch deckle-ed album (1/4-inch hinge).
Figure 22. Examples of album prints from an advertisement for the Velox Rapid Printer (detail of figure 8), The Photo Finisher, 1955

The snapshot study sample includes 4 examples of snapshots where a hinge is still attached, including one instance with 9 album print photographs still bound in their original album (figure 36). However, it seems that hinges were frequently torn off, as traces of hinges can be found much more frequently than the hinges themselves. Sometimes the tear of the hinge is not clean and pieces remain (see image); more often, slight to moderate feathering is seen on only one edge 


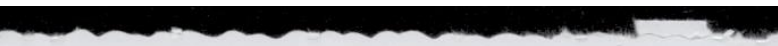

Example of an edge with a piece of the hinge remaining

of a snapshot (typically the left for landscape orientation and the top for portrait orientation), with the remainder of the edges showing irregular or basic deckle edges.

The sample includes 49 examples of snapshots that can be categorized as album prints by this criteria (15.3\%). They range from 1950, the year after the type's release, to 1964, with the mean in 1955.

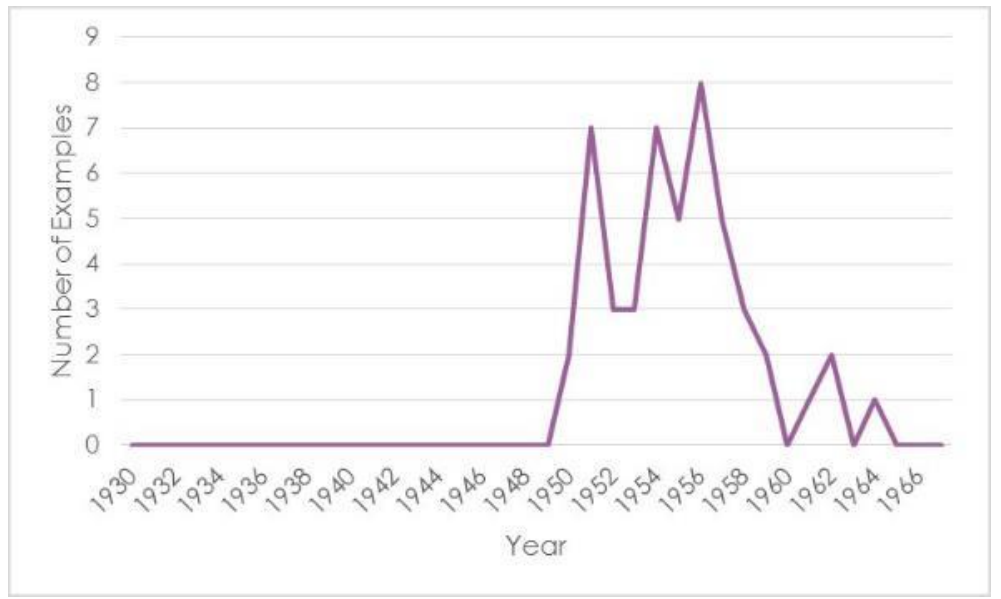

Table 9. Date distribution of album prints 
Examples:

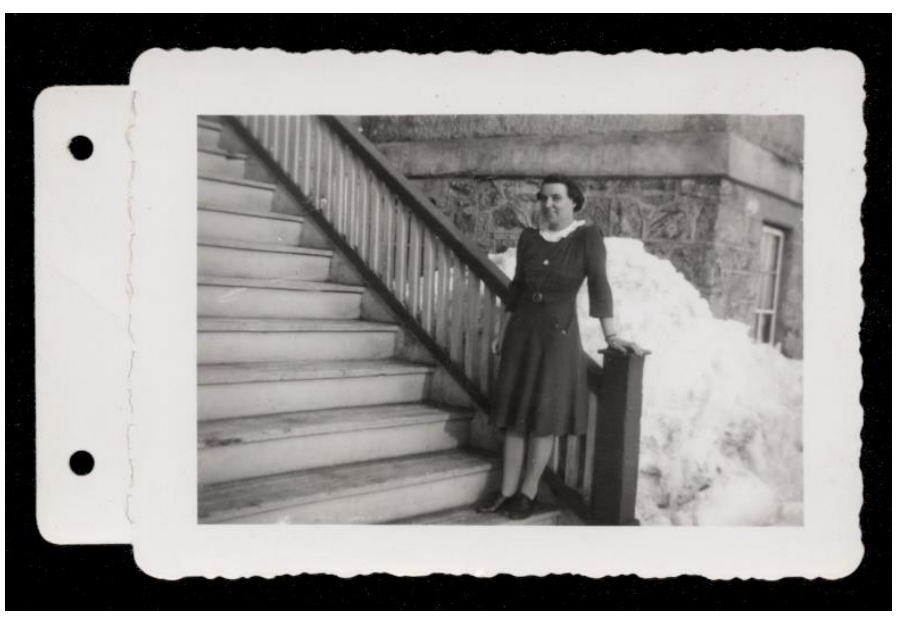

Figure 23. Album print snapshot with attached hinge of the earlier type, no date

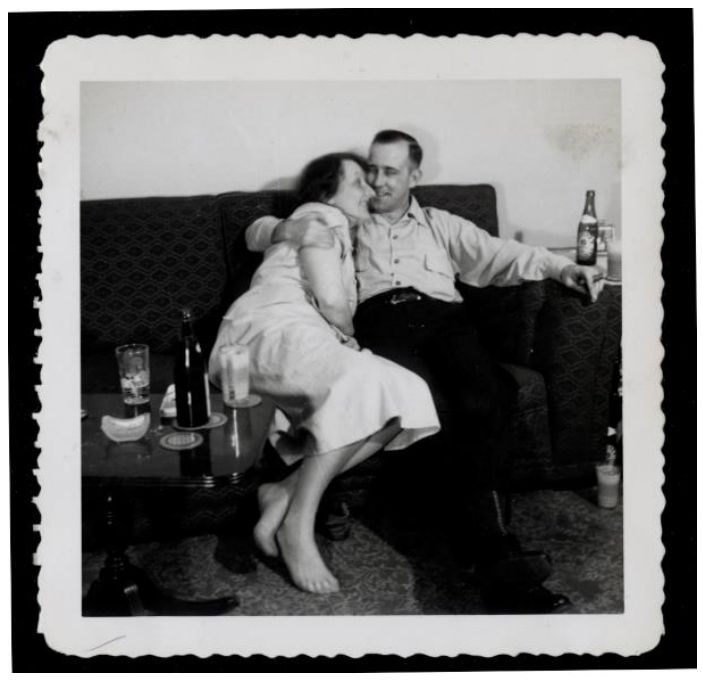

Figure 25. Album print snapshot with hinge traces and feathering (left), dated 1951

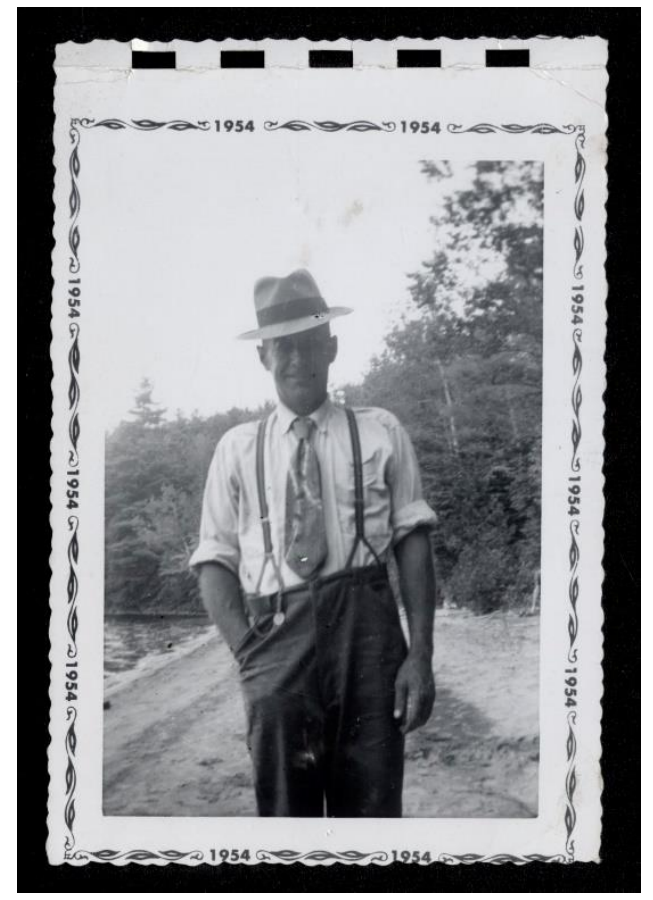

Figure 24. Album print snapshot of the five-hole type, 1954

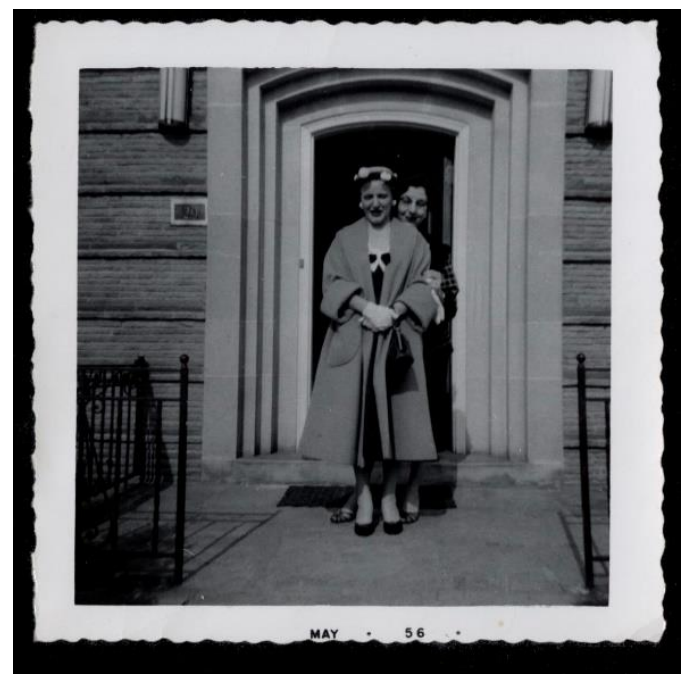

Figure 26. Album print snapshot with feathering (left), dated 1956 


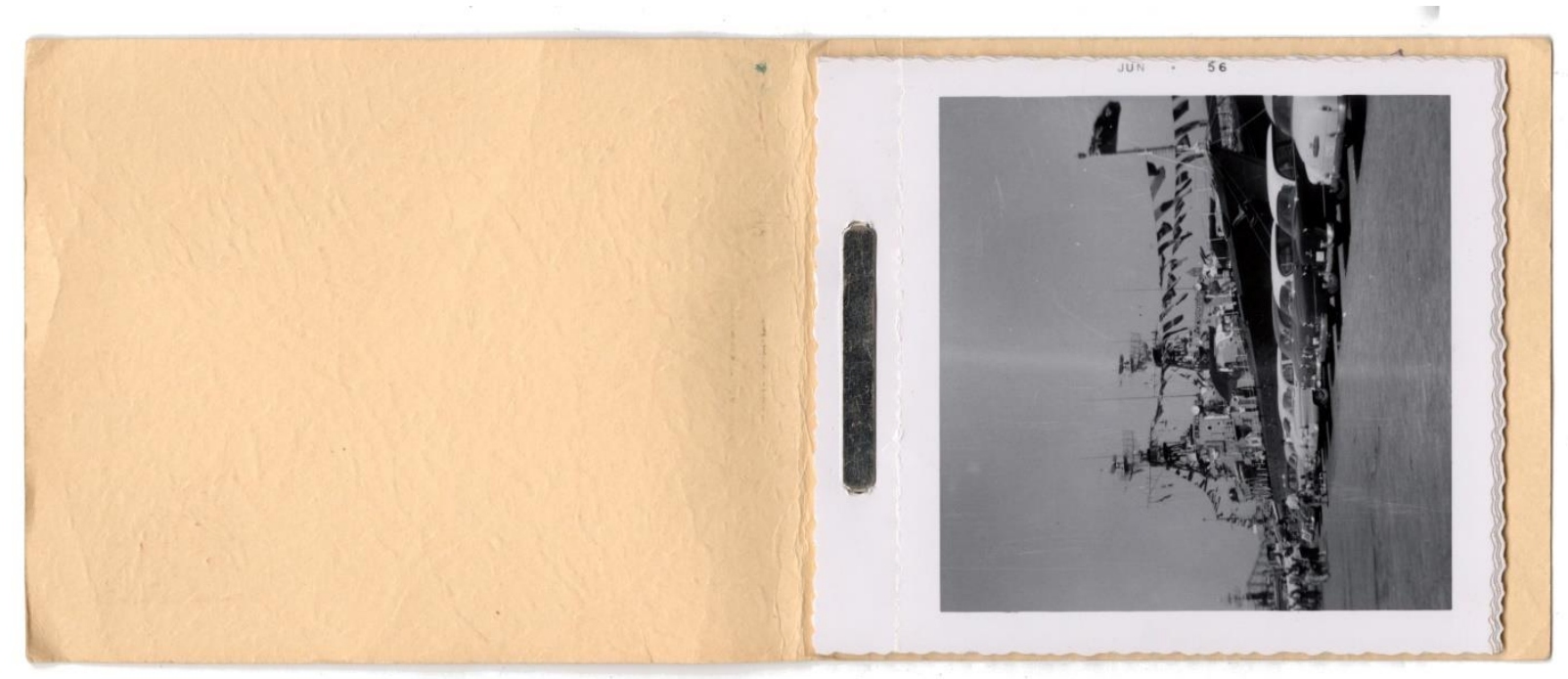

Figure 27. Album print snapshots bound in their original album, dated 1956 


\section{The Polaroid}

From their introduction in 1948, Polaroid prints had edges similar to the wave deckle edge described above. Though the original patent for the print design refers to this edge as "a curved line resembling a deckle" rather than as a deckle edge specifically, the edge has come to be generally described as a deckle edge. ${ }^{51}$

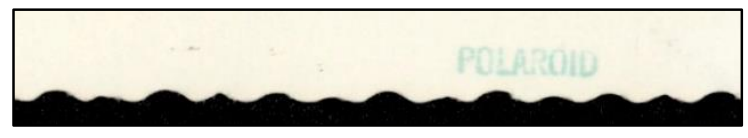

The original Polaroid prints had this edge on all four sides; by the late 1950s only the two shorter sides were deckled, although the year of and reason for this change is as yet undetermined. ${ }^{52}$ Polaroid prints are easily distinguished from other prints with similar edges, as the versos are stamped "Polaroid." Feathering on one of the shorter sides is common, as the process requires a tab to be torn off the final print (see figure 39). The choice of the deckle edge for the Polaroid may in part be a consequence of this inherent tearing. As noted above in relation to the album print, uneven edges are torn more easily and attractively than straight ones.

The sample included 4 Polaroid prints: two from 1950, and one each from 1954 and 1959. The earliest three have four deckle edges, while the latest has two. A non-dated example shows a deckle edge Polaroid still attached to its triangular tab (figure 39).

${ }^{51}$ William J. McCune Jr. [assignor to Polaroid Corporation], Photographic product, U. S. Patent 2,612,452, filed November 2, 1948, and issued September 30, 1952; see for instance Art of the American Snapshot, p. 157.

52 The book on the history of Polaroid (Christopher Bonanos, Instant: The Story of Polaroid (New York: Princeton Architectural Press, 2012) does not mention the deckle edges anywhere. 
The Polaroid's deckle edge is partially a practical choice, as the nature of the process requires easily-torn perforations without sharp edges. However, the patent itself notes the edge is also intended to be an attractive framing for the image..$^{53}$

\section{Examples:}

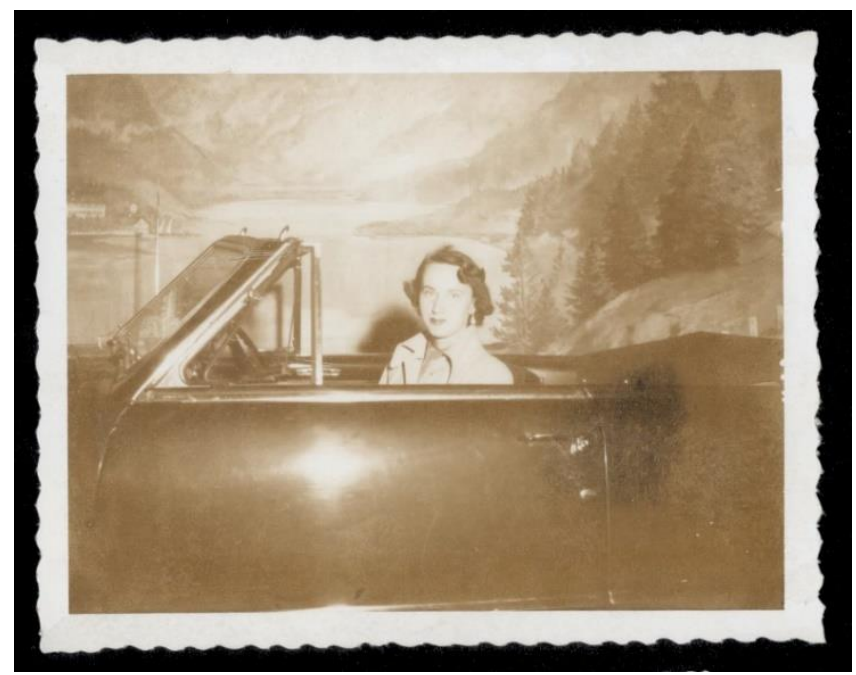

Figure 28. Polaroid snapshot with four deckle edges, dated 1950
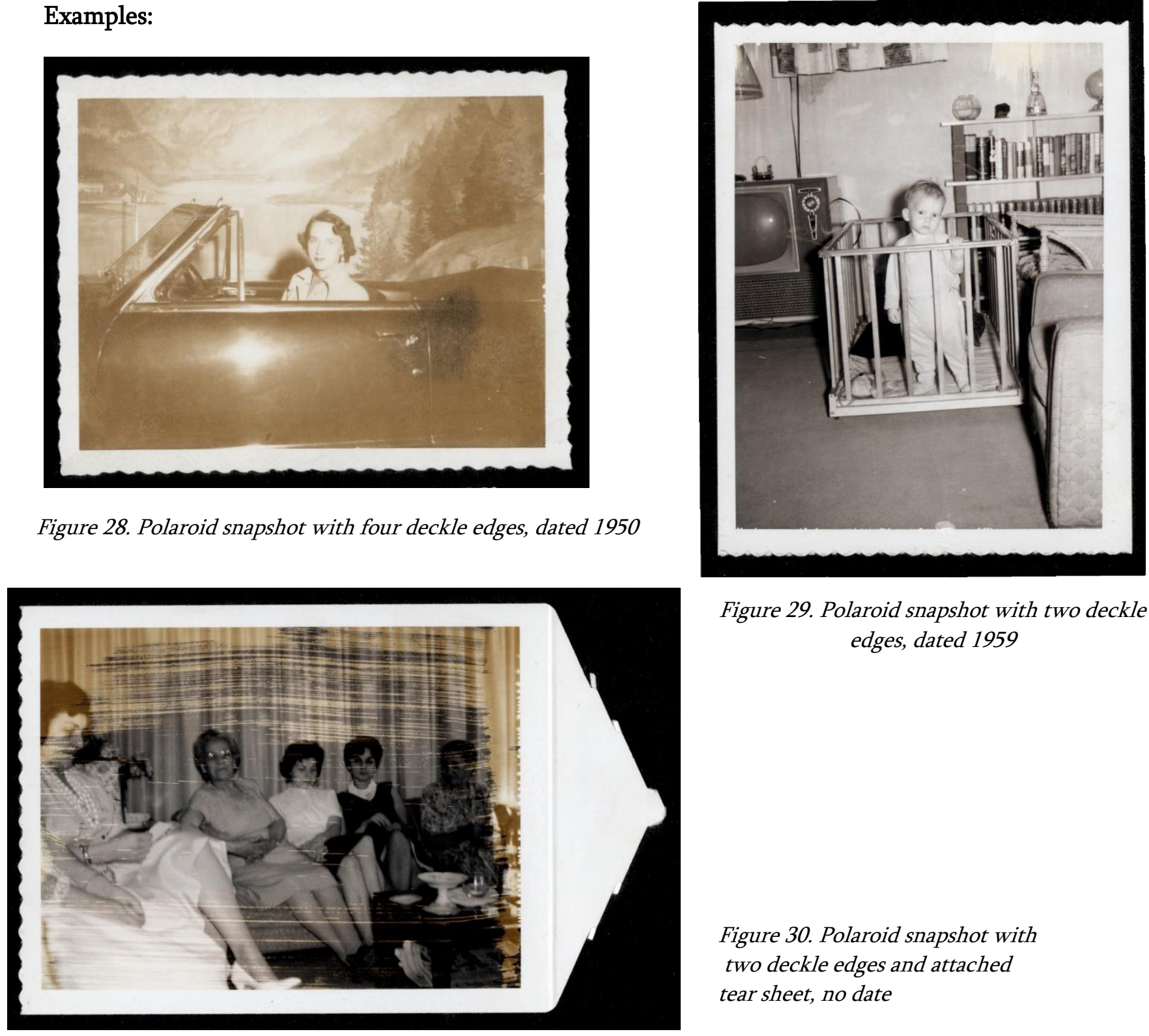

Figure 29. Polaroid snapshot with two deckle edges, dated 1959

Figure 30. Polaroid snapshot with two deckle edges and attached tear sheet, no date

${ }^{53}$ McCune, Photographic product. 


\section{The Concave Deckle Edge}

This deckle edge type is another that is closely related to the basic deckle edge; indeed, the basic deckle edge pattern is seen on three edges. However, the pattern on one of the shorter edges varies. The variant edge displays an exact inverse of the basic deckle edge, with rounded dips corresponding to the hills seen in the basic. All edges are cleanly cut.

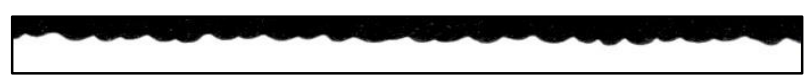

There are 63 examples of snapshots with the concave deckle edge in the sample, $16.5 \%$ of the whole, making it the third most frequent type seen in the sample. This edge type does not appear until 1955, but continues to the last snapshot in the data set, in 1967. The mean is 1959 .

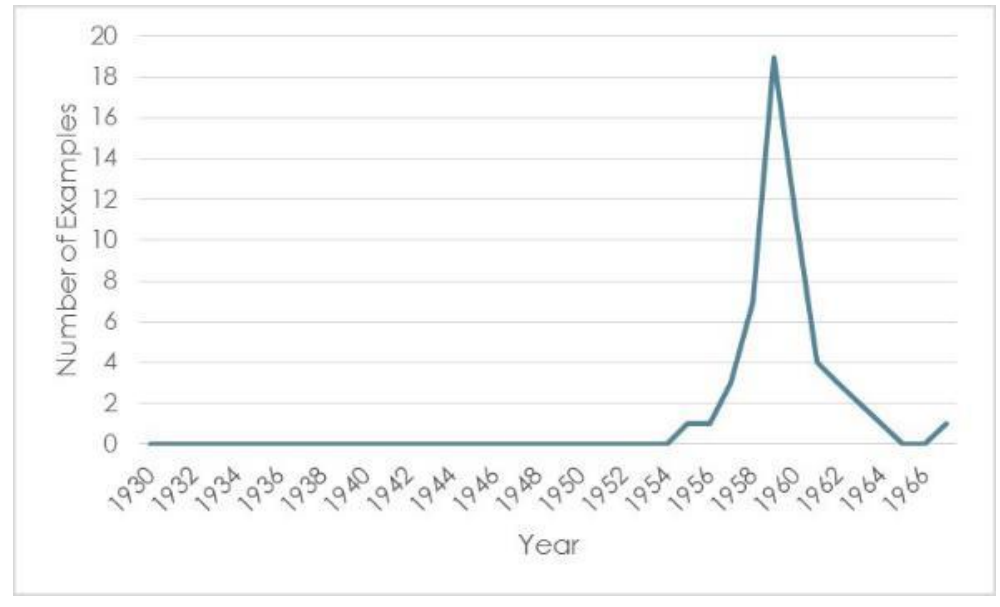

Table 10. Date distribution of the concave deckle edge

As the distinctive edge of this type matches up exactly with the basic edge, it can be concluded that this type of deckle edge relates to a particular variety of cutting technique. The concave edge 
is always on one of the shorter sides, while the longer sides display even basic edges. This edge type, then, suggests a method of cutting deckle edge roll paper.

Additionally, all 53 examples with a concave edge also display a border date stamp. This fact, combined with the 1955 date of first appearance, strongly suggests a link between its appearance and that of the the Kodak Velox Rapid Printer Type IV, released in 1955. This combined printer cutter was designed for use with roll paper and included an "electrical numbering stamp." 54 Though only a single example of the concave edge was found for the years 1955 and 1956, its appearance increases dramatically from 1957, probably the result of a delay between the release and the widespread use of this type of equipment.

\section{Examples:}

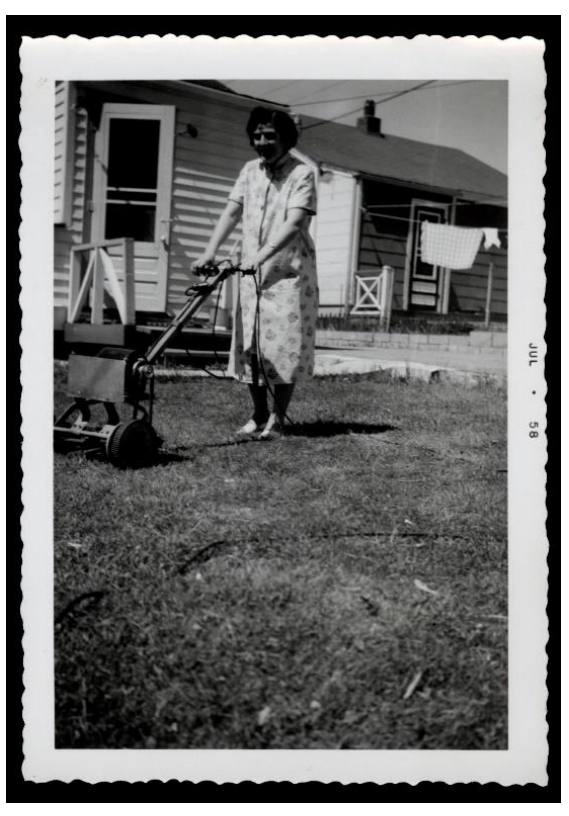

Figure 31. Snapshot with a concave deckle edge (bottom), dated 1958

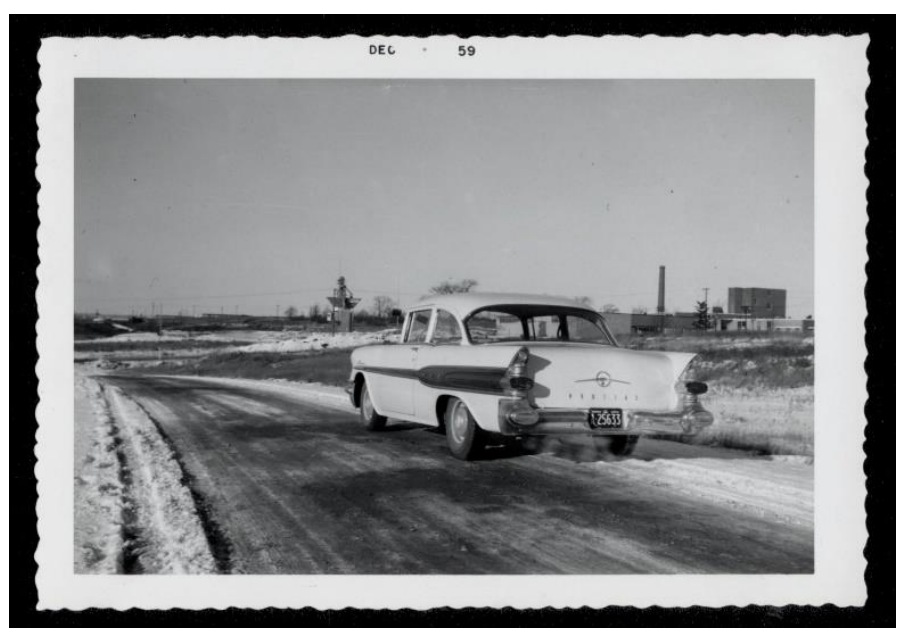

Figure 32. Snapshot with a concave deckle edge (right), dated 1959

${ }^{54}$ Eastman Kodak Company, The Photo Finisher, Volume 27 Number 1, Spring 1955. 


\section{The Ornamental Deckle Edge}

Like the chunky and concave deckle edges, the ornamental deckle edge appears in conjunction with the basic deckle edge. The ornamental deckle edges display an even, sweeping pattern, which can be described as: three hills, one hill, two hills, three hills, one hill, three hills, one hill, two hills. As is the case for the chunky deckle edge, basic deckle edges appear opposite one another on the longer sides of the print, while the other two opposing edges bear the ornamental pattern. Some snapshots show feathering on one of the ornamental edges, indicating they were attached to a hinge like album prints.

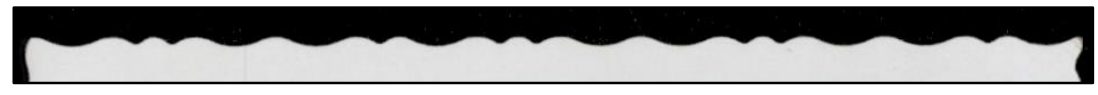

The sample contains 31 examples of snapshots with ornamental edges, 11 of which show feathering on one edge, comprising 9.7\% of the whole. They range from 1956 to 1963, although it should be noted no feather edges are present in the sample after 1959. The mean is 1958.

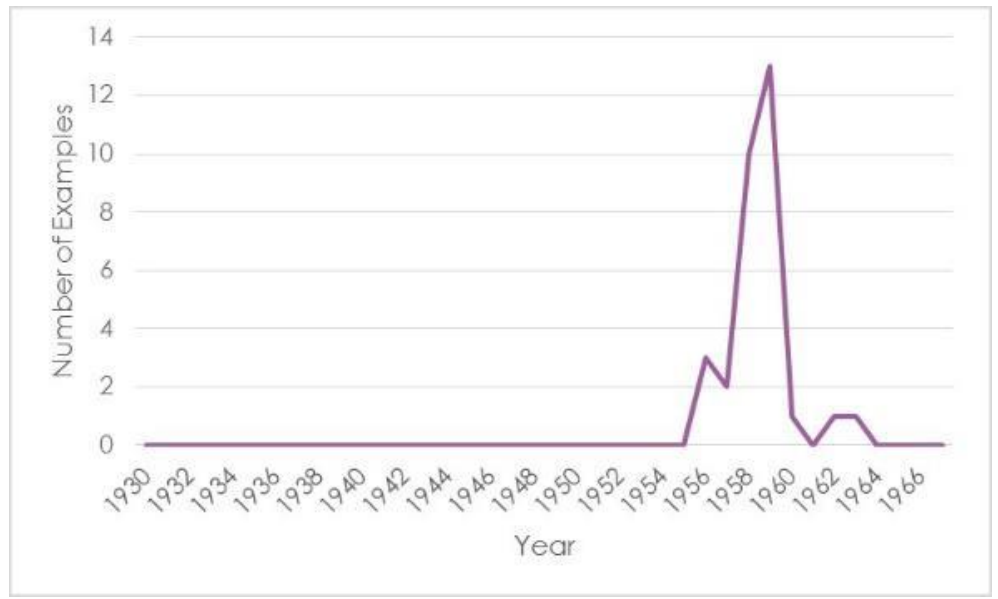

Table 11. Date distribution of the ornamental deckle edge 
The opposing ornamental edges are the exact inverse patterns of one another, as is seen in the opposing edges of the concave type. Again this suggests that the edge was created by a cutter for roll paper. Unlike the concave deckle edges, border printed dates are seen in less than half of examples, suggesting the device is not the same as that which produced border printed dates on every snapshot. Because of the 1956 date of this edge's first appearance, there is a possible link with the Kodak Power Trimmer, released in 1956, but this does not explain the album cut variety.

Examples:

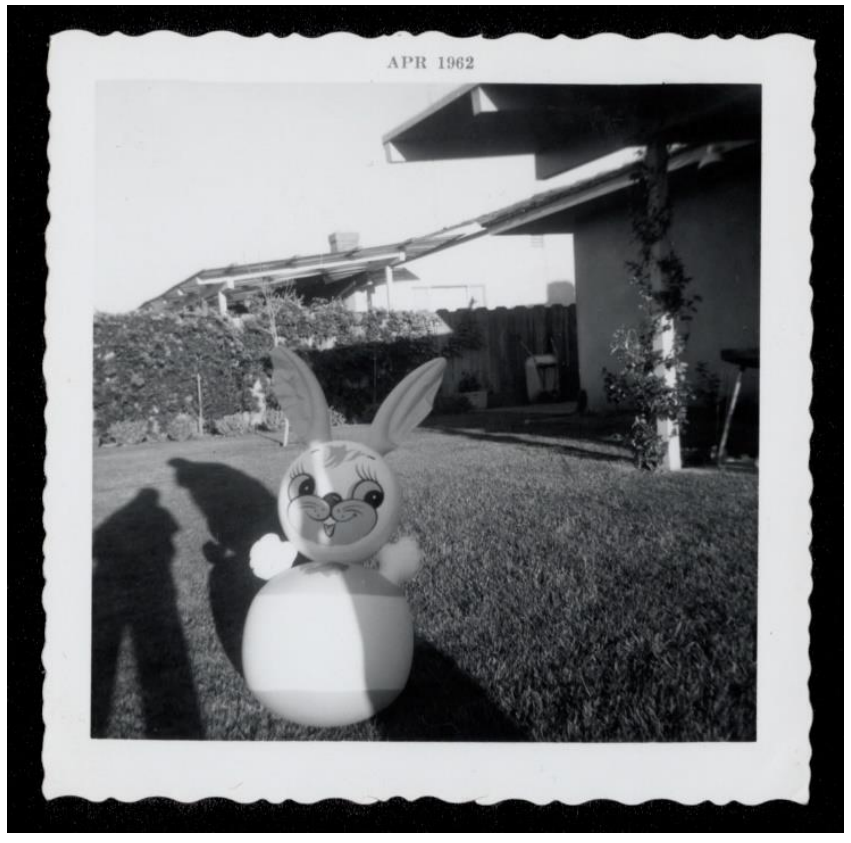

Figure 33. Snapshot with ornamental edges (top and bottom), dated 1962

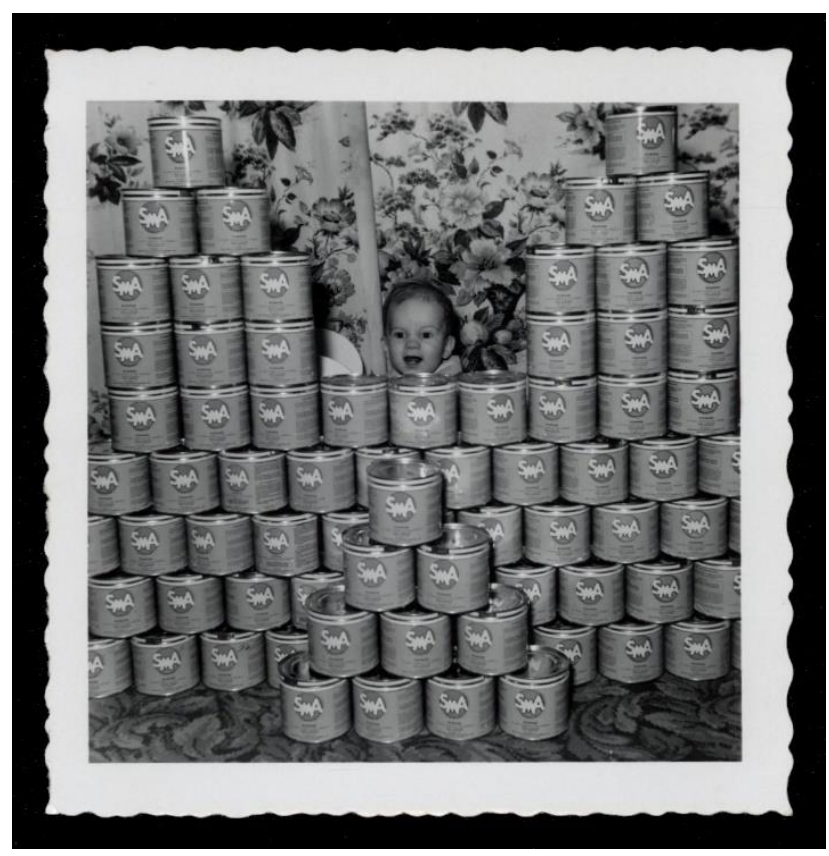

Figure 34. Snapshot with ornamental edges (left and right), dated 1959. The left edge shows feathering. 


\section{Other Edge Types}

The wider set of undated deckle edge snapshots from the AMC provided another two edge types in three examples. The edge seen on the first example is choppy, sharp, and slanted, but with a regular pattern including rounded tops, and without feathering (figure 35). The second edge is a regular pattern of hills with varying widths (figure 36). This edge is seen on two snapshots, one

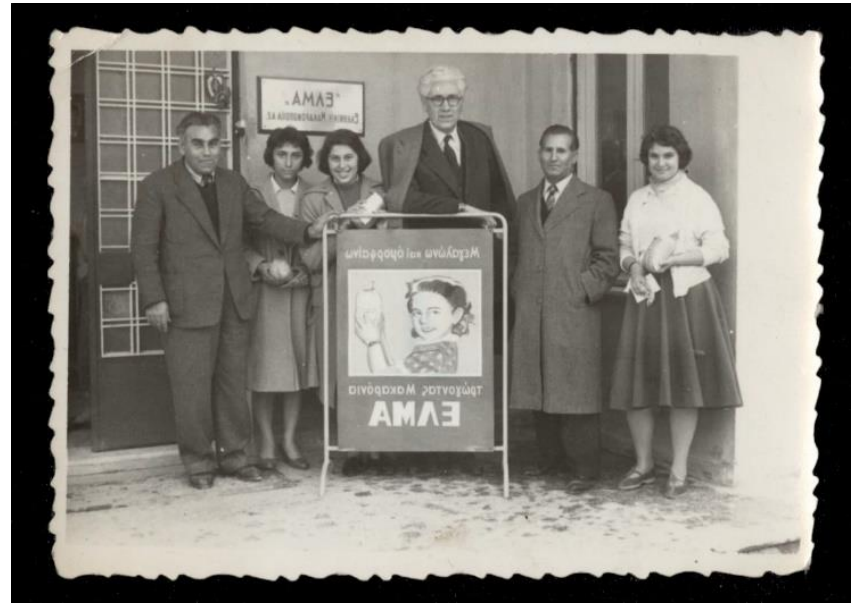

Figure 35. Snapshot with a variant edge type, no date

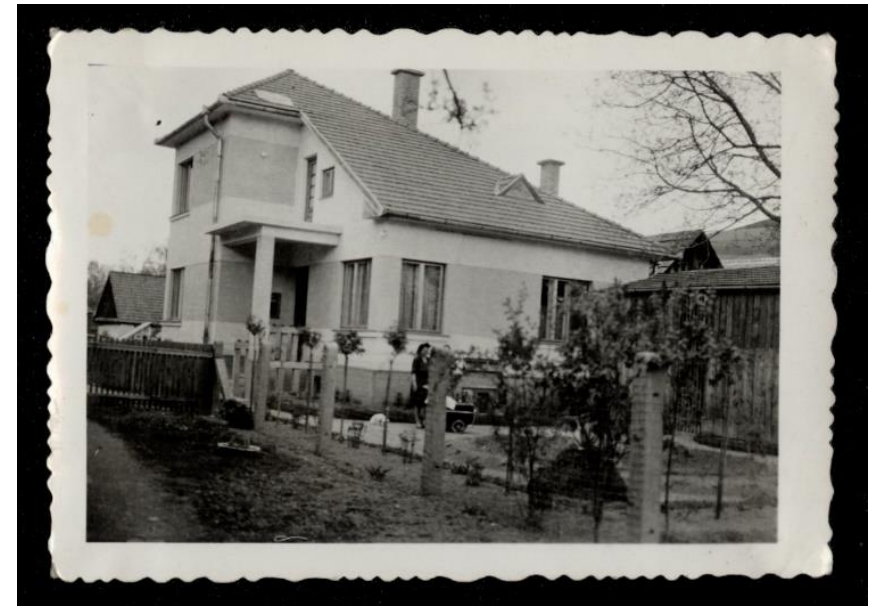

Figure 36. Snapshot with a variant edge type, backstamped Agfa-Lupex, no date

printed on paper backstamped Ridax (a paper made by Belgian company Gevaert) and the other on paper backstamped Agfa-Lupex.

These findings strongly suggest regional and/or brand variation in the appearance of deckle edges, a topic for future research. 


\section{Chapter 6. Advertising}

As has been established, Kodak was central to the dissemination of products for the creation of deckle edge snapshots in North America. Kodak, of course, not only sold its products, but also promoted them. Consumer print ads have received the most attention from scholars, particularly those intended for magazines ${ }^{55}$, but Kodak also offered its photofinishers a wide array of branded posters, window and counter display materials, print envelopes, and paper "stuffers" to give to customers in the envelopes holding their finished prints. The majority advertised specific Kodak products or services as well as the brand itself. These materials were in their turn advertised in trade publications such as The Kodak Salesman and The Photo Finisher, offered at minimal prices or occasionally for free. Various trade publications also contained ads targeting photofinishers specifically, promoting new photo-finishing products and paper.

While the bulk of Kodak's advertising was devoted to cameras, film, and, in consumer ads, the general promotion of picture-taking, scarcely a Kodak product lacked promotion. The principal paper used to print snapshots, Velox, was frequently advertised to both consumers and photo-finishers. Enlargements were a common subject of the advertisements on print envelopes and paper stuffers. A common type of stuffer that was slipped over one of a set of finished prints encouraged the enlargement of this "great" picture.

\footnotetext{
${ }^{55}$ See, for instance, West, Kodak and the Lens of Nostalgia; Kotchemidova, "Why We Say Cheese,"; Greenough, "Fun Under the Shade of the Mushroom Cloud," p. 165; and Sarah Kennel, "Quick, Casual, Modern: 1920-1939," in The Art of the American Snapshot, pp. 94-99.
} 
At the same time, Kodak advertising also affected the appearance and popularity of snapshots by using less explicit means. As Christina Kotchemidova states, Kodak's frequent visual use of snapshots in books, magazines, and ads implicitly showed the public what snapshots "should" look like. ${ }^{56}$ These "snapshots" were usually made specifically for the company, taken by professional photographers aiming for an "amateur" look. ${ }^{57}$ What Kotchemidova does not mention, however, is the way Kodak made it clear that these images were supposed to be snapshots: borders. A white border in a Kodak ad indicates that a photograph is intended to be an illustration of a snapshot (see, for examples, figures 37-40). This is illustrated very clearly in ads like the one in figure 40 . The ad contains two photographs of the same scene, looking equally professional. However, the first, with no borders, shows a man taking a photograph of a posed group, who look at his camera. The second image depicts the group as seen from the man's camera. This second image has white borders and a slight curl, indicating it is the snapshot of the scene rather than the scene itself. The white border was also used to indicate that partially obscured photographs were snapshots, and used as a quick visual shorthand in line-drawings (figures 38 and 39). The white border is never mentioned or advertised, yet it is clearly assumed to be an inherent feature of the snapshot..$^{58}$

Kodak thus had two ways to promote the deckle edge for snapshots. Considering how many deckle edge related products they offered from 1940s onwards, they seem to have many good reasons to promote it, which makes it all the more surprising that the deckle edge snapshot

\footnotetext{
${ }^{56}$ Kotchemidova, “Why We Say 'Cheese,” pp. 5, 10, 13-14.

57 Ibid., 17-18.

${ }^{58}$ The topic of the white border as an aspect of snapshot appearance is an interesting one deserving of further study, particularly as it is still used as a shorthand for "snapshot" in visuals today.
} 


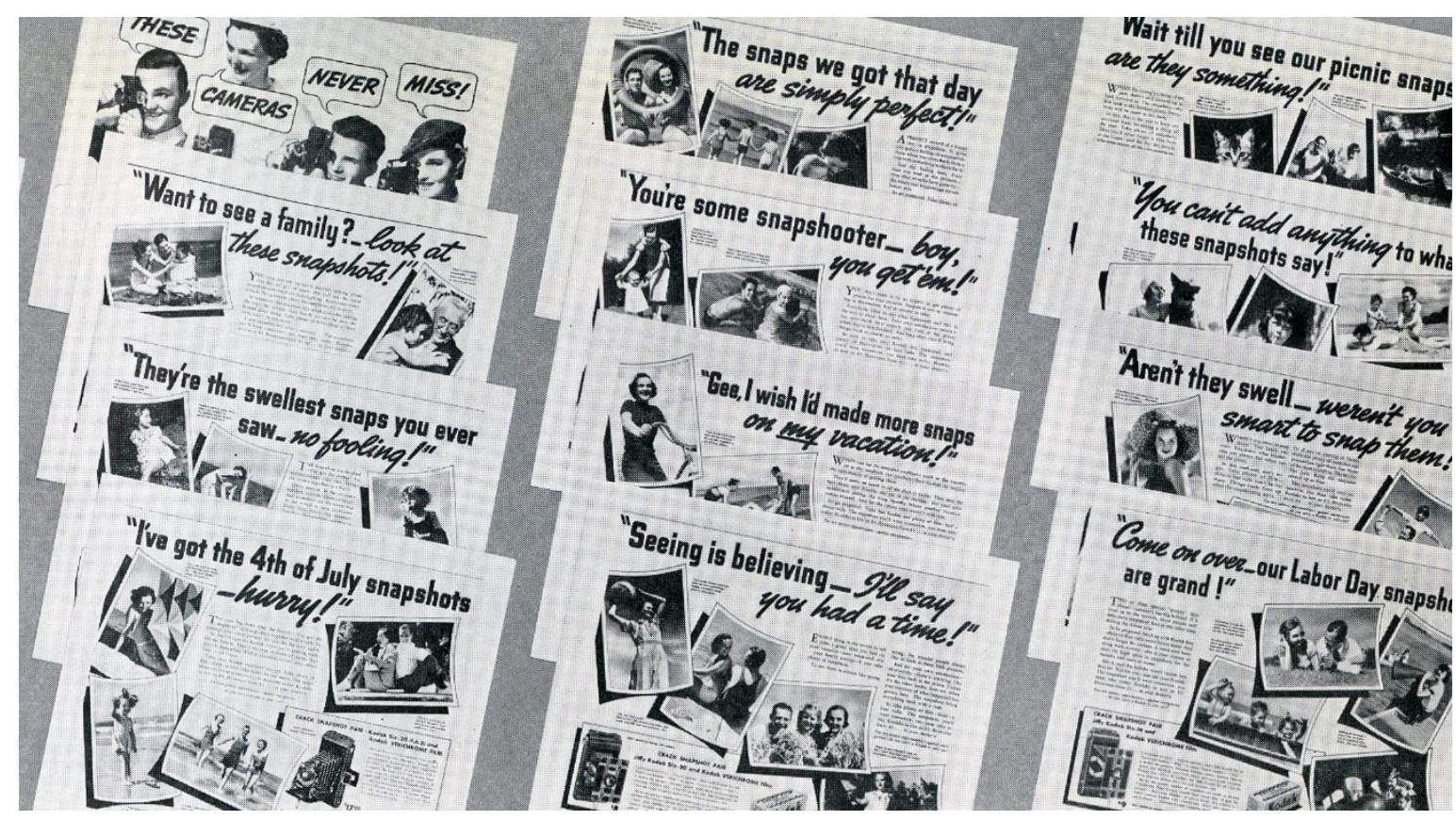

Figure 37. Illustration of Kodak's various print ads for their summer campaign, Kodak Salesman, May 1937
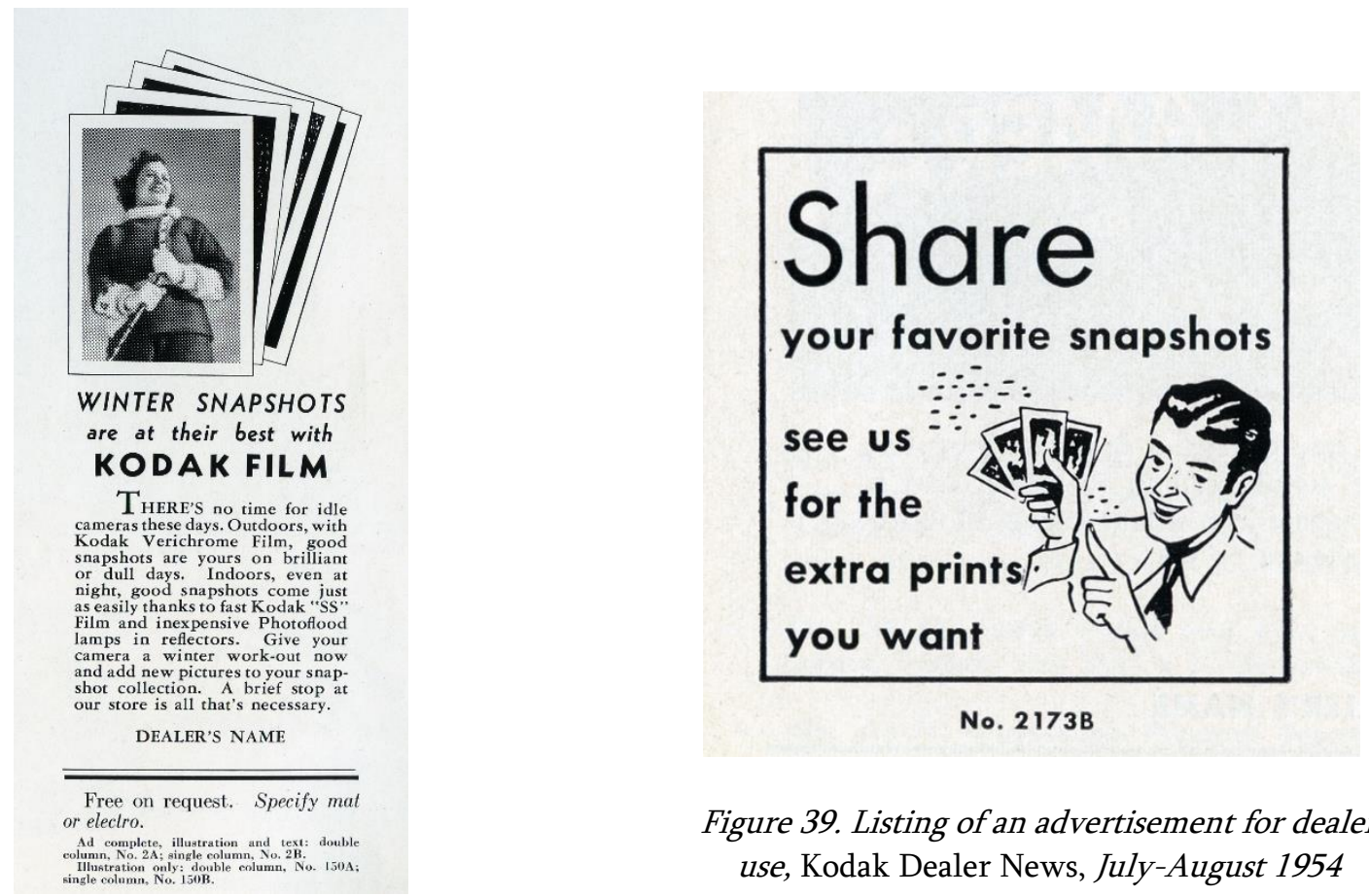

Figure 39. Listing of an advertisement for dealer use, Kodak Dealer News, July-August 1954

Figure 38. Listing of an advertisement for dealer use, Kodak Salesman, December 1937 


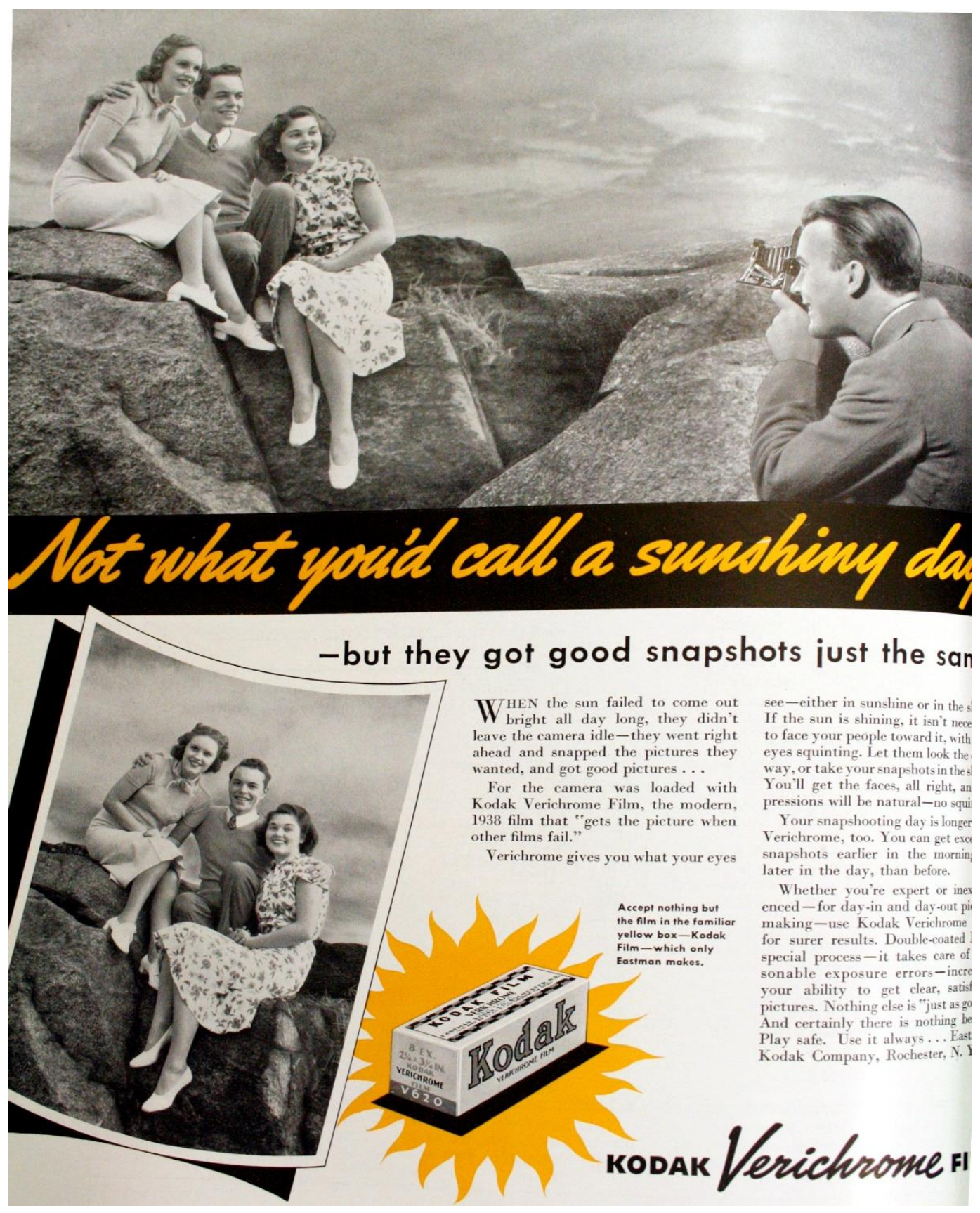

Figure 40. Advertisement for Kodak film, Kodak Salesman, May 1938 
itself makes very few appearances in Kodak's promotional material of the period. No Kodak print ads or advertising materials in this period, consumer or trade, promote the deckle edge as a potential feature of snapshots.

The use of deckle edge snapshots as illustrations is surprisingly rare as well. While the 1940 Studio Light ad for the Eastman Deckle-Edge Trimmer (figure 4) shows a deckle edge snapshot being cut, no other Kodak ads—consumer or trade-depict deckle edge snapshots before 1949. In 1949 Kodak released album print paper, intended for use in small bound albums. As has been discussed, this paper type came only in deckle edge form, and in ads showing both individual album-cut prints and the bound albums, the deckle edge is clearly delineated. This is the case for articles and ads in trade publications as well as those intended for consumers (figures 5, 21-22). However, the deckle edge itself was never mentioned as a special feature. When the ad copy discusses advantages of the type, it focuses instead on print size. At its release the album print is described as "a 'natural' tie-in with the trend towards oversize prints," a refrain repeated through successive advertisements. ${ }^{59}$ Ads for the albums and album prints continued through the early 1950s, always including depictions of the deckle edge.

Interestingly, the inclusion of a deckle edge snapshot in consumer ads that were not for the album print is almost non-existent. The only example currently identified is a 1955 Canadian Kodak newspaper ad for the Brownie Holiday Flash Camera (figure 41). Like many ads of its type, the image includes a large image of a snapshot; unlike most, the snapshot is shown with a prominent deckle edge, outlined in black and even enhanced by a shadow on one side. The edge

\footnotetext{
${ }^{59}$ Eastman Kodak Company, Advertisement, The Photo Finisher, Volume 21 Number 7, January 1949, pp. 6-7; for other examples see for instance advertisements in The Photo Finisher September 1949 (p. 3) and January 1950 (p.10).
} 


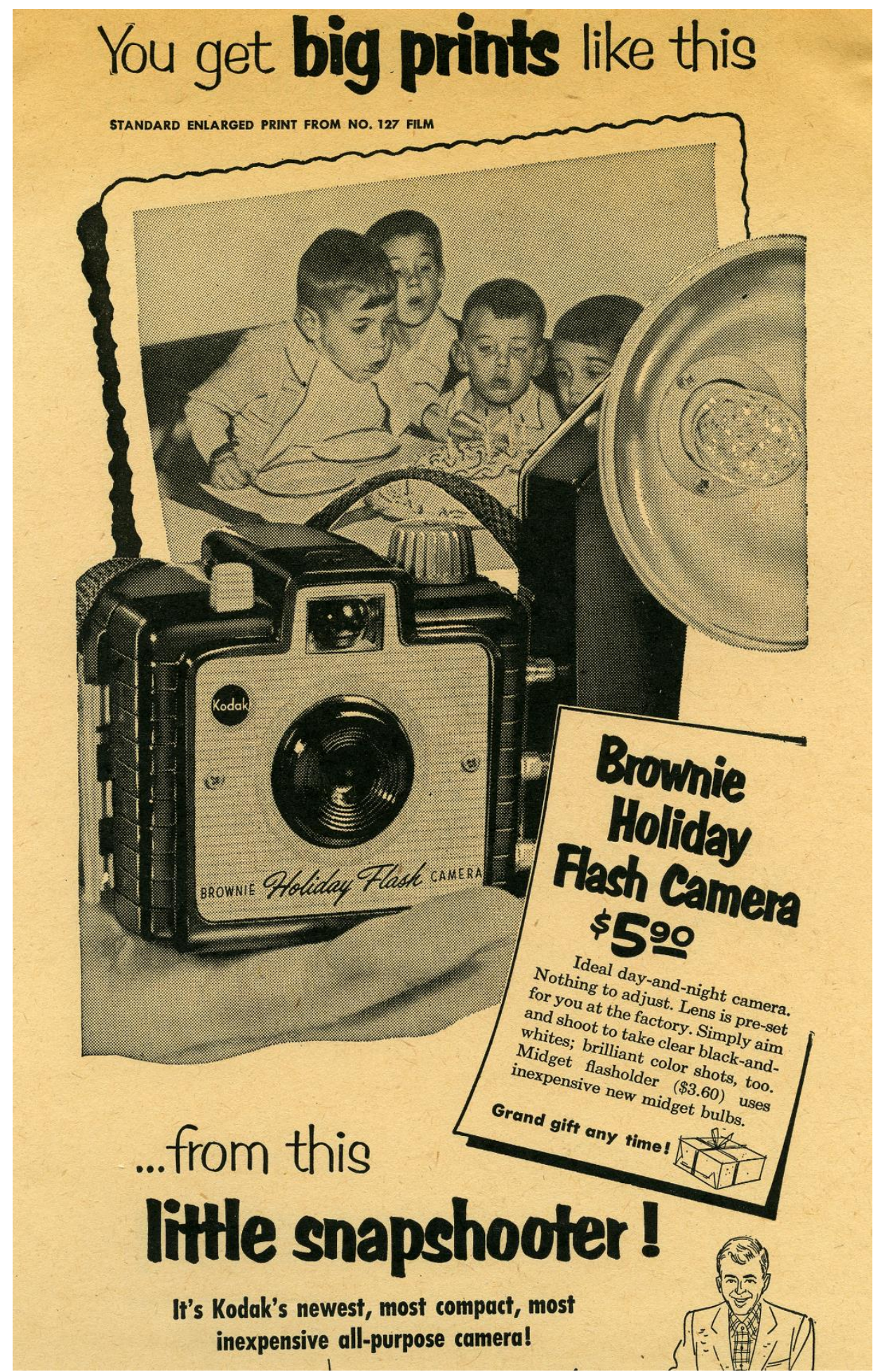

Figure 41. Newspaper advertisement for the Brownie Holiday Flash Camera showing a snapshot with clear deckle edges, 1955 
is not remarked on—not surprising considering that the object being advertised is the camera, not the print. While this integration of the deckle edge into the existing framework of broader Kodak imagery is interesting, it is curious that this trend did not continue. No consumer Kodak ads in successive years show deckle edges, despite the frequent use of snapshot imagery.

The depiction of the deckle edge snapshot in Kodak trade publications is generally associated with the release of new devices for its creation (see figures 6-8). However, from the mid-1950s the deckle edge was occasionally also used in ads and promotions for Velox paper (figures 42 and 43), the first instance occurring in 1954. Here deckle edge snapshots were mostly shown individually, sometimes alongside straight-edge snapshots. Sometimes coiled rolls of paper were also depicted with deckle edges (figure 44). However, straight-edge snapshots predominated, and the use of the deckle edge in trade advertisements disappears entirely by the early 1960s.

These findings show that Kodak apparently made little effort to popularize the deckle edge snapshot. The earliest snapshot in our sample dates from 1930; the earliest Kodak ad depicting any kind of deckle edge snapshot dates from 1949, and the earliest depicting a nonalbum print dates from 1954. Considering Kodak's policy of promoting all aspects of its products and photo-finishing services, this omission is particularly surprising. Throughout the trade publications Kodak is constantly coming up with new ways to sell snapshots to the public; why didn't they ever try promoting the deckle edge as one of these ways? While this question lies beyond the scope of this work, it illustrates a notable instance where Kodak, for once, was not 


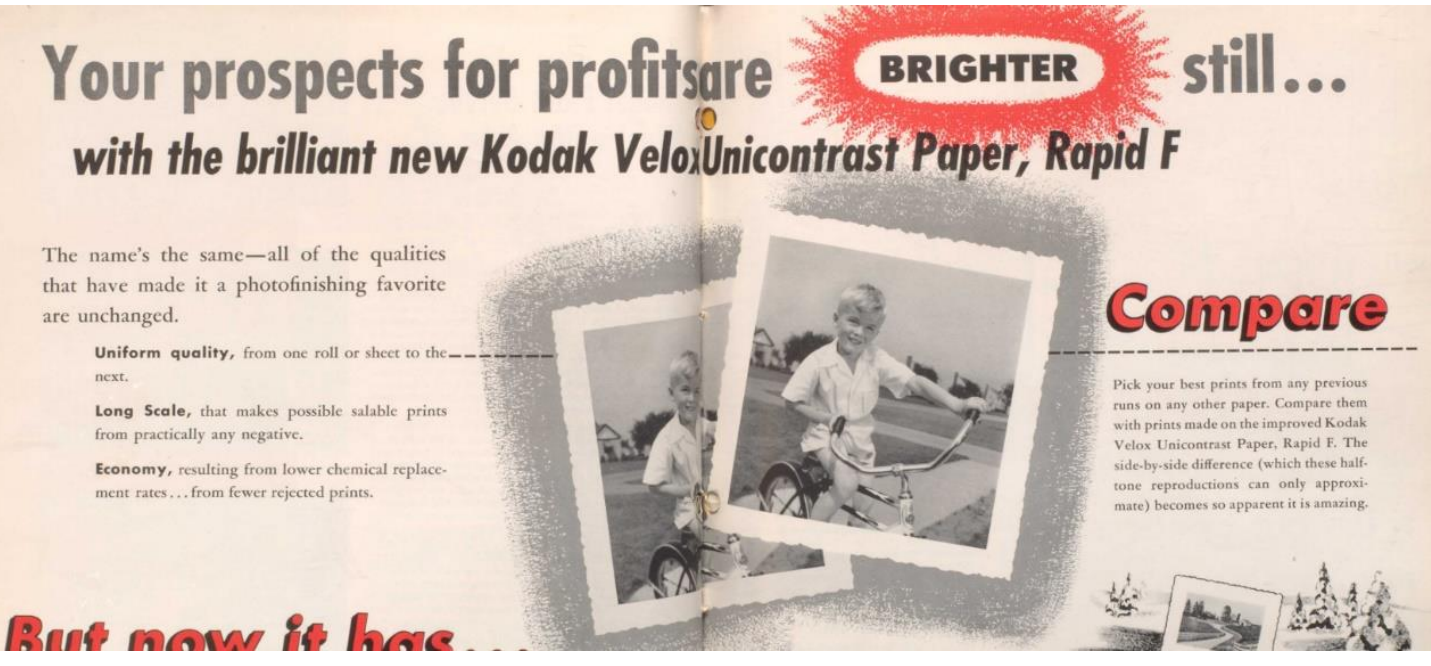

Figure 42. Advertisement for Velox paper featuring deckle edge snapshots, The Photo Finisher, Autumn 1954

\section{Here's how KODAK VELOX PREMIER PAPER F makes possible such spectacular results}

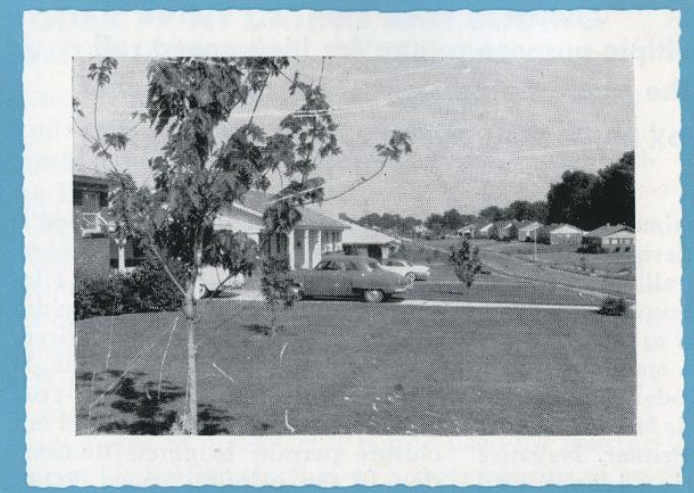

Reproduction of print made on standard paper in use by photo flnishers.

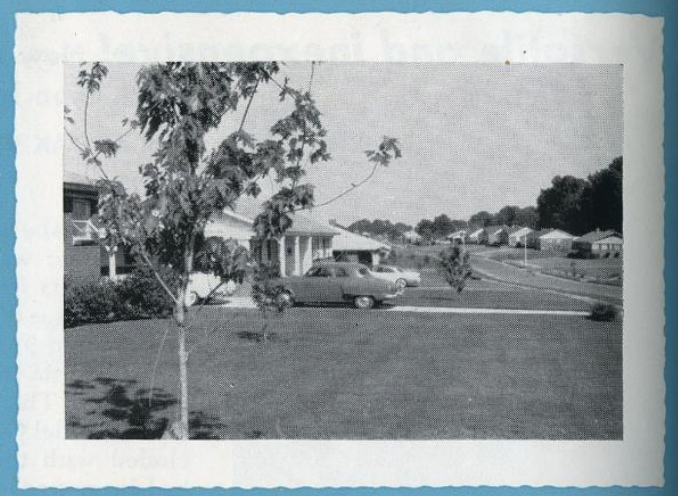

Reproduction of print on Kodak Velox Premier Paper (F). Both prints made from the same scratched negative!

Figure 43. Advertisement for Velox paper featuring deckle edge snapshots, The Photo Finisher, Summer 1957 


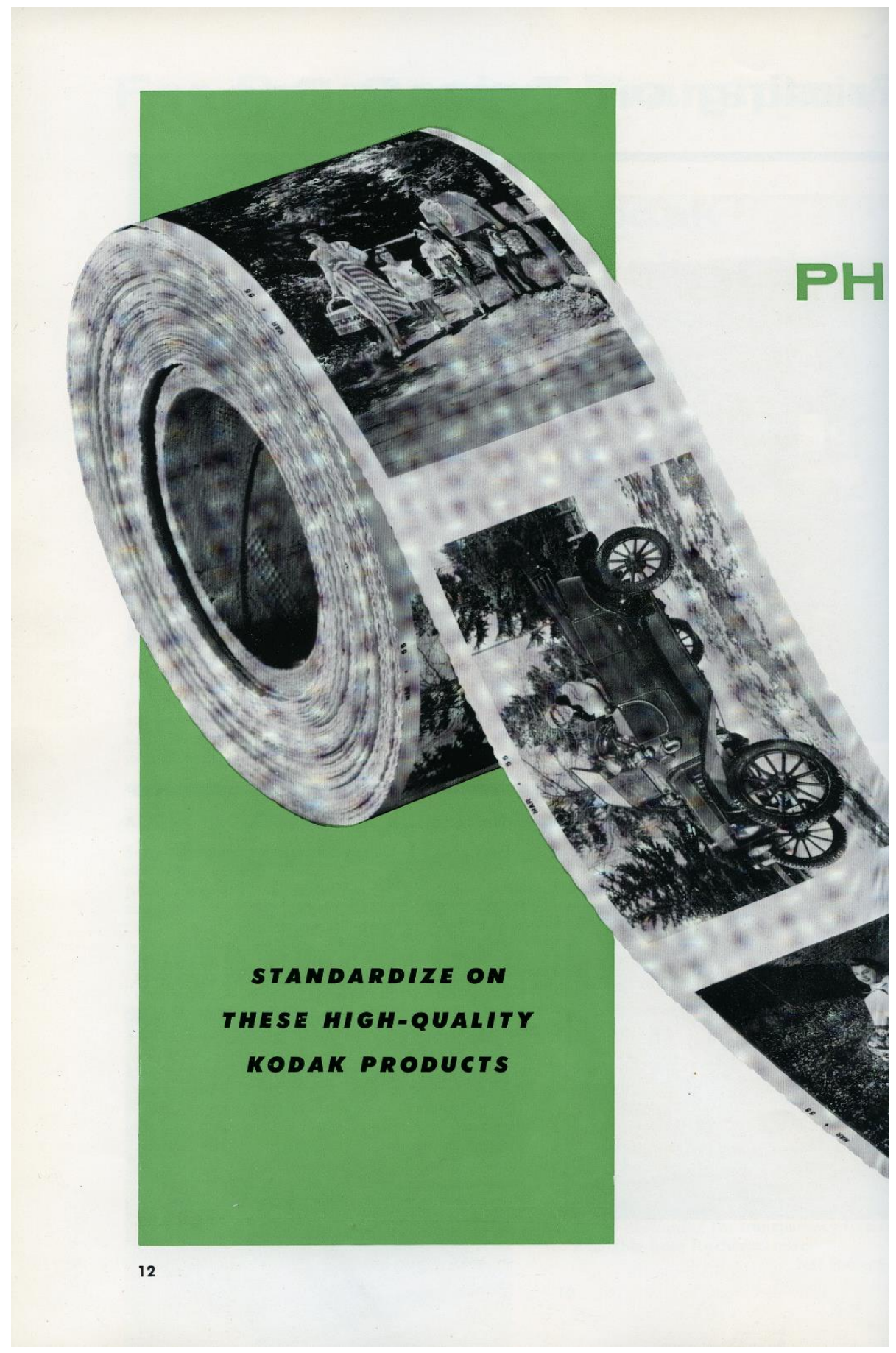

Figure 44. Advertisement for Velox paper featuring a roll of snapshots with deckle edges, The Photo Finisher, 1957 
behind a trend in snapshooting. In selling deckle edge materials Kodak catered to a taste of the public with regards to snapshots, but they do not appear to have created it, at least not directly. The next chapter discusses areas where Kodak did use and promote the deckle edge in photorelated materials, which no doubt had an impact of the rise of this type of snapshot. 


\section{Chapter 7. Influences}

Having established that the deckle edge snapshot was apparently not created as a Kodak marketing gimmick, the question arises: where did it come from? If it wasn't actively promoted, how did it become popular? While the present sources provide no definite answer, an examination of the wider context of photographic presentation offers suggestions.

Attention to the presentation of photographs, of course, is nothing new. Cased images could come with elaborately stamped mats, and cartes-des-visite could come mounted on coloured board. Cabinet cards, in fact, were sometimes presented with decorative edges not unlike deckle edges (figure 45). By the 1920s, snapshots as well as commercial studio portraits were receiving decorative framing; photographically printed decorative borders on snapshots were not uncommon (figure 46). ${ }^{60}$ The application of a deckle edge to a snapshot, then, can be seen as part of a wider interest in framing and enhancing even an "ordinary" photographic image.

The use of deckle edges specifically on snapshots can be linked to its use elsewhere.

Though Kodak did not promote the deckle edge as a feature of a snapshot, they did promote it for two other products: the portrait mount and the Christmas card.

From the early twentieth century, the most common form of presentation for commercial portraits was a thick paper mount or folder which photographs could be slipped into. Kodak advertised different styles regularly in its publication for professional photographers, Studio

${ }^{60}$ Like the deckle edge, the printed decorative border has received no attention in secondary literature, and it is unknown when it began. However, numerous examples can be found through the 1920s and 1930s, including two in the study sample displaying both a border and a deckle edge. 


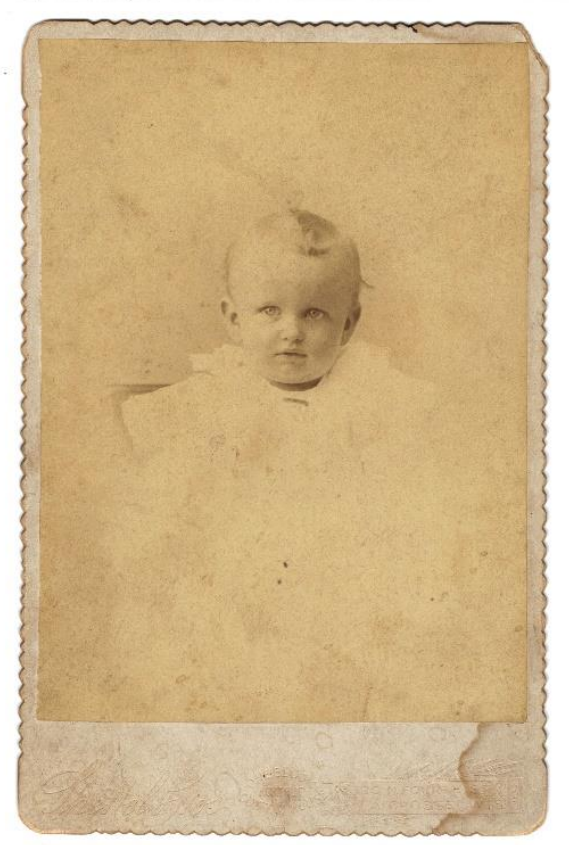

Figure 45. Cabinet card with decorative edges, late $19^{\text {th }}$ century

An Inslip Folder for High Grade Work

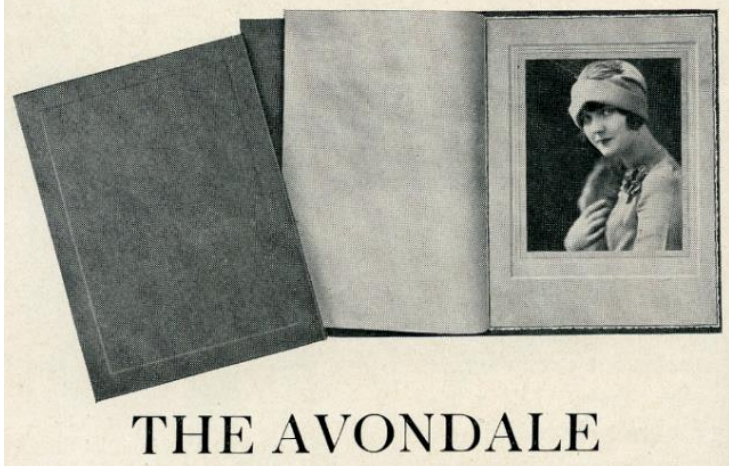

The heavy weight Craftsman stock alone speaks value. All edges deckled. Design on insert is set in a beveled plate sunk. The cover has no ornamentation-the final touch of finish is a slightly beveled ruling around the edges. An added touch is the featherweight paper fly-leaf as a protection to the portrait.

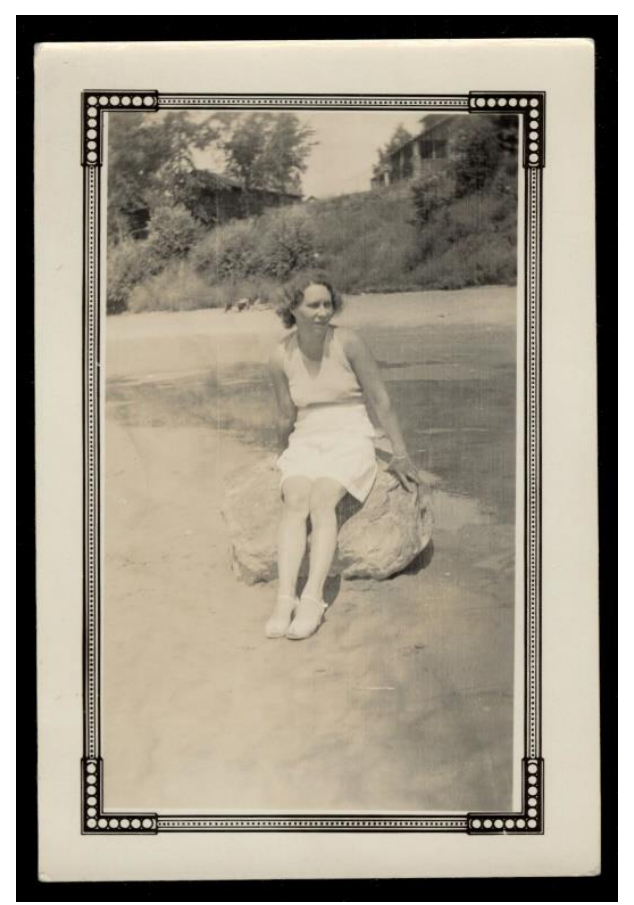

Figure 46. Snapshot with printed decorative border, dated 1934

Figure 47. Advertisement for a portrait folder with deckle edges, Studio Light, 1928
Figure 48. Detail of a portrait folder with deckle edges, 1920 s-1930s 
Light. Through the 1920s and 1930s, deckle edges were common features of the advertised folders, with the deckle edges always specifically noted as a feature in the text, associated with quality and craft (figure 47). The first example of a folder with deckle edges, in 1921, is described as "the style that brings 'top notch' prices." ${ }^{61}$ In 1922 a deckle edge mount "expresses by its very look—quality—exclusiveness." while a 1924 deckle edge folder supposedly "makes [moderatepriced portraits] look good value." ${ }^{62}$ For a 1926 style deckle edges themselves are noted as being "in strict keeping with the quality appearance of these mounts." ${ }^{3}$

In paper, a true deckle edge is a side-effect of the process of making individual sheets of paper, the result of an imperfect seal around the frame (the deckle) holding the paper fibres in place. By the late $19^{\text {th }}$ century, as paper-making became more mass-produced, the deckle edge became a status symbol. ${ }^{64}$ It is certainly this image of quality that Kodak's use of the deckle edge in the folder was aiming to evoke. However, examination of deckle edge folders from the period betrays the truth—that these "craftsman deckle edges" are in fact machine-cut (figure 48). ${ }^{65}$ The implication of quality seems to be behind Kodak's other use of the deckle edge outside of the snapshot. Through the period in question, Kodak annually advertised Christmas cards that photofinishers could make with a customer's own snapshots in a pre-made template. In 1938, Kodak introduced the deckle edge as an option on these cards, stating to photofinishers that "the

${ }^{61}$ Eastman Kodak Company, Advertisement, Studio Light, Volume 12 Number 7, September 1921, p. 32.

62 Eastman Kodak Company, Advertisement, Studio Light, Volume 14 Number 5, July 1922, p. 32; Eastman Kodak Company, Advertisement, Studio Light, Volume 16 Number 2, April 1924, p. 32.

${ }_{63}$ Eastman Kodak Company, Advertisement, Studio Light, Volume 18 Number 7, September 1926, p. 32.

${ }^{64}$ Dard Hunter, Papermaking. The History and Technique of an Ancient Craft, 1947 (Reprint: Dover Publications, New York, 1978), p. 456.

65 "Craftsman deckle edge" is a term used in a number of Kodak's mount and folder ads in the 1920s. 


\section{Here are the 7 new designs}

This full-page greeting card ad will appear in Novemer in magazines such as MACLEAN'S, SATURDAY EVENING POST and LIFE.

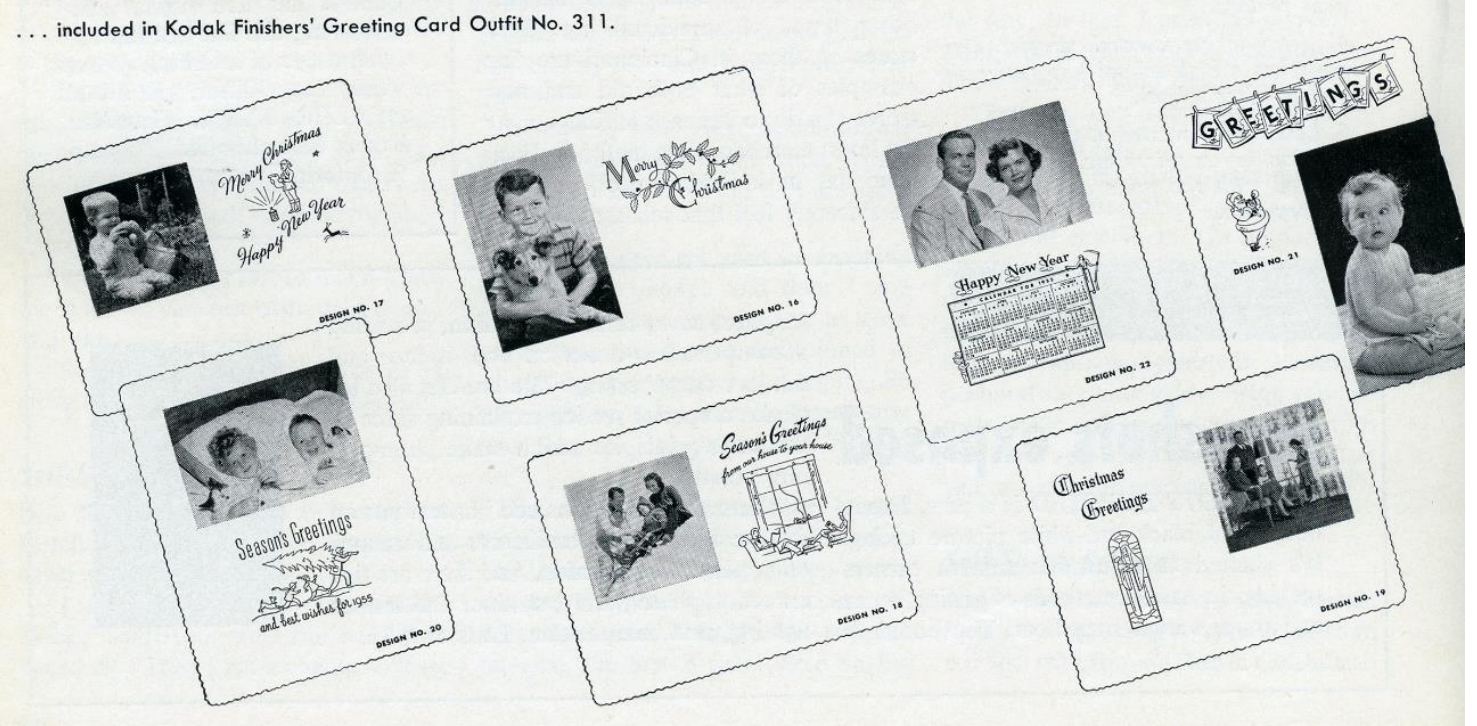

Figure 49. Advertisement for new Christmas cards with deckle edges, Kodak Dealer News, September- October 1954

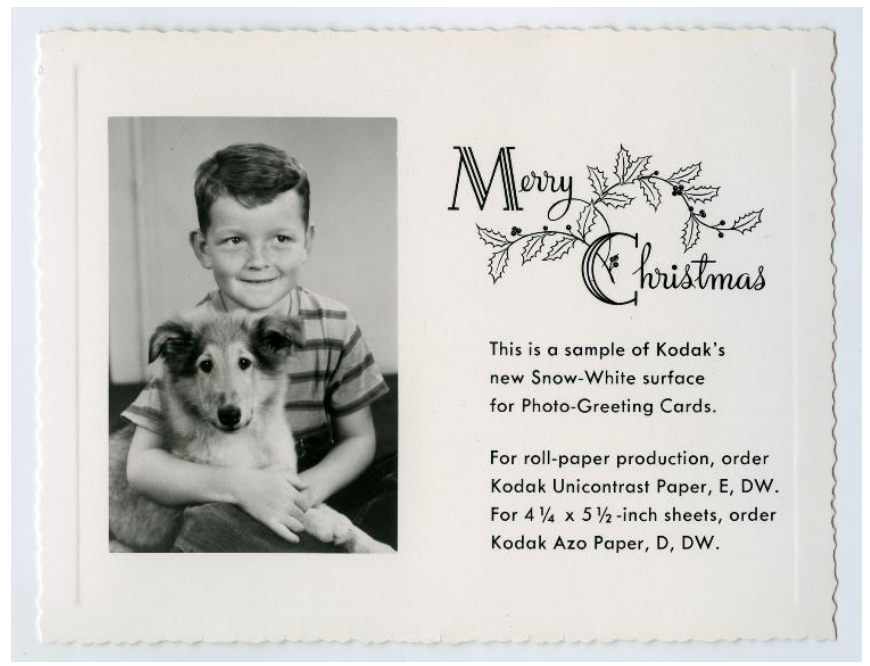

Figure 50. Sample deckle edge Christmas card, insert in The Photo Finisher, 1954

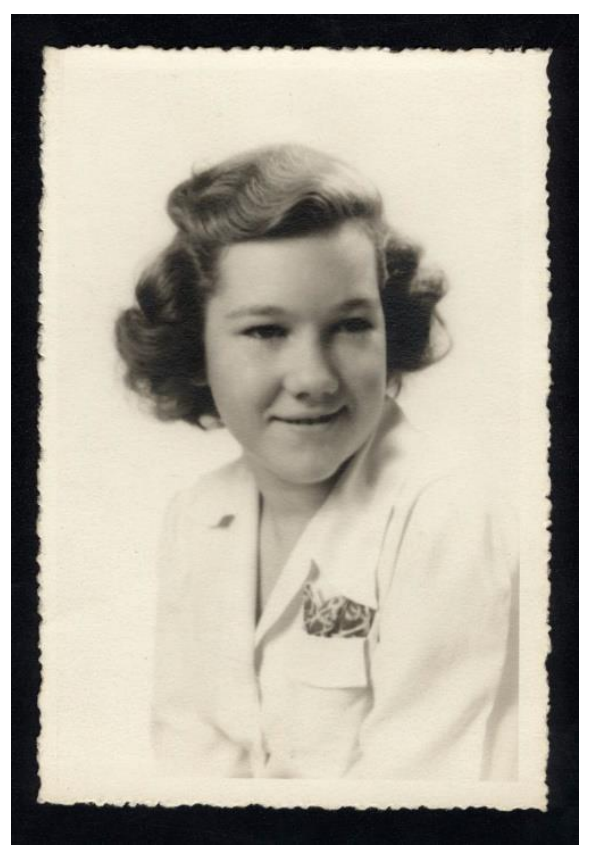

Figure 51. Studio portrait with deckle edges, undated 
rich appearance of the deckle edge cards is bound to carry a wide appeal." ${ }^{\prime 66}$ Deckle edge photo Christmas cards were offered and displayed as an option through the 1940s; by 1954, all new designs for the cards had deckle edges (figure 49). The deckle edges were always prominently featured in illustrations. New designs introduced in 1959 were all straight-edge, although they co-existed with deckle edge designs until 1963, when the deckle edge option for cards disappeared. A 1954 edition of The Photo Finisher included an insert with a sample card, verifying that the deckle edges were cut, at least by that date (figure 50). The edge type on the card is concave-interesting as the 1954 date precedes the earliest date in the sample, 1955. An explanation could be that Kodak was using the concave type of edge cutter itself before selling it to photofinishers.

The photo Christmas cards were intended to be special— "personal" is the word repeated throughout the ad copy. They were printed on the thicker, richer Azo paper rather than the Velox commonly used for snapshots. The use of a deckle edge fits within this context.

Through these two applications of the deckle edge to photo-related objects, we can get some sense of the ways in which the deckle edge itself was regarded at the time it began to be applied to snapshots. The deckle edge of the photo mount and the Christmas card was explicitly tied to quality and exclusiveness, commandeering the prestige of handmade paper simply by mimicking its edge. Kodak made this association repeatedly through the 1920s and 1930s, even if it was never applied directly to the deckle edge snapshot. It can thus be concluded that the

${ }^{66}$ Eastman Kodak Company, Kodak Salesman, Volume 24, Number 11, October 1938, p. 8. 
deckle edge snapshot arose out of a desire for the same connotations. A simple cut could imply a particular photograph was higher quality, something more than just an "ordinary" snapshot. It is not difficult to image why this might appeal to consumers, as a physical representation of an emotional sentiment.

The precise link between deckle edge photograph mount and deckle edge snapshot is not yet clear; however, it seems likely to be the deckle edge studio portrait. These certainly existed (see figure 51). Unfortunately, an examination of their proliferation and dates was beyond the scope of this project. Interestingly, the earliest patents for the application of deckle edges to photographs (filed in 1929 and 1930) show not snapshots with deckle edges, but head- andshoulders portraits (see figures 1 and 2). Additionally, Kodak's first deckle edge cutter, released in 1940, is advertised not in The Photo Finisher, the periodical aimed at commercial processors of snapshots, but Studio Light, the periodical for professional, mostly studio portrait photographers. Thus it seems likely that a systematic study of commercial studio portraits in the 1920s and 1930s would yield examples of deckle edge portraits, probably preceding the first instances of deckle edge snapshots themselves.

If the deckle edge studio portrait was indeed popular in this period, it is not surprising that its use was also adopted for the snapshot. From the introduction of the first Kodak in 1888, amateurs have used their cameras predominantly for taking portraits. ${ }^{67}$ Kodak certainly abetted in this desire: their manual for amateur snapshooting, How to Make Good Pictures, published in

67 Waggoner, “Photographic Amusements," pp. 27-30. 
37 editions from 1912 to 1997, devoted more of its pages to portraiture than any other topic. ${ }^{68}$

The deckle edge would have been an inexpensive way to impart a studio portrait presentation to an amateur snapshot, particularly snapshot portraits.

${ }^{68}$ This book has never been the subject of any concentrated study, but this is certainly true of most of its editions, for instance: Eastman Kodak Company, How to Make Good Pictures, 1 ${ }^{\text {st }}$ edition. (Rochester, NY: Eastman Kodak, 1912); Eastman Kodak Company, How to Make Good Pictures, 27th edition (Rochester, NY: Eastman Kodak, 1942; Eastman Kodak Company, How to Make Good Pictures, 29th edition. (Rochester, NY: Eastman Kodak, 1952);). 


\section{Conclusion}

Prior to this study, the deckle edge, like other physical characteristics of the snapshot, received no attention from scholars discussing snapshots. It was not regarded as a source of information about the snapshot prints on which it was found. However, this study demonstrates that the deckle edge can in fact be revealing. The objects and the trade literature have provided dates for the deckle edge snapshot's period of popularity: the 1930s to the 1960s, with a peak in the 1950s. It has been discovered that deckle edges were applied to snapshots by a variety of devices, and that these devices created variations in the appearance of the deckle edge. An examination of these edge types reveals that "deckle edge" is in fact a loose term for various types of patterned and/or irregular edge, most of which resemble the deckle edge of handmade paper only tentatively. These edge types can in turn be used to tie the snapshots displaying them to particular methods of manufacture, bearing testimony to the changes in the photofinishing industry in the period, and allowing for the more precise dating of individual snapshots.

Some gaps in the study remain. My study confined itself to North American snapshots and materials; it is likely that the deckle edge snapshot had a different history in Europe, and possible its popularity first arose there. Kodak, after all, sold a deckle edge paper cutter in the United Kingdom first, before North America (from 1934 and 1940, respectively). The few European snapshots contained within the sample suggest that edge types, and consequently methods of manufacture, followed different patterns across the Atlantic. A sister study of 
European deckle edge snapshots would be beneficial in tracing the trajectories of the deckle edge snapshot.

Kodak trade literature, an important primary source for this study, has not yet been studied. A deeper understanding of the ways in which this literature addressed and reflected the practical goings-on of photofinishers would help to assess the weight which should be given to the conclusions drawn from it. Information on Kodak sales figures of deckle edge related materials would be extremely valuable. Additionally, a significant limitation to the longitude of this study is the lack of information on Kodak wholesale products after 1955, after which the Condensed Price List ceased publication. If information on Kodak prices and products after this period could be located, it could bring clarity to the decline of the deckle edge snapshot in the 1960s, bookending the history of its manufacture.

Finally, as discussed in the last chapter, it appears likely that the deckle edge studio portrait was the predecessor to the deckle edge snapshot. Commercial studio portraiture of this period, particularly forms of presentation, has received little to no attention from scholars. A similar study using both material objects and trade literature (such as Studio Light and the variety of manuals and handbooks for professional photographers current in the period) could investigate this hypothesis, and provide a better understanding of the relation between popular photographs and aspects of their presentation.

That said, my study has started to tell the previously untold story of the deckle edge. In the 1920s, the deckle edge on paper was considered a look of quality, its associations with handmade paper implying craft, even if, by that period "deckle edges" were often artificially 
manufactured. Folders and mounts for studio portraits frequently promoted the inclusion of deckle edges. At some point, it seems likely that the deckle edge was applied to the studio portrait print itself, a cheaper option that nonetheless partook of the prestigious look of handmade paper. This simple and inexpensive method of presentation appealed to the consumers of snapshots. The earliest devices for applying deckle edges to photographs focused on methods of tearing, but by the late 1930s cutting devices took over. The tearing method created an unpredictable, unique pattern for the edge; the cutting devices created a regular pattern designed to approximate this look. Both patterns were referred to as a deckle edge. Variations on this cut deckle edge pattern were introduced along with new devices, with the term eventually encompassing a rather large variety, united mainly by their contrast to the straight edge. The deckle edge could be used as a practical choice as well as a decorative one, with both album cut prints and Polaroids using the deckle edge to ease and mask the tearing required by the format. Interest in the deckle edge peaked in the mid to late 1950s. The reason for this peak is not clear, although it is seen both in the objects and in the trade literature. However, before the mid-1950s Kodak appears to have made little effort to promote the deckle edge as a feature, or the deckle edge related materials it sold. From around 1954, Kodak began to reproduce deckle edges as illustrations, and to highlight the ability of its photofinishing devices to create them. Considering Kodak's sway in the market, it is possible that this increased attention-late as it was in the lifetime of the deckle edge snapshot—resulted in increased interest.

As noted, available Kodak sources dwindle in the period in which the study sample indicates a sharp decline in the popularity of the deckle edge snapshot, the early to mid-1960s. It 
is thus unclear when they stopped selling deckle edge paper or paper cutters with deckle edge blades. However, Kodak's mid-1950s interest in the deckle edge snapshot appears not to have lasted, as reproductions of deckle edge snapshots and promotions of deckle edge blades decline by the end of the decade. Indeed, even the deckle edge option for Christmas cards, a mainstay of Kodak products from 1938, was gone by 1963 . The reasons for this are unclear. Perhaps it was due to a simple loss of interest on the behalf of the consumers. Even if the period of Kodak's strongest interaction with the deckle edge was in the late 1950s, the look had been around since the 1930s, and may have begun to look old-fashioned and outdated. Perhaps, or perhaps in tandem, it was the increasing loss of interest in black and white snapshots themselves. By the 1960s, colour snapshots were more popular, both in practice and in advertising. The deckle edge was predominantly a form of presentation, and colour is its own form of presentation. Even in the over 15,000 snapshots surveyed to create the study sample, the author has never seen a colour snapshot with deckle edges.

What, then, can a deckle edge tell us about a snapshot? First, it can tell us when it was likely to have been made. A deckle edge snapshot is most likely to have come from the period 1940-1960; the edge pattern of each deckle edge type can narrow the range down further, sometimes virtually guaranteeing it was made after a particular year. The edge type can also tell us if the snapshot was made with roll paper, printed on an individual sheet, or intended for binding in a small album. It can tell us if the edges were machine-cut or hand-cut, providing clues about the size, economical success, and technological savvy of the establishment in which it was printed. 
Furthermore, the deckle edge snapshot as a phenomenon can tell us something about the relationship between societal trends and snapshots. The deckle edge speaks to an interest in the appearance of the snapshot as an object, not just the appearance of its image. Through the nineteenth century, photographs almost always had some kind of frame—a case, a mat, a folder. While some of these presentational forms were practical, embellishment of the frame was common, even if it was just through the application of a simple line border. Like the frame of a painting, the frame of a photograph indicated that the image was valuable and worth looking at. The rise of amateur snapshot photography led to larger numbers of photographs being taken, and more cheaply. However, the deckle edge indicates that the ubiquity of images did not erase the desire to make them appear more special by framing them. Whether this particular method of framing originated with consumers, photofinishers, or product manufacturers, it succeeded because of this desire consumers have. ${ }^{69}$ It is easy, perhaps, to dismiss snapshots as "boring pictures. ${ }^{" 70}$ The existence of the snapshot deckle edge serves as a reminder that snapshots were not boring to those who made and consumed them, because who would put a boring picture in a frame?

This study demonstrates the value in examining the snapshot not merely for its image content, but as a physical object rooted in historical context. The deckle edge snapshot existed in a particular time period. It was made by particular devices, appealing to particular tastes, promoted (or not) because of particular industry choices. Devices, tastes, and industry choices

\footnotetext{
${ }^{69}$ A desire which still exists; witness, for instance, the popularity of apps designed to enhance user's snapshots. ${ }^{70}$ The term "boring pictures" is used by Geoffrey Batchen to describe snapshots, albeit somewhat tongue-in-cheek. Batchen, "Snapshots," p. 121
} 
have changed tremendously during the 125 years of the snapshot's existence. Studies like ours can illuminate those changes, allowing for a more detailed and nuanced examination of the history of snapshots, and of popular photography in general. 


\section{Bibliography}

\section{Primary Sources}

\section{Patents}

Dodge, Prestel O. Deckle-edging device. U. S. Patent 1,820,303, filed February 12, 1929, and issued August 25, 1931.

Dodge, Prestel O. Paper deckling device, U.S. Patent 1,846,094, filed May 13, 1930, and issued February 23, 1932.

McCune Jr., William [assignor to Polaroid Corporation]. Photographic product. U. S. Patent 2,612,452, filed November 2, 1948, and issued September 30, 1952.

\section{Kodak Publications}

Eastman Kodak Company. Condensed Price List. Rochester NY: Eastman Kodak Company, 1940.

----. Condensed Price List. Rochester NY: Eastman Kodak Company, 1941.

----. Condensed Price List. Rochester NY: Eastman Kodak Company, 1949.

----. Condensed Price List. Rochester NY: Eastman Kodak Company, 1955.

---- How to Make Good Pictures, $1^{\text {st }}$ edition. Rochester, NY: Eastman Kodak, 1912.

----How to Make Good Pictures, 27th edition. Rochester, NY: Eastman Kodak, 1941.

---- How to Make Good Pictures, 29 ${ }^{\text {th }}$ edition. Rochester, NY: Eastman Kodak, 1952.

----. The Kodak Salesman. Volume 24 Number 10 (October 1938).

----. The Photo Finisher. Volume 21 Number 7 (January 1949).

----. The Photo Finisher. Volume 26 Number 4 (Winter 1954). 
---. The Photo Finisher. Volume 27 Number 1 (Spring 1955).

----. The Photo Finisher. Volume 28 Number 3 (Summer 1956).

----. The Photo Finisher. Volume 29 Number 4 (Autumn 1957).

----. Trade Circular, June 1949

Kodak Limited., Kodak Photographic Apparatus and Materials (London: Kodak Limited, 1934), p.192.

\section{Secondary Sources}

Batchen, Geoffrey. "Snapshots. Art history and the ethnographic turn." Photographies Vol. 1, No. 2, September 2008, 121-142.

Berger, Lynn. "Snapshots, or: Visual Culture's Clichés." Photographies, Volume 4, Issue 2 (2011): 175-190.

Bonanos, Christopher. Instant: The Story of Polaroid. New York: Princeton Architectural Press, 2012.

Chalfen, Richard. "Redundant Imagery: Some Observations on the Use of Snapshots in American Culture." Journal of American Culture, Volume 4, Issue 1 (March 1981): 106113.

—. Snapshot Versions of Life. Bowling Green, Ohio: Bowling Green State University Popular Press, 1987.

Coe, Brian and Gates, Paul. The Snapshot Photograph. The rise of popular photography 18881939. London: Ash and Grant, 1977.

Green, Jonathan (ed). The Snap-Shot. Millerton, NY: Aperture, 1974.

Greenough, Sarah, Kennel, Sarah, Waggoner, Diane, and Witkovsky, Matthew S. The Art of the American Snapshot, 1888-1978. Washington: National Gallery of Art, 2007. 
Heiferman, Marvin. Now is Then. Snapshots from the Maresca Collection, edited by Marvin Heiferman. New York: Princeton Architectural Press, 2008, 41-53.

Hirsch, Julia. Family Photographs. Content, Meaning and Effect. New York and Oxford: Oxford University Press, 1981.

Hunter, Dard. Papermaking. The History and Technique of an Ancient Craft. 1947. Reprint: Dover Publications, New York, 1978.

Jacobs, David L. "Domestic Snapshots: Toward a Grammar of Motives." Journal of American Culture, Volume 4, Issue 1 (March 1981): 93-105.

Kotchemidova, Christina. "Why We Say "Cheese": Producing the Smile in Snapshot Photography." Critical Studies in Media Communication, Volume 22, Issue 1 (March 2005): 2-25.

Langford, Martha. Suspended Conversations. The Afterlife of Memory in Photographic Albums. Montreal and Kingston: McGill-Queen's University Press, 2001.

Nickel, Douglas R. Snapshots. The Photography of Everyday Life 1888 to the present. San Francisco: San Francisco Museum of Modern Art, 1998.

Reiakvam, Oddlaug. "Reframing the Family Photograph." The Journal of Popular Culture, Volume 25, Issue 4, (March 1993): 39-68.

Waldie, D. J. Close to Home. An American Album. Los Angeles: The J. Paul Getty Museum, 2004.

West, Nancy Martha. Kodak and the Lens of Nostalgia. Charlottesville, VA: University of Virginia Press, 2000. 